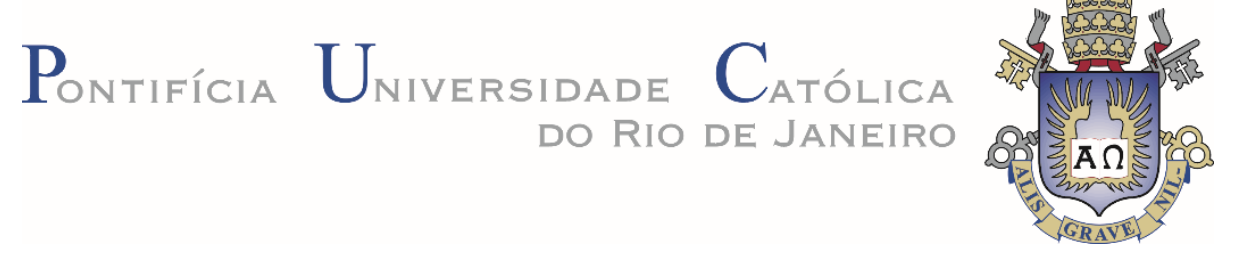

Igor de Oliveira Barreto

\title{
Avaliação do Comportamento Dinâmico de Sistemas Elétricos de Potência com Penetração de Fontes Renováveis Considerando Dispositivos de Armazenamento de Energia
}

Dissertação de Mestrado

Dissertação apresentada como requisito parcial para obtenção do grau de Mestre pelo Programa de PósGraduação em Engenharia Elétrica do Departamento de Engenharia Elétrica da PUC-Rio.

Orientador: Prof. Armando Martins Leite da Silva Coorientador: Prof. Jorge Luiz de Araújo Jardim 


\section{Avaliação do Comportamento Dinâmico de Sistemas Elétricos de Potência com Penetração de Fontes Renováveis Considerando Dispositivos de Armazenamento de Energia}

Dissertação apresentada como requisito parcial para obtenção do grau de Mestre pelo Programa de PósGraduação em Engenharia Elétrica da PUC-Rio. Aprovada pela Comissão Examinadora abaixo.

Prof. Armando Martins Leite da Silva

Orientador

Departamento de Engenharia Elétrica - PUC-Rio

Prof. Jorge Luiz de Araújo Jardim

Coorientador

HPPA Consultoria

Prof. Zulmar Soares Machado Júnior Universidade Federal de Itajubá - UNIFEI

Dr. Carlos Alberto da Silva Neto Operador Nacional do Sistema Elétrico - ONS 
Todos os direitos reservados. É proibida a reprodução total ou parcial do trabalho sem autorização da universidade, do autor e do orientador.

\section{Igor de Oliveira Barreto}

Graduou-se em Engenharia Elétrica com ênfase em Sistemas Elétricos de Potência pela Pontifícia Universidade Católica do Rio de Janeiro em 2009. Atualmente trabalha como engenheiro de sistemas de potência na área de planejamento da operação elétrica no Operador Nacional do Sistema Elétrico.

Ficha Catalográfica

Barreto, Igor de Oliveira

Avaliação do Comportamento Dinâmico de Sistemas Elétricos de Potência com Penetração de Fontes Renováveis Considerando Dispositivos de Armazenamento de Energia / Igor de Oliveira Barreto; orientador: Armando Martins Leite da Silva; coorientador: Jorge Luiz de Araújo Jardim. - 2020.

125 f.: il. color. $30 \mathrm{~cm}$

Dissertação (mestrado) - Pontifícia Universidade Católica do Rio de Janeiro, Departamento de Engenharia Elétrica, 2020.

Inclui bibliografia

1. Engenharia Elétrica - Dissertações. 2. Controle de Frequência. 3. Sistema de Potência Isolado. 4. Armazenamento de Energia. 5. Energia Renovável Intermitente. I. Leite da Silva, Armando Martins. II. Jardim, Jorge Luiz de Araújo. III. Pontifícia Universidade Católica do Rio de Janeiro. Departamento de Engenharia Elétrica. IV. Avaliação do Comportamento Dinâmico de Sistemas Elétricos de Potência com Penetração de Fontes Renováveis Considerando Dispositivos de Armazenamento de Energia. 


\section{Agradecimentos}

Primeiramente agradeço a Deus pela minha saúde, a da minha família e das pessoas que tenho carinho e consideração.

À minha noiva Nathalia Lopes Cunha por estar sempre ao meu lado, me apoiando e cuidando da nossa família com todo amor e carinho, em especial da nossa filha Maria Antônia Cunha Barreto, que nasceu durante o curso de pósgraduação e deu sentido às nossas vidas.

Aos meus pais, Acacio Barreto Neto e Tania de Oliveira Barreto, pela criação, formação de valores e caráter, e por me proporcionar todo suporte para que eu pudesse me desenvolver em todos os momentos da minha vida. À minha irmã Indd de Oliveira Barreto e meus sobrinhos Pedro Antônio e Ivie Maria.

Aos meus amigos de infância que permanecem unidos e compartilham momentos de lazer e alegria.

Aos meus orientadores Armando Martins Leite da Silva e Jorge Luiz de Araújo Jardim pela experiência excepcional de compartilhar conhecimentos com referências tão importantes para 0 setor elétrico. Estendendo esses agradecimentos aos professores Ricardo Prada, Delberis Lima, Eduardo Pires, Eduardo Pacheco e Mauro Schwanke.

À Pontifícia Universidade Católica do Rio de Janeiro - PUC-Rio e a CAPES pelos auxílios concedidos, e aos amigos de formação da graduação e da pósgraduação, com os quais compartilhei vários momentos em sala de aula de angústia e de felicidade.

Ao Operador Nacional do Sistema Elétrico - ONS, em especial aos meus superiores antigos Rogério Amado e Mário Daher, e atuais Fernando Machado e Sumara Ticom, que auxiliaram na minha formação durante esses dez anos de carreira no Operador. Aos amigos engenheiros aposentados César Martins, 
Maria de Lourdes Leite e Sérgio Martins que são referências para mim. Aos demais amigos do ONS pelas experiências compartilhadas, em especial aos engenheiros Pedro Henrique dos Santos e Fabricio Andrade Mourinho que me auxiliaram nesta dissertação como coorientadores.

O presente trabalho foi realizado com apoio da Coordenação de Aperfeiçoamento de Pessoal de Nível Superior - Brasil (CAPES) - Código de Financiamento 001. 


\section{Resumo}

Barreto, Igor de Oliveira. Avaliação do Comportamento Dinâmico de Sistemas Elétricos de Potência com Penetração de Fontes Renováveis Considerando Dispositivos de Armazenamento de Energia. Rio de Janeiro, 2020. 125p. Dissertação de Mestrado Departamento de Engenharia Elétrica, Pontifícia Universidade Católica do Rio de Janeiro.

O aumento da penetração de fontes de energia intermitentes é uma realidade dentro da matriz energética brasileira. A utilização em larga escala de energia renovável diminui a flexibilidade operativa com a redução da inércia equivalente sincronizada no sistema, podendo colocar em risco a segurança e a qualidade do suprimento de energia dos sistemas elétricos de potência com a diminuição da capacidade de regulação de frequência. Com expectativas de crescimento acentuado, surgem os dispositivos de armazenamento de energia (Energy Storage Devices - ESD) como uma alternativa viável para contornar essas dificuldades, principalmente quando se trata de um sistema de potência isolado. Nesta dissertação, avalia-se o comportamento dinâmico do sistema elétrico do estado de Roraima, através de uma metodologia desenvolvida para quantificar a penetração de energia renovável intermitente em sistemas isolados. Avalia-se também como a utilização de dispositivos de armazenamento de energia podem contribuir para o controle de frequência, observando as vantagens que tais dispositivos podem acarretar nesse sistema. A construção do Mapa de Decisão pode auxiliar as análises tanto na etapa de planejamento como na fase de programação e operação dos sistemas. Nas simulações realizadas foi possível constatar que a utilização de ESD pode promover um aumento significativo na penetração de usinas renováveis intermitentes, como eólica e solar fotovoltaica, em sistemas de potência isolados.

\section{Palavras-chave}

Controle de Frequência; Sistema de Potência Isolado; Armazenamento de Energia; Energia Renovável Intermitente 


\section{Abstract}

Barreto, Igor de Oliveira. Dynamic Assesment of Electric Power Systems With Renewable Sources and Energy Storage Devices. Rio de Janeiro, 2020. 125p. Dissertação de Mestrado - Departamento de Engenharia Elétrica, Pontifícia Universidade Católica do Rio de Janeiro.

The increase in the penetration of intermittent energy sources is a reality within the Brazilian energy matrix. The large-scale use of renewable energy decreases the operational flexibility with the reduction of the equivalent inertia synchronized in the system, which can endanger the safety and quality of the energy supply of electric power systems with the reduction of the frequency regulation capacity. With expectations of sharp growth, energy storage devices (ESD) appear as a feasible alternative to overcome these difficulties, particularly when it comes to an isolated power network. In this dissertation, the dynamic assessment of the electrical system of the state of Roraima is evaluated, using a methodology developed to quantify the penetration of intermittent renewable energy in isolated systems. It is also evaluated how the use of energy storage devices can contribute to frequency control, observing the advantages that such devices can bring to this system. The construction of the Decision Map can assist the analyses during the planning, programming and operation phases. In the simulations carried out, it was possible to verify that the use of ESD can promote a significant increase in the penetration of intermittent renewable plants, such as wind and solar photovoltaic, in isolated power systems.

\section{Keywords}

Frequency Control; Isolated Power System; Energy Storage; Intermittent Renewable Energy 


\section{Sumário}

$\begin{array}{ll}\text { Resumo } & 6\end{array}$

$\begin{array}{ll}\text { Abstract } & 7\end{array}$

1 Introdução 18

1.1. Considerações Iniciais 18

1.2. Objetivos 21

1.3. Estruturação da Dissertação 21

2 Armazenamento de Energia 23

2.1. Introdução 23

2.2. Principais Tecnologias para Armazenadores de Energia 23

2.2.1. Mecânica 24

2.2.2. Elétrica 25

2.2.3. Eletroquímica 26

2.2.4. Térmica 26

2.2.5. Química 27

$\begin{array}{ll}\text { 2.2.6. Outras Tecnologias } & 27\end{array}$

2.3. Aplicações em Sistemas Elétricos de Potência 28

2.3.1. Deslocamento de Geração 28

2.3.2. Suavização da Intermitência de Fontes Renováveis 29

2.3.3. Controle de Carga da Ponta 32

2.3.4. Regulação de Tensão 34

2.3.5. Regulação de Frequência $\quad 35$

2.3.6. Auxílio ao Reestabelecimento 36

2.4. Viabilidade do Uso no Sistema Elétrico Brasileiro 37

3 Controle de Frequência 38

3.1. Introdução 38

3.2. Fundamentos do Controle de Frequência 38

3.2.1. Equação de Oscilação 39

3.3. Regulação de Frequência $\quad 41$

3.3.1. Regulação Primária 42

3.3.1.1. Regulação Própria do Sistema Elétrico 43

3.3.1.2. Regulador de Velocidade Isócrono 44 
3.3.1.3. Regulador de Velocidade com Queda de Velocidade 46

3.3.1.4. Esquema Regional de Alívio de Carga 48

3.3.2. Regulação Secundária 49

4 Modelagem Dinâmica dos Dispositivos de Armazenamento de Energia 52

4.1. Introdução 52

4.2. Modelo Dinâmico do ESD 52

4.2.1. Controle de Potência Ativa 55

4.2.2. Controle de Potência Reativa 56

4.3. Modelagem dos Demais Elementos do Sistema de Roraima 58

5 Simulações e Resultados 59

5.1. Introdução 59

5.2. Características do Sistema Elétrico 59

5.3. Metodologia Aplicada 62

5.3.1. Método de Definição da Contingência Mais Severa 63

5.4. Análise do Sistema Isolado de Roraima 64

5.4.1. Resultados das Simulações Dinâmicas 69

5.4.1.1. Simulações com 60\% de Penetração de Fotovoltaicas e 10\% de ESD 73

5.4.1.2. Simulações com $60 \%$ de Penetração de Fotovoltaicas e $95 \%$ de

Redução de Geração Fotovoltaica $\quad 79$

5.4.1.3. Simulações com $10 \%$ de ESD e $95 \%$ de Redução de Geração

Fotovoltaica 82

5.4.1.4. Conclusões das Simulações Dinâmicas 84

6 Conclusões $\quad 85$

6.1 Trabalhos Futuros $\quad 86$

$\begin{array}{lll}7 & \text { Referências bibliográficas } & 88\end{array}$

$\begin{array}{ll}\text { A Apêndice - Movimento Rotacional } & 91\end{array}$

B Apêndice - Parâmetros do Caso de Referência 92

C Apêndice - Modelos do Sistema Roraima 98 


\section{Lista de figuras}

Figura 1.1 - Previsão de Crescimento da Capacidade de Armazenamento de Energia (MW) [2].

Figura 2.1 - Principais tecnologias de armazenamento de energia. Adaptada de [12].

Figura 2.2 - Deslocamento de geração para a carga pesada.

Figura 2.3 - Suavização da intermitência de geração fotovoltaica.

Figura 2.4 - Suavização da intermitência de geração fotovoltaica com bloqueio por nuvem.

Figura 2.5 - Suavização da intermitência de geração eólica. 31

Figura 2.6 - Controle de carga da ponta. 33

Figura 2.7 - Controle de regulação de tensão. 35

Figura 2.8 - Controle de regulação de frequência. 36

Figura 3.1 - Diagrama esquemático típico de regulação de frequência. 42

Figura 3.2 - Diagrama esquemático de um regulador de velocidade isócrono. 45

Figura 3.3 - Resposta no tempo de uma unidade geradora com regulador de velocidade isócrono [16].

Figura 3.4 - Diagrama esquemático de um regulador de velocidade com queda de velocidade. 46

Figura 3.5 - Resposta no tempo de uma unidade geradora com regulador de velocidade com queda de velocidade [16]. $\quad 47$

Figura 3.6 - Compartilhamento de carga por duas unidades geradoras com regulador de velocidade com queda de velocidade [16].

Figura 3.7 - Comportamento de uma unidade geradora considerando atuação da Regulação Primária e da Regulação Secundária. Adaptada de [17]. 50

Figura 3.8 - Comportamento de diversas unidades geradoras considerando atuação da Regulação Primária e da Regulação Secundária. 51

Figura 4.1 - Estrutura de um Sistema de Armazenamento de Energia 53

Figura 4.2 - Esquema de um Voltage Source Converter (VSC) 53

Figura 4.3 - Diagrama de Blocos do Controle de Potência Ativa do Modelo de ESD.

Figura 4.4 - Diagrama de Blocos do Controle de Potência Reativa do Modelo de ESD. $\quad 57$

Figura 5.1 - Diagrama geoelétrico do estado de Roraima. 60 
Figura 5.2 - Resultados das simulações considerando a redução de $40 \%$ da geração fotovoltaica. $\quad 69$

Figura 5.3 - Resultados das simulações considerando a redução de $65 \%$ da geração fotovoltaica. $\quad 70$

Figura 5.4 - Resultados das simulações considerando a redução de $80 \%$ da $\begin{array}{ll}\text { geração fotovoltaica. } & 70\end{array}$

Figura 5.5 - Resultados das simulações considerando a redução de 95\% da geração fotovoltaica.

Figura 5.6 - Resultado das simulações considerando um ESD de 15\% da geração total do sistema.

Figura 5.7 - Resultado das simulações considerando um ESD de 10\% da geração total do sistema.

Figura 5.8 - Resultado das simulações considerando um ESD de 5\% da geração total do sistema.

Figura 5.9 - Frequência do Sistema para Reduções de Geração Fotovoltaicas Distintas Considerando um ESD de $10 \%$ da Geração Total do Sistema e $60 \%$ de Penetração de Usinas Fotovoltaicas.

Figura 5.10 - Carga na Subestação Centro 13,8 kV para Reduções de Geração Fotovoltaicas Distintas Considerando um ESD de 10\% da Geração Total do Sistema e 60\% de Penetração de Usinas Fotovoltaicas. 74

Figura 5.11 - Potência Ativa do ESD para Reduções de Geração Fotovoltaicas Distintas Considerando um ESD de $10 \%$ da Geração Total do Sistema e $60 \%$ de Penetração de Usinas Fotovoltaicas.

Figura 5.12 - Tensão no Barramento de 69 kV na Subestação Boa Vista para Reduções de Geração Fotovoltaicas Distintas Considerando um ESD de $10 \%$ da Geração Total do Sistema e 60\% de Penetração de Usinas Fotovoltaicas.

Figura 5.13 - Potência Reativa do ESD para Reduções de Geração Fotovoltaicas Distintas Considerando um ESD de 10\% da Geração Total do Sistema e 60\% de Penetração de Usinas Fotovoltaicas.

Figura 5.14 - Contingência Simulada para Reduções de Geração Fotovoltaicas Distintas Considerando um ESD de $10 \%$ da Geração Total do Sistema e $60 \%$ de Penetração de Usinas Fotovoltaicas.

Figura 5.15 - Potência Elétrica da UTE Bonfim para Reduções de Geração Fotovoltaicas Distintas Considerando um ESD de 10\% da Geração Total do Sistema e $60 \%$ de Penetração de Usinas Fotovoltaicas. 
Figura 5.16 - Potência Mecânica da UTE Bonfim para Reduções de Geração Fotovoltaicas Distintas Considerando um ESD de 10\% da Geração Total do Sistema e 60\% de Penetração de Usinas Fotovoltaicas. 78

Figura 5.17 - Frequência de Todas as Unidades Geradoras do Sistema para 95\% de Redução de Geração Fotovoltaicas Considerando um ESD de 10\% da Geração Total do Sistema e $60 \%$ de Penetração de Usinas Fotovoltaicas.

Figura 5.18 - Frequência do Sistema para Redução de 95\% de Geração Fotovoltaicas e $60 \%$ de Penetração de Usinas Fotovoltaicas Considerando Valores Distintos de ESD.

80

Figura 5.19 - Frequência do Sistema no Momento da Perturbação para Redução de $95 \%$ de Geração Fotovoltaicas e $60 \%$ de Penetração de Usinas Fotovoltaicas Considerando Valores Distintos de ESD.

Figura 5.20 - Potência Ativa de ESD para Redução de $95 \%$ de Geração Fotovoltaicas e $60 \%$ de Penetração de Usinas Fotovoltaicas Considerando Valores Distintos de ESD.

Figura 5.21 - Frequência do Sistema para Redução de 95\% de Geração Fotovoltaicas e 10\% de ESD Considerando Valores Distintos de Penetração de Usinas Fotovoltaicas.

82

Figura 5.22 - Carga na Subestação Centro 13,8 kV para Redução de 95\% de Geração Fotovoltaicas e 10\% de ESD Considerando Valores Distintos de Penetração de Usinas Fotovoltaicas.

Figura 5.23 - Potência Ativa do ESD para Redução de 95\% de Geração Fotovoltaicas e 10\% de ESD Considerando Valores Distintos de Penetração de Usinas Fotovoltaicas.

Figura B.1 - Parâmetros de Inicialização e Definição de Constantes do Caso de

Referência. $\quad 92$

Figura B.2 - Parâmetros de Barramentos do Caso de Referência. 93

Figura B.3 - Parâmetros de Circuitos e Transformadores do Caso de Referência.

95

Figura B.4 - Parâmetros de Elementos Shunts de Barra do Caso de Referência.

Figura B.5 - Parâmetros de Grupo Base e Grupo Limite de Barra, Definição de Área e Transformadores com o Tap Congelado no Caso de Referência. 97 Figura C.1 - Diagrama de blocos do modelo de máquina síncrona com polos salientes - SM04. 
Figura C.2 - Diagrama de blocos do modelo de máquina síncrona com polos lisos - SD05.

Figura C.3 - Diagrama de blocos do modelo de regulador de velocidade GOV08.

Figura C.4 - Diagrama de blocos do modelo de regulador de velocidade GOV11.

102

Figura C.5 - Diagrama de blocos do modelo de regulador de velocidade GOV19.

Figura C.6 - Diagrama de blocos do modelo de regulador de tensão - AVR23.

Figura C.7 - Diagrama de blocos do modelo de regulador de tensão - AVR24.

Figura C.8 - Diagrama de blocos do modelo de regulador de tensão - AVR25.

Figura C.9 - Diagrama de blocos do modelo estabilizador PSS - PS06. 112

Figura C.10 - Malha de Controle da Potência Ativa. 118

Figura C.11 - Malha de Controle da Potência Reativa.

Figura C.12 - Malha de Detecção de Subtensão e Sobretensão.

Figura C.13 - Limites de Corrente Ativa e de Corrente Reativa.

Figura C.14 - Proteções da Usina Fotovoltaica. 


\section{Lista de tabelas}

Tabela 5.1 - Empreendimentos de Geração Vencedores no Leilão de Geração no 01/2019-ANEEL. 61

Tabela 5.2 - Carga por Barramento do Sistema Isolado de Roraima. $\quad 64$

Tabela 5.3 - Capacidade Instalada das Usinas do Sistema Isolado de Roraima.

65

Tabela 5.4 - Despacho de cada usina por patamar de penetração de UFV no

Sistema Isolado de Roraima. $\quad 67$

Tabela 5.5 - Capacidade Nominal dos Dispositivos de Armazenamento de Energia.

68

Tabela 5.6 - Casos de referência para análise dinâmica do Sistema Isolado de Roraima.

Tabela C.1 - Parâmetros do modelo SM04 (UTE Monte Cristo Sucuba, UTE Palmaplan e UTE Baliza 2) 99

Tabela C.2 - Parâmetros do modelo SM05 (UTE Bonfim, UTE Cantá, UTE Baliza 1, UTE Pau Rainha, UTE Santa Luz e UTE Forte de São Joaquim) 101 Tabela C.3 - Parâmetros do modelo GOV08 (UTE Jaguatirica II vapor) 102 Tabela C.4 - Parâmetros do modelo GOV11 (UTE Jaguatirica II gás) 103 Tabela C.5 - Parâmetros do modelo GOV19 (UTE Bonfim, UTE Cantá, UTE Baliza 1, UTE Pau Rainha, UTE Santa Luz e UTE Forte de São Joaquim)

Tabela C.6 - Parâmetros do modelo GOV19 (UTE Monte Cristo Sucuba, UTE Palmaplan e UTE Baliza 2) 105

Tabela C.7 - Parâmetros do modelo AVR23 (UTE Jaguatirica II gás) 107

Tabela C.8 - Parâmetros do modelo AVR23 (UTE Jaguatirica II vapor) 107

Tabela C.9 - Parâmetros do modelo AVR24 (UTE Monte Cristo Sucuba, UTE

Palmaplan e UTE Baliza 2) 109

Tabela C.10 - Parâmetros do modelo AVR25 (UTE Bonfim, UTE Cantá, UTE Baliza 1, UTE Pau Rainha, UTE Santa Luz e UTE Forte de São Joaquim)

Tabela C.11 - Parâmetros do modelo PS06 (UTE Jaguatirica II gás) 113

Tabela C.12 - Parâmetros do modelo PS06 (UTE Jaguatirica II vapor) 114 Tabela C.13 - Parâmetros do modelo PS06 (UTE Pau Rainha, UTE Santa Luz e UTE Forte de São Joaquim) 
Tabela C.14 - Parâmetros do modelo PS06 (UTE Bonfim, UTE Cantá, UTE Monte Cristo Sucuba, UTE Palmaplan, UTE Baliza 1 e UTE Baliza 2) 116

Tabela C.15 - Parâmetros do modelo simplificado para os Dispositivos de Armazenamento de Energia no controle de Potência Ativa 117

Tabela C.16 - Parâmetros do modelo simplificado para os Dispositivos de Armazenamento de Energia no controle de Potência Reativa 117

Tabela C.17 - Parâmetros do modelo do Controle de Usinas Fotovoltaicas 123

Tabela C.18 - Parâmetros de Ajuste do Esquema Regional de Alívio de Carga para o Sistema Roraima 124

Tabela C.19 - Parâmetros de Ajuste de Proteção de Sobretensão 125

Tabela C.20 - Parâmetros da Modelagem de Carga 125 


\section{Nomenclatura}

$\delta$ - ângulo do rotor

$\alpha$ - aceleração angular

$C$ - capacitância

$D$ - coeficiente de amortecimento

$G$ - condutância

$H$ - constante de inércia

$i$ - corrente

$1 / R$ - energia de regulação da máquina

$R$ - estatismo

$f$ - frequência

$K$ - ganho de um controlador

$Z$ - impedância

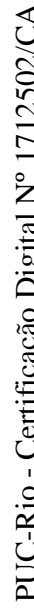

$p_{f}$ - número de polos da máquina síncrona

$S_{\text {base }}$ - potência aparente nominal

$P$ - potência ativa

$P_{G}$ - potência de um gerador

$P_{\text {carga }}$ - potência de uma carga

$P_{e}$ - potência elétrica

$P_{m}$ - potência mecânica

$Q$ - potência reativa

$V$ - tensão

$T$ - torque

$T_{a}$ - torque acelerante

$T_{e}$ - torque elétrico

$T_{m}$ - torque mecânico

$W$ - trabalho

$\omega$ - velocidade angular

$\omega_{\text {ref }}$ - velocidade angular de referência 


\section{Siglas e Abreviações}

ANEEL: Agência Nacional de Energia Elétrica

BESS: Battery Energy Storage System (Sistema de Armazenamento por Baterias)

CA: Corrente Alternada

CAES: Compressed Air Energy Storage (Armazenamento por Ar Comprimido)

CAISO: California Independent System Operator (Operador Independente do Sistema da Califórnia)

CC: Corrente Contínua

CMSE: Comitê de Monitoramento do Setor Elétrico

DLC: Double-layer Capacitors (Capacitores de Dupla Camada)

EPE: Empresa de Pesquisa Energética

ERAC: Esquema Regional de Alívio de Carga

ESD: Energy Storage Devices (Dispositivos de Armazenamento de Energia)

ESS: Energy Storage System (Sistemas de Armazenamento de Energia)

EV: Electrical Vehicle (Veículo Elétrico)

FB: Flow Battery (Bateria de Fluxo)

FESS: Flywheel Energy Storage System (Volante de Inércia)

HFC: Hydrogen Fuel Cells (Armazenamento de Hidrogênio com Células

Combustíveis)

HVDC: High Voltage Direct Current (Transmissão CC em Alta Tensão)

MME: Ministério de Minas e Energia

ONS: Operador Nacional do Sistema

PHS: Pumped Hydro Storage (Armazenamento por Bombeamento de Água)

SEB: Sistema Elétrico Brasileiro

SIN: Sistema Interligado Nacional

SMES: Super-Conductive Magnetic Energy Storage (Supercondutores

Magnéticos Armazenadores de Energia)

TES: Thermal Energy Storage (Sistema de Armazenamento Térmico)

UFV: Usina Fotovoltaica

UHR: Usina Hidrelétrica Reversível

UTE: Usina Térmica

V2G: Vehicle to Grid (Veículos Elétricos na Rede)

VSC: Voltage Source Converter (Conversor Fonte de Tensão) 


\section{Introdução}

\section{1.}

\section{Considerações Iniciais}

A integração de fontes renováveis intermitentes, como geração eólica e fotovoltaica, é uma realidade dentro da matriz energética brasileira. A expectativa de crescimento dessas fontes se mantém na política energética do país, dada a pressão socioambiental para substituição de fontes baseadas em combustíveis fósseis e usinas hidrelétricas que necessitam de grandes reservatórios. Em termos de planejamento da operação elétrica, o aumento da penetração de fontes de energia intermitentes diminui a flexibilidade operativa, podendo colocar em risco a segurança e a qualidade do suprimento de energia dos sistemas elétricos de potência.

A substituição de geradores síncronos convencionais por fontes renováveis intermitentes vem sendo amplamente debatida no setor elétrico e tem como consequência a redução da inércia girante do sistema, provocando uma diminuição da capacidade de regulação primária e, consequentemente, aumento das taxas de variação de frequência na rede. Os dispositivos de armazenamento de energia (Energy Storage Devices - ESD) surgem como uma alternativa viável para contornar essas dificuldades. Esta visão foi abordada em [1], onde se utilizou de armazenamento de energia de ação rápida para fornecer suporte dinâmico no controle de frequência em sistemas isolados com alta penetração de geração por fontes renováveis, com simulações de interrupção abrupta de geração. Ou seja, em futuro próximo, com a substituição progressiva de unidades síncronas convencionais por energia eólica e fotovoltaica, haverá um enfraquecimento da resposta inercial dos sistemas de energia, principalmente em redes isoladas, sendo sugestiva a utilização de dispositivos de armazenamento de energia.

Há expectativas de crescimento acentuado no segmento de armazenamento de energia para os próximos 20 anos, conforme publicado pela 
Bloomberg NEF [2]. Nesta mesma publicação, há previsão da capacidade instalada de armazenamento de energia alcançar $1.095 \mathrm{GW}$ com $2.850 \mathrm{GWh}$ somando investimentos da ordem de U\$ 662 bilhões como visto na Figura 1.1. Para esse caso não estão contempladas as usinas hidrelétricas reversíveis (UHR).

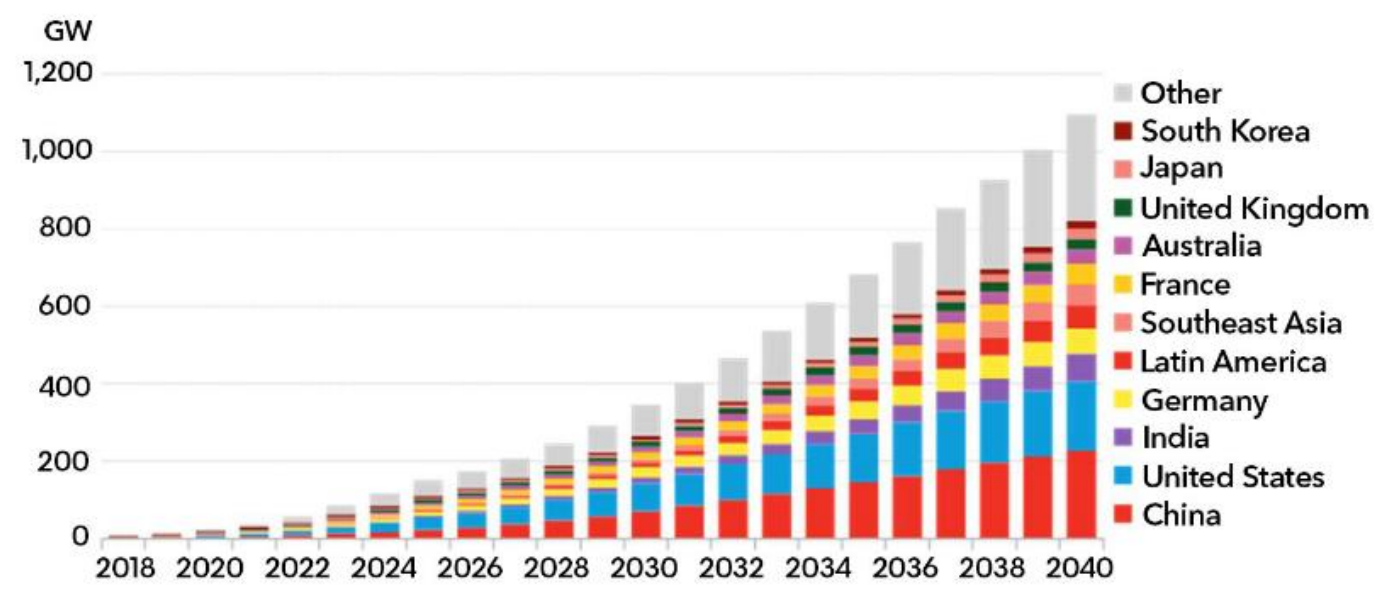

Figura 1.1 - Previsão de Crescimento da Capacidade de Armazenamento de Energia (MW) [2].

Segundo os pesquisadores, isto será possível devido à queda dos custos das baterias de íon de lítio, além dos 85\% de redução já realizada entre 2010 e 2018. Esta redução está sendo motivada principalmente pelo crescimento do mercado de veículos elétrico (EV) e de equipamentos eletrônicos.

O desenvolvimento dessa tecnologia e a redução de custos de produção vêm tornando economicamente viáveis diversas aplicações em sistemas de potência. Uma das aplicações de sistemas de armazenamento de energia por bateria (Battery Energy Storage System - BESS) pode ser no controle de tensão local [3], coordenado com outros elementos do sistema, mesmo considerando alta penetração de fontes intermitentes. Aplicações utilizando Veículos Elétricos (Electrical Vehicle - EV) conectados ao sistema elétrico, denominado de "vehicle to grid - V2G", podem auxiliar no controle de frequência enquanto estão estacionados em uma estação de carregamento [4]. Essa aplicação foi analisada em ilhas portuguesas [5] em comparação com outros tipos de armazenamento, concluindo que o controle de frequência é bem sucedido quando realizado através de armazenadores de energia. 
Nos casos de aplicações de armazenamento em micro redes com geração distribuída, uma metodologia baseada em algoritmo genético foi concebida para determinação do dimensionamento ótimo, tipo e localização do ESD em sistemas de distribuição, garantindo custos reduzidos e melhorando a qualidade do sistema em termos de perdas de energia, níveis de tensão e carregamento dos ramais de distribuição [6]. Também já foi avaliado um método [7] para a utilização de sistemas de armazenamento em conjunto com painéis fotovoltaicos, para que sejam cumpridos os requisitos de variação de frequência da rede para planta de geração, exigida pelas regras do sistema local.

Pelo lado dos consumidores, principalmente os comerciais e pequenas indústrias, a utilização de armazenamento de energia já alcançou benefícios econômicos interessantes quando múltiplas aplicações em conjunto auxiliaram o sistema elétrico [8], Neste caso, consumidores comerciais diminuíram seus custos com a redução da demanda de pico (Peak Shaving) e obtenção de receita pela participação no mercado de regulação de frequência da CAISO (California Independent System Operator). Portanto, o dimensionamento considerando a tecnologia aplicada, tipo e localização, e a viabilidade econômica do uso de armazenamento estão diretamente relacionados com as aplicações que esses dispositivos devem cumprir no sistema elétrico de potência.

Para sistemas isolados, o comportamento de ESD na dinâmica e no reestabelecimento de energia também deve ser avaliado como uma alternativa de planejamento e operação de sistemas elétricos. Um método foi apresentado [9] para dimensionamento de armazenamento de energia fornecendo uma reserva de potência a ser utilizada na etapa de regulação primária da frequência e aplicado em [10], especificamente para sistemas isolados com constantes de inércia equivalente reduzidas. Este controle de frequência pode ser apresentado como uma solução de armazenamento de energia multinível [11], onde diferentes tipos de armazenadores associados podem efetivamente regular a frequência do sistema, auxiliando tanto na etapa de resposta inercial como na etapa de regulação primária e secundária da frequência.

Neste contexto, soluções utilizando ESD podem ser aplicadas no sentido de permitir aumento na participação de fontes renováveis de forma segura e robusta, e também, aumentar a eficiência econômica desse subsistema elétrico, com a substituição de geradores síncronos convencionais por fontes renováveis intermitentes menos custosas. Entretanto, não se sabe qual o montante de penetração dessas novas fontes renováveis e qual seria 0 melhor 
dimensionamento de ESD que equilibrasse a relação custo-benefício e desempenho dinâmico.

\section{2.}

\section{Objetivos}

Com a apresentação das considerações iniciais e um resumo das principais referências na área, o objetivo desta dissertação é avaliar o comportamento dinâmico de sistemas elétricos isolados, utilizando como exemplo o caso do estado de Roraima que apresenta esta característica desde a interrupção da interligação Brasil - Venezuela, onde soluções utilizando ESD podem ser aplicadas no sentido de permitir aumento na participação de fontes renováveis. A metodologia proposta consiste na substituição gradual de geradores síncronos convencionais atualmente instalados por fontes renováveis intermitentes e dispositivos de armazenamento de energia, analisando os respectivos benefícios no desempenho dinâmico do sistema elétrico daquela região.

\section{3.}

\section{Estruturação da Dissertação}

Esta dissertação está organizada da seguinte forma:

- No Capítulo 1, apresenta-se a introdução desta dissertação, com uma visão atual da utilização de dispositivos de armazenamento de energia e a perspectiva para o futuro;

- No Capítulo 2, discutem-se as características e conceitos gerais dos principais sistemas de armazenamento de energia. Em seguida, são apresentadas as principais aplicações em sistemas elétricos de potência com seus pontos positivos e negativos, indicando a viabilidade do uso no Sistema Elétrico Brasileiro.

- No Capítulo 3, apresentam-se os fundamentos do controle de frequência e como é a regulação de frequência em sistemas elétricos de potência. 
- No Capítulo 4, apresenta-se a modelagem dinâmica de sistemas de armazenamento de energia ESS utilizada nas simulações.

- No Capítulo 5, as características do sistema elétrico de Roraima e as simulações realizadas neste sistema isolado são apresentadas. É também proposta uma metodologia para avaliar quais são as melhores decisões de planejamento e de operação do ponto de vista de desempenho dinâmico deste sistema elétrico.

- No Capítulo 6, finalmente, apresentam-se as conclusões desta dissertação e as sugestões para trabalhos futuros. 
2

\section{Armazenamento de Energia}

\section{1.}

\section{Introdução}

Neste capítulo apresenta-se uma breve descrição dos principais sistemas de armazenamento de energia que podem ter sua aplicação vislumbrada nos sistemas elétricos de potência, destacando as características mais relevantes de cada tipo de armazenador de energia. Foram utilizados estudos específicos como referência [12] [13] com as definições, avaliações e usabilidade de cada tecnologia de armazenamento, incluindo como essas questões estão sendo discutidas no âmbito do planejamento [14].

Adiante, são apresentadas as principais aplicações em sistemas elétricos de potência com seus pontos positivos e negativos, indicando a viabilidade do uso no Sistema Elétrico Brasileiro (SEB).

\section{2.}

\section{Principais Tecnologias para Armazenadores de Energia}

Para apresentar as principais tecnologias para armazenamento de energia fez-se uma classificação das tecnologias existentes para armazenamento de energia que foi adaptada de [12] como pode ser visto pela Figura 2.1. 


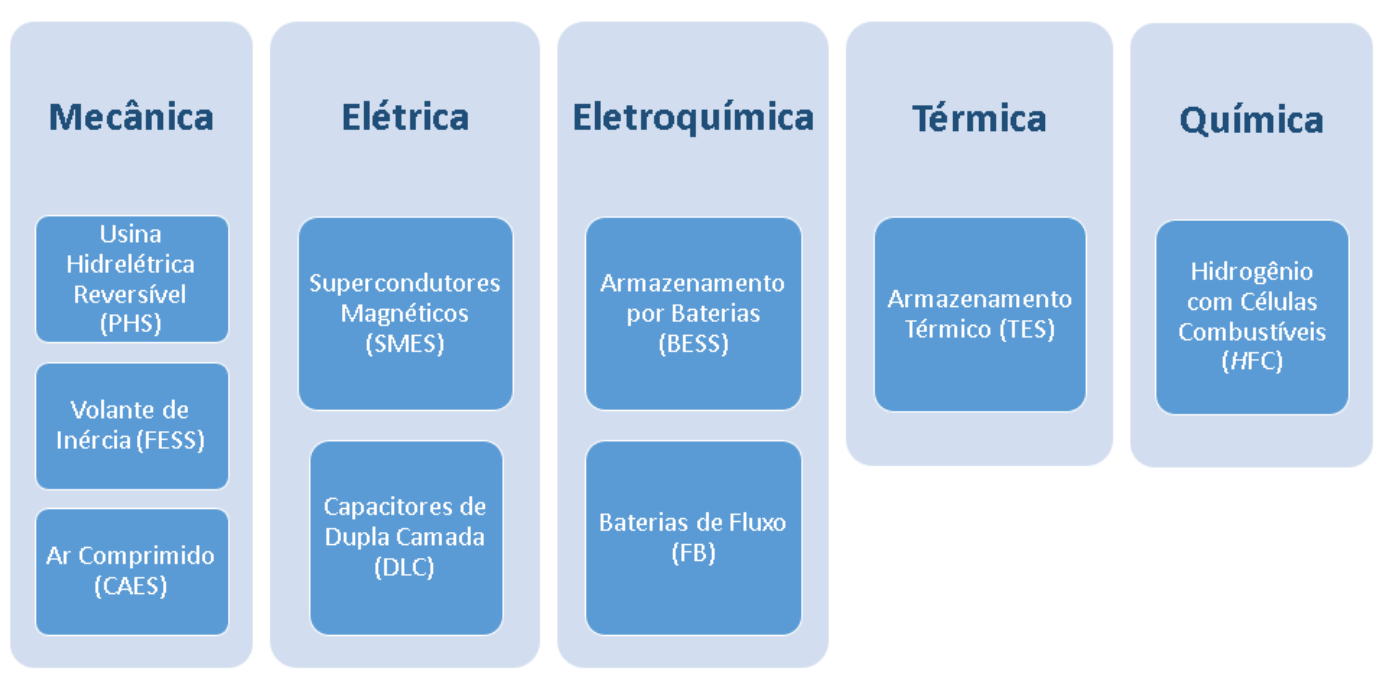

Figura 2.1 - Principais tecnologias de armazenamento de energia. Adaptada de [12].

\subsection{1.}

\section{Mecânica}

As tecnologias de armazenamento de energia mecânica armazenam energia sob a forma cinética ou potencial. O Armazenamento de Energia por Bombeamento de Água (Pumped Hydro Storage - PHS), conhecida nacionalmente como Usina Hidrelétrica Reversível - UHR, considera o excedente de energia do sistema para bombear água do reservatório à jusante (altura inferior) para o reservatório à montante (altura superior), armazenando energia que poderá ser utilizada acionando as turbinas em períodos de elevada demanda de geração. O PHS tem elevado tempo de vida útil, ciclos de operação ilimitados com eficiência típica em torno de $80 \%$ e sua utilização está diretamente relacionada com as características geográficas da região. Em um estudo de caso [15], associado com uma planta de geração eólica, o PHS mostrou-se eficiente auxiliando na utilização máxima da fonte renovável em que o excedente de geração bombeava água para um reservatório.

O Volante de Inércia (Flywheel Energy Storage System - FESS) é um dispositivo mecânico dotado de uma massa girante cilíndrica que permite o armazenamento de energia cinética. O FESS pode consumir energia acelerando a massa girante até permanecer em uma velocidade limite armazenando energia, e assim, quando necessário, reverter para o modo geração fornecendo energia elétrica ao sistema até a sua capacidade de armazenamento. Esse dispositivo é melhor aproveitado durante pequenos períodos de tempo, 
principalmente na qualidade e continuidade do serviço. Apesar de eficiente nos ciclos de operação, o FESS apresenta perdas significativas quando não estão em utilização. O Sistema de Armazenamento por Ar Comprimido (Compressed Air Energy Storage - CAES) utiliza a oferta adicional de energia elétrica para comprimir o ar em estruturas subterrâneas ou em tanques de armazenamento que, posteriormente, podem ser utilizados juntamente com o gás natural na geração de energia elétrica em turbinas sob pressão. A baixa eficiência do CAES atrelada às limitações geográficas para aproveitamento desse tipo de armazenamento reduz a possibilidade de utilização nos sistemas de potência.

\subsection{2.}

\section{Elétrica}

Os sistemas de armazenamento de energia elétrica, são assim caracterizados, pelo princípio de armazenamento através de campo eletromagnético/eletrostático. São dois principais tipos de armazenamento utilizando essa tecnologia: Os Supercondutores Magnéticos (Super-Conductive Magnetic Energy Storage - SMES) e os Capacitores de Dupla Camada (DoubleLayer Capacitors - DLC). Os SMES armazenam energia em um campo magnético criado pela passagem de corrente numa bobina constituída por um material supercondutor para ser exportada ao sistema elétrico quando necessário, através do sistema de controle de potência desse dispositivo. Esses sistemas apresentam tempos rápidos de resposta e ciclos de operação eficientes, mas quase não são utilizados em sistemas de potência em função de suas aplicações serem limitadas com capacidades nominais reduzidas, atendendo somente controle de qualidade de energia em pequenas instalações industriais.

Os DLCs são constituídos por duas camadas metálicas (eletrodos), impregnadas com um material dielétrico constituído por um líquido eletroquímico (eletrólito), onde a energia é armazenada quando se tem excedente de geração e descarregada quando necessário. Os supercapacitores não são indicados para armazenamentos por longos períodos de tempo pois apresentam elevada taxa de auto descarga, entretanto possuem eficiência elevada e são facilmente recicláveis. Atualmente sua aplicação ainda é restrita em sistemas de energia em função do custo elevado de investimento e da baixa densidade de energia. 


\subsection{3.}

\section{Eletroquímica}

As tecnologias de armazenamento de energia eletroquímica armazenam energia através de reações químicas e são as mais utilizadas no mercado. As principais utilizações de Armazenamento por Baterias (Battery Energy Storage System - BESS) são através de baterias de chumbo-ácido ( $\mathrm{PbA})$, baterias de sódio-enxofre ( $\mathrm{NaS}$ ) e baterias de íons de lítio (Li-ion). São compostas por várias células eletroquímicas em série ou em paralelo para se obter a tensão e a capacidade de armazenamento desejada. Essas células possuem um eletrólito que separam dois eletrodos (anodo e catodo), onde há troca de elétrons permitindo a circulação de uma corrente elétrica no circuito elétrico externo. A pequena dimensão e peso, o rápido tempo de resposta e o menor custo de investimento são as principais características que tornam os BESS o sistema de armazenamento de maior progressão nos sistemas elétricos de potência do mundo. Mesmo com elevada eficiência no ciclo de operação, pode haver redução significativa do tempo de vida útil quando a profundidade de descarga das baterias não é realizada de forma adequada. As Baterias de Fluxo (Flow Battery - FB) apresentam funcionamento parecido com as baterias anteriores, nesse caso, os eletrólitos circulam para o eletrodo (anodo e catodo) por meio de bombas, onde também ocorrem as reações químicas.

\subsection{4.}

\section{Térmica}

Os Sistemas de Armazenamento Térmicos (Thermal Energy Storage TES) são sistemas que permitem a conversão de energia elétrica em energia térmica por meio de aquecedores resistivos que podem ser termicamente armazenados em reservatórios com isolamento adequado que dissipem pouco calor. Nos períodos de necessidade de geração, a energia térmica armazenada pode ser utilizada no acionamento de turbinas a vapor para geração de energia elétrica. Pela dificuldade na baixa eficiência nos ciclos de operação e na manutenção da temperatura armazenada sem que haja perdas de calor, faz com que esse tipo de armazenamento não seja selecionado como o melhor armazenador de energia. 


\subsection{5.}

\section{Química}

O Armazenamento de Hidrogênio com Células Combustíveis (Hydrogen Fuel Cells - FC) consiste em utilizar a energia elétrica excedente através do armazenamento do hidrogênio resultante da eletrólise da água, processo que permite separar o hidrogênio e o oxigênio contidos na molécula de água. $O$ hidrogênio pode ser armazenado em um tanque como gás comprimido ou no estado líquido a baixas temperaturas por longos períodos de tempo, possuindo grande densidade de energia. Nos períodos de necessidade de geração, utilizase o hidrogênio armazenado combinado com o oxigênio presente na atmosfera em uma célula combustível que através de reação eletroquímica produz energia elétrica e como subproduto água. A eficiência desse sistema de armazenamento baseado em hidrogênio é baixa $(\leq 50 \%)$ em comparação com as demais. Entretanto, estudos demonstram a viabilidade desta tecnologia em sistemas elétricos, tendo já sido aplicada em sistemas isolados e em centrais elétricas híbridas.

\subsection{6.}

\section{Outras Tecnologias}

Adicionalmente, já é considerado o uso de Veículos Elétricos (Electrical Vehicle - EV) em aplicações do sistema elétrico de potência de forma a contribuir com a segurança e robustez da operação, denominado de "vehicle to grid - V2G" [4]. Além disso, existem outros tipos de armazenamento de energia muito pouco utilizados que não serão comentados na presente dissertação por não ter aplicações nos sistemas elétricos de potência. 


\section{3.}

\section{Aplicações em Sistemas Elétricos de Potência}

Existem diferentes tipos de aplicação de armazenamento de energia que podem ser utilizados em sistemas elétricos de potência. Inclusive, esses dispositivos podem estar disponíveis para o operador, para os agentes de geração, transmissão e distribuição e até para os consumidores. Neste item, serão apresentadas as principais aplicações para o sistema elétrico brasileiro.

\subsection{1.}

\section{Deslocamento de Geração}

Dispositivos de armazenamento de energia podem ser aplicados para deslocamento temporal de geração renovável, por exemplo eólica e fotovoltaica. Neste caso, o principal objetivo é armazenar energia nos períodos de grande oferta para fornecer energia nos momentos de maior necessidade. Usinas fotovoltaicas juntamente com dispositivos de armazenamento, podem propiciar energia fora do horário de insolação diário, ou seja, teriam sua geração deslocada no tempo. Já do ponto de vista de usinas eólicas, o excedente de geração, normalmente no patamar de carga leve, pode ser deslocado e aproveitado em um patamar maior de carga.

A Figura 2.2 mostra um exemplo em que há deslocamento da geração fotovoltaica até o fim do patamar de carga pesada fazendo com que a geração solar contribua no momento de maior carga do sistema. Isto é obtido pelo efeito combinado da geração fotovoltaica com armazenamento. 


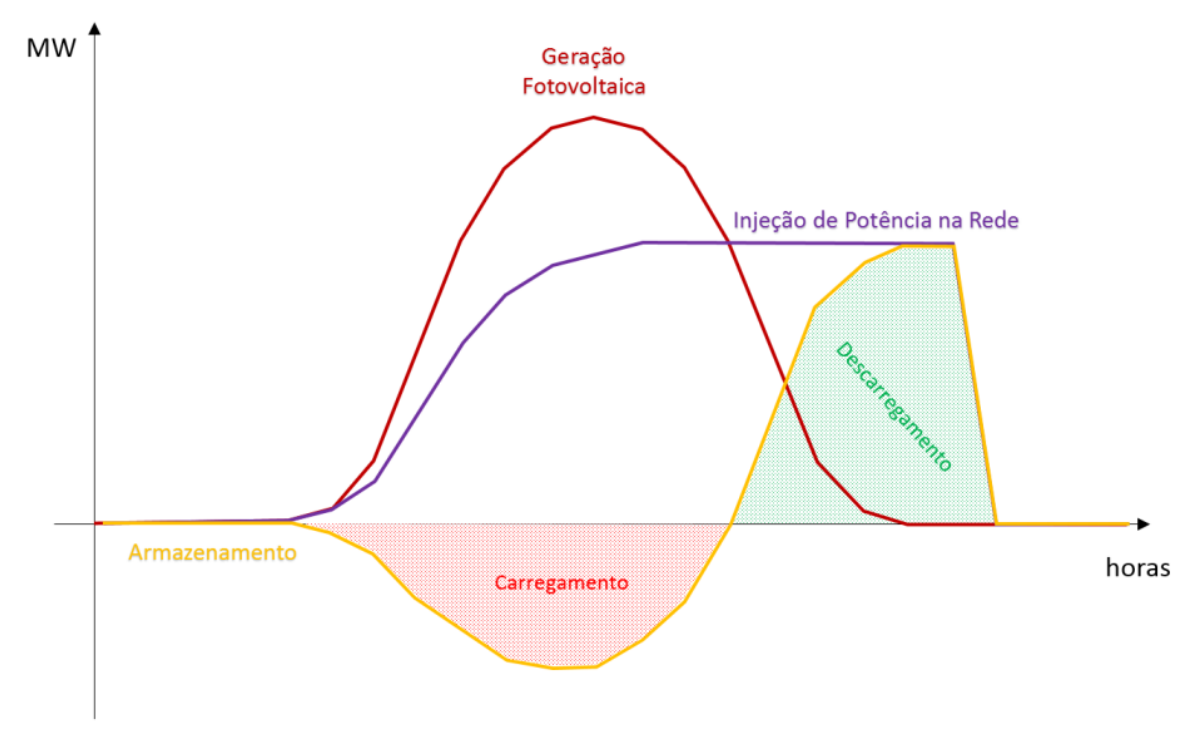

Figura 2.2 - Deslocamento de geração para a carga pesada.

Qualquer que seja o interesse no deslocamento temporal de um sistema de geração, uma estrutura de armazenamento pode viabilizar essa aplicação. No entanto, para essa atividade, torna-se necessário uma boa capacidade de armazenamento em MWh e também, alta capacidade de injeção de potência instantânea em MW. Outro ponto, é a precificação dos benefícios dessa aplicação em relação a não utilização de dispositivos de armazenamento. Em alguns países, o preço da energia é cotado por patamar e até por hora, enquanto em outros países não se tem distinção de preço da energia durante o dia, o que elimina o equilíbrio econômico financeiro dessa aplicação.

\subsection{2.}

\section{Suavização da Intermitência de Fontes Renováveis}

A crescente participação de fontes renováveis na matriz de geração trouxe a preocupação dos operadores do sistema com a intermitência deste tipo de energia. A geração eólica depende da velocidade dos ventos e de quão constantes eles são. Assim, a curva de geração eólica tem grande variabilidade durante as horas do dia. A geração fotovoltaica depende da incidência solar sobre os painéis receptores e também apresentam alta variabilidade diária quando há bloqueios por tempo fechado ou nuvens. Ademais, evidentemente, só 
há geração durante o período diurno. Nesse sentido, o uso de dispositivos de armazenamento de energia pode suavizar a intermitência dessa geração durante o dia de forma a tornar a operação do sistema elétrico mais previsível e com isso, mais robusta.

Na Figura 2.3 temos a utilização de armazenamento para modular a injeção de potência na rede integrada à geração fotovoltaica. Modelos de previsão estabelecem um valor de injeção de potência na rede e o comportamento da curva de geração fotovoltaica cria um excedente de geração que carrega os dispositivos de armazenamento. Posteriormente, fora do horário de incidência solar, esse excedente poderá ser utilizado nos momentos de pico de carga do sistema.

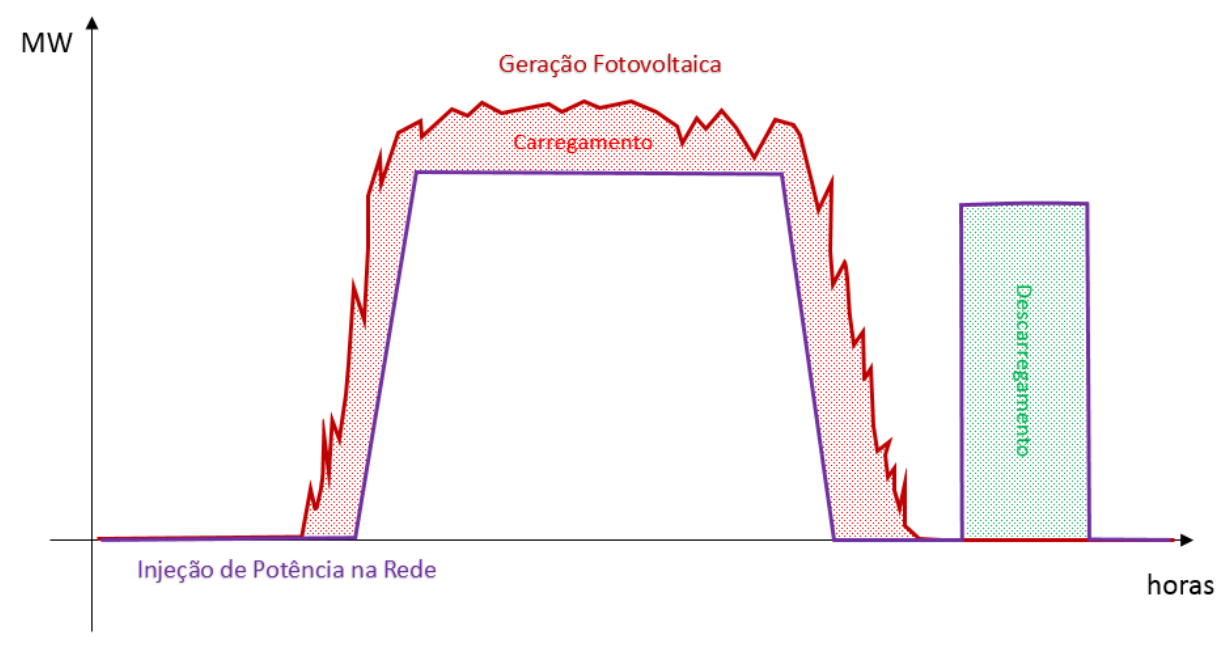

Figura 2.3 - Suavização da intermitência de geração fotovoltaica.

Em caso de sombra ou tempo fechado não previstos pelos modelos, os dispositivos de armazenamento auxiliam na modulação da injeção de potência na rede, utilizando o excedente de energia que foi armazenada antes da interrupção de incidência solar; ver Figura 2.4. 


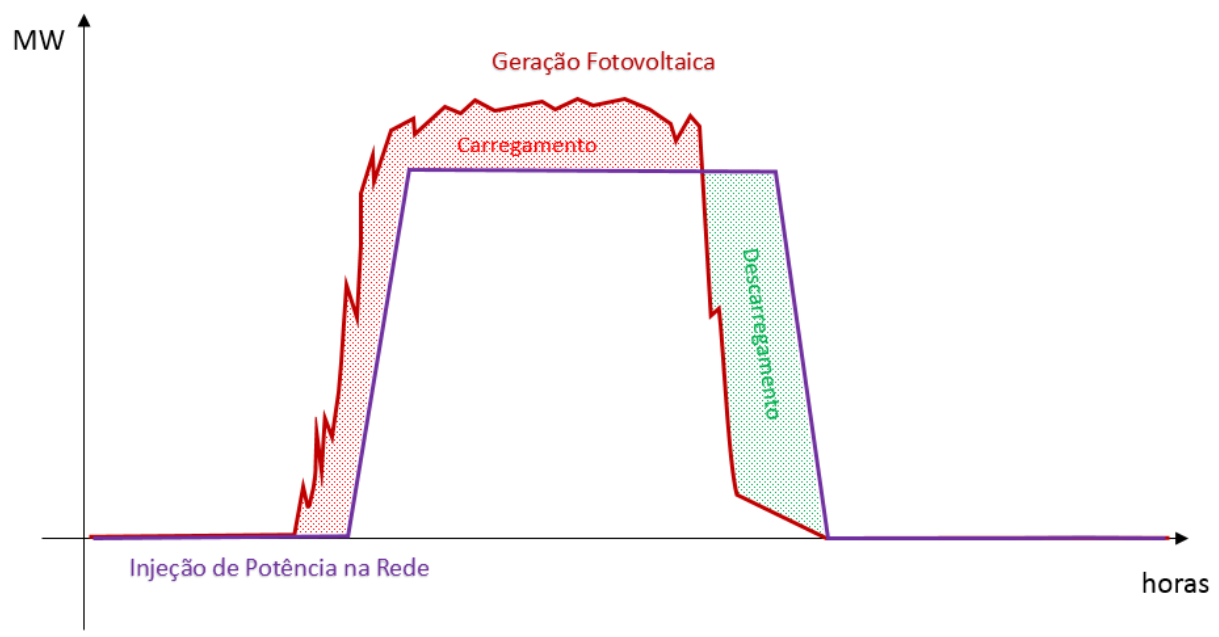

Figura 2.4 - Suavização da intermitência de geração fotovoltaica com bloqueio por nuvem.

Uma ilustração da variabilidade da geração eólica durante o dia pode ser vista na Figura 2.5, com faixas de previsão de geração que são definidas através de modelos de previsão. Assim, com o auxílio integrado de dispositivos de armazenamento de energia, a programação da operação poderia definir patamares de injeção de potência na rede, através de geração eólica, dentro da faixa de previsão. Desta forma, quando a geração de energia eólica fosse superior ao montante programado, os dispositivos storages armazenariam energia, e quando fosse inferior ao programado, forneceria energia para o sistema.

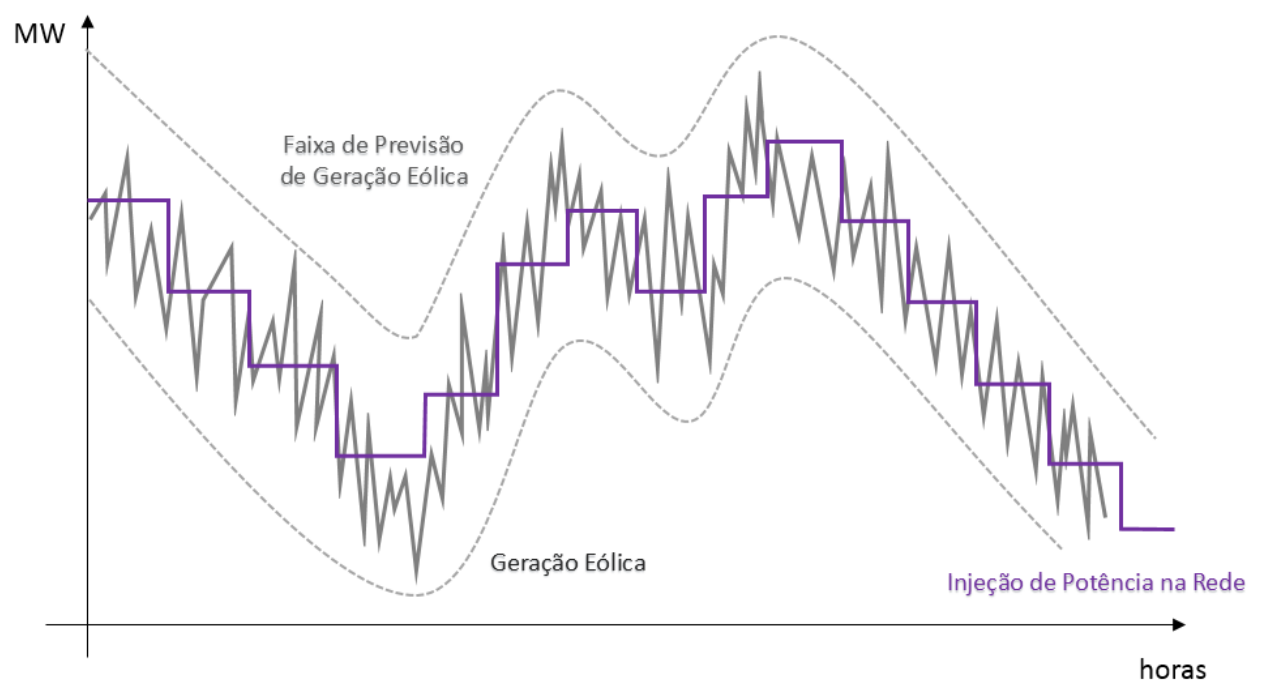

Figura 2.5 - Suavização da intermitência de geração eólica. 
Essa aplicação ajuda a promover ainda mais a participação de fontes renováveis na matriz de geração atentando para a segurança operativa e maior controle da programação e operação do sistema.

\subsection{3.}

\section{Controle de Carga da Ponta}

O controle de carga da ponta (período de maior consumo) recebe uma atenção especial nos sistemas elétricos de potência, dado a sua importância para o planejamento de expansão da transmissão. Linhas de transmissão e transformadores de potência são dimensionados no longo prazo para atendimento à maior demanda do sistema, que normalmente ocorre em um período de 3 horas durante um dia. Além disso, para atender esse pico de demanda, ocasionalmente, utiliza-se geração térmica (preços elevados e ambientalmente poluente) no chamado "fechamento da ponta de carga".

As aplicações de dispositivos de armazenamento de energia para controle de carga da ponta podem reduzir as perdas elétricas da transmissão por estarem localizadas próximo a carga reduzindo o montante de potência a ser transmitido, e também, postergar investimentos em expansão de linhas de transmissão e de transformadores que apresentam as piores condições de carregamento em regime normal de operação.

No que tange o custo da operação, ou seja, valor necessário para suprir toda a demanda de energia solicitada naquele instante, quando em períodos de elevado pico de demanda, são programados despachos de geração térmica, elevando o custo operativo. Com o uso de armazenamento para minimizar esse pico de demanda, pode não ser necessário o despacho de geração térmica, evitando o aumento do custo de operação.

A Figura 2.6 mostra um exemplo teórico de como poderia ser realizada a gestão do dispositivo de armazenamento de energia no controle de carga da ponta. Aproveita-se o período de menor consumo de energia para armazenar energia que será fornecida ao sistema no período de pico de demanda no ano zero $(A+0)$. Assim, quanto maior a potência e a capacidade de armazenamento, mais próximo de 200 MVA seria o comportamento da demanda vista pelo sistema. Na análise que segue, se supõe que essa seja uma curva de carga atendida por três transformadores de 100 MVA, que suportem $30 \%$ de 
sobrecarga em casos de contingência. Para o ano $A+0$, o carregamento de cada um dos transformadores, em regime normal de operação, está em torno de $85 \%$, ou seja, próximo a 260 MVA. Em caso de contingência de um dos três transformadores, o carregamento dos dois transformadores remanescentes será próximo a $130 \%$, ou seja, no limite do atendimento ao critério $n-1$ estabelecido no setor elétrico nacional. Para o planejamento da expansão, considerando cinco anos à frente, com um crescimento natural da carga dessa subestação, um novo transformador de 100 MVA seria necessário para atendimento aos critérios de $\mathrm{N}$ e $\mathrm{N}-1$. Entretanto, o uso de dispositivos de armazenamento de energia poderia postergar o investimento em um novo transformador fazendo o controle de carga da ponta. $O$ controle das baterias não permitiria sobrecargas em regime normal de operação, e em casos de contingência, atrelados a um esquema especial de proteção, forneceriam energia até o limite de sobrecarga dos transformadores remanescentes. Dependendo da capacidade de armazenamento e da potência instantânea do conjunto, investimentos podem ser postergados além dos 5 anos sugeridos neste exemplo teórico.

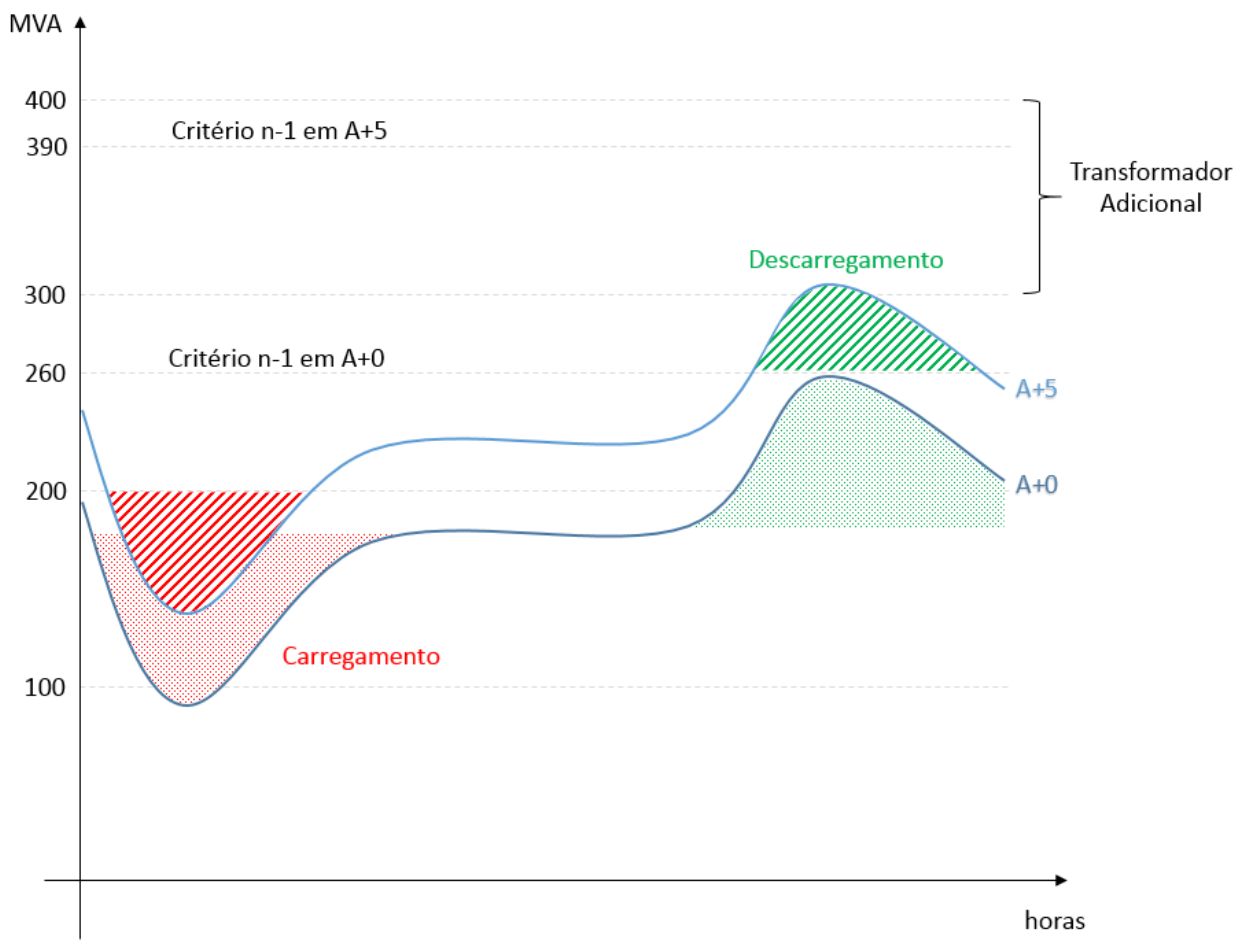

Figura 2.6 - Controle de carga da ponta. 
Vários podem ser os interesses na gestão e controle de carga da ponta. Nem sempre os períodos de pico de demanda de energia acontecem em poucas horas, em horários já conhecidos ou em todos os meses do ano. Para análise dessa aplicação utilizando armazenamento de energia é necessário o entendimento de toda a situação para que seja tomada a decisão mais eficiente possível.

\subsection{4.}

\section{Regulação de Tensão}

No Brasil, a qualidade do fornecimento de energia elétrica pelas distribuidoras é objeto de fiscalização da Agência Nacional de Energia Elétrica ANEEL. Há preocupação dos centros de operação em controlar a tensão dentro da faixa recomendada nos procedimentos de rede utilizando todos os recursos que proveem potência reativa. Os dispositivos de armazenamento de energia também podem cumprir essa função tanto em regime normal de operação quanto em contingências severas no sistema elétrico.

Nessa aplicação, o principal foco é no distúrbio de grande porte, quando o sistema necessita de recursos adicionais de potência reativa com tempo de resposta adequado para que não se chegue ao colapso. Conforme a Figura 2.7, parametriza-se uma banda morta maior para que as variações naturais de tensão sejam controladas com outros recursos da rede e que a contribuição dos dispositivos de armazenamento de energia aconteça em situações mais graves.

É possível também controlar a tensão juntamente com outros equipamentos de fornecimento de potência reativa reduzindo a banda morta, contudo, exigiria esforço adicional dos dispositivos de armazenamento que absorveriam ou forneceriam potência reativa a todo momento, reduzindo assim a vida útil dos elementos.

Pela Figura 2.7, nota-se a absorção de potência reativa (Mvar positivo) quando a tensão ultrapassa o limite superior da banda morta pré-definida e injeção de potência reativa (Mvar negativo) quando a tensão ultrapassa o limite inferior da faixa. Evidentemente, quando menor for a banda morta, maior será a quantidade de operações efetuadas por esse dispositivo de armazenamento de energia. Assim, a utilização da aplicação de regulação de tensão torna o sistema elétrico mais robusto e resistente a distúrbios severos. 


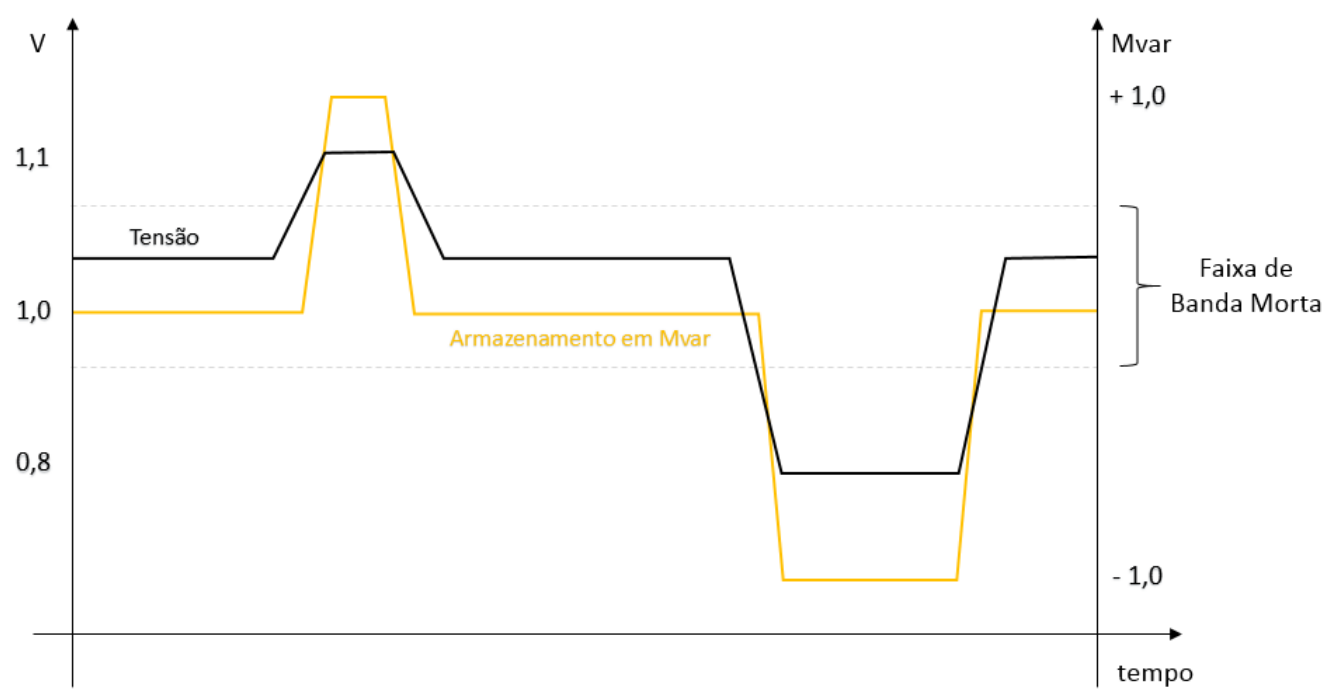

Figura 2.7 - Controle de regulação de tensão.

Não seria economicamente viável realizar um investimento em armazenadores de energia apenas para esta aplicação, quando se têm outros equipamentos que cumprem o mesmo papel com custos reduzidos. Entretanto, também se deve considerar esta aplicação na análise de viabilidade do empreendimento.

\subsection{5.}

\section{Regulação de Frequência}

Existem diversas aplicações nos sistemas de potência de dispositivos de armazenamento de energia efetuando a regulação primária de frequência, principalmente em sistemas isolados que não possuem elementos de geração excedentes para sincronizar na rede de operação. Assim, perde-se a capacidade de controlar o balanço carga - geração e consequentemente a frequência do sistema.

O comportamento destes dispositivos quanto à frequência fica evidente na Figura 2.8 com a curva de capabilidade do elemento armazenador. Dada uma banda morta de frequência e de consumo/injeção de potência, em casos de subfrequência no sistema, os dispositivos de armazenamento injetarão potência ativa de forma a neutralizar o balanço carga - geração, descarregando a energia armazenada. Por outro lado, em casos de sobrefrequência, os dispositivos de 
armazenamento consumirão ainda mais potência ativa, também de forma a neutralizar o balanço carga - geração, carregando o sistema de armazenamento de energia.

Pelo rápido tempo de resposta, esses dispositivos storages são importantes no controle de frequência em casos de distúrbios e podem aumentar de forma significativa a segurança sistêmica da operação.

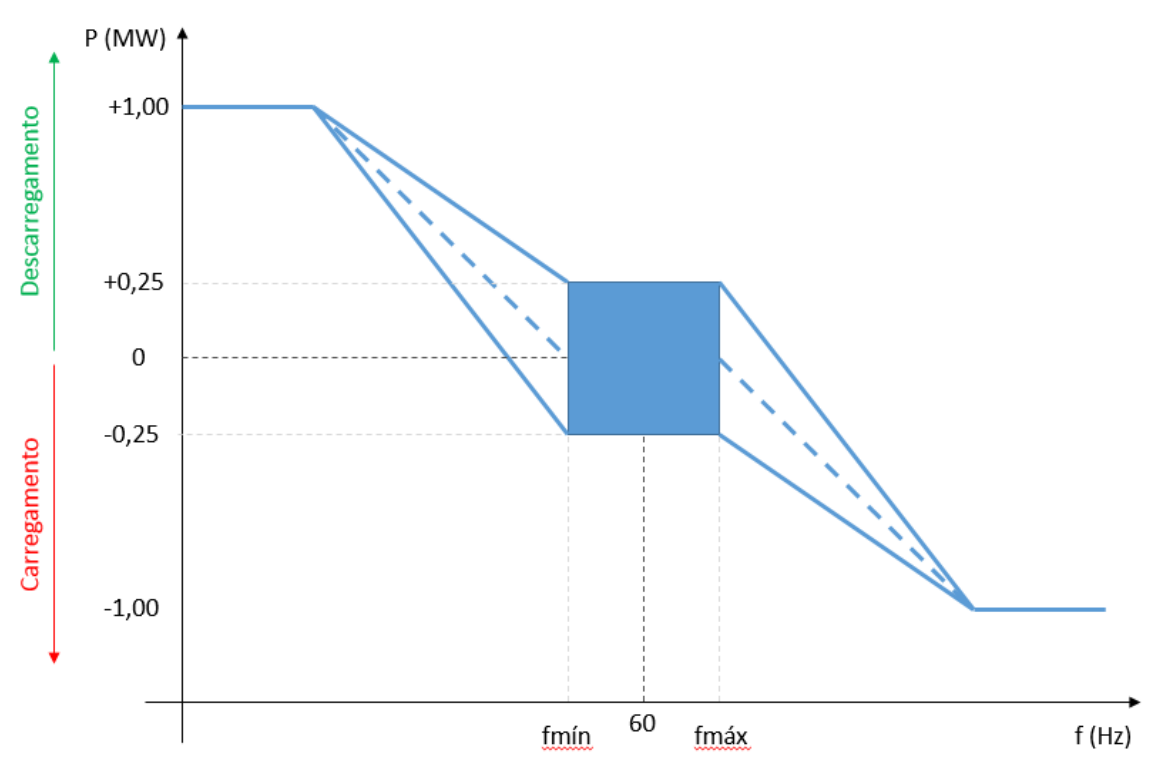

Figura 2.8 - Controle de regulação de frequência.

\subsection{6.}

\section{Auxílio ao Reestabelecimento}

Em sistemas elétricos radiais, remotos ou isolados, onde se tem uma ligação frágil com um sistema mais robusto, é comum que contingências entre esses sistemas provoquem interrupções totais de energia no sistema mais frágil. Além disso, o reestabelecimento do sistema contingenciado é realizado a partir do sistema mais resistente.

Com a aplicação de dispositivos de armazenamento de energia em sistemas elétricos mais frágeis, abre a possibilidade desse sistema elétrico não sofrer interrupção total no fornecimento de energia, ficando os elementos armazenadores com parte da carga, limitado ao valor de potência nominal de 
fornecimento de energia, também denominado de ilhamento. Se por algum motivo, mesmo dotado de armazenamento de energia, houver a interrupção total das cargas do sistema, esses dispositivos podem iniciar a recomposição das cargas até a sincronização com a rede completa (black start).

\section{4.}

\section{Viabilidade do Uso no Sistema Elétrico Brasileiro}

Com a evolução de estudo dos tipos de armazenamento de energia e das respectivas aplicações em sistemas elétricos de potência, tem-se a possibilidade de implantação dessa tecnologia no Sistema Elétrico Brasileiro.

É notório que a fragilidade de um sistema elétrico está diretamente ligada à necessidade de se investir nessa rede de transmissão, e que sistemas elétricos robustos e altamente malhados, em uma escala de prioridades, só devem ser contemplados com investimentos adicionais se forem estritamente necessários.

O Sistema Interligado Nacional (SIN) é planejado para atender ao critério da perda de um elemento de transmissão (i.e., "N-1") sem causar distúrbios ao sistema e por isso, cada vez mais se apresenta um sistema elétrico robusto e menos susceptível a defeitos. Adicionalmente, o SIN tem uma grande capacidade de regularização dos seus reservatórios em usinas hidrelétricas, o que é explorado pela programação da operação para se efetuar o despacho ótimo sistêmico. Desta forma, a viabilidade do uso de dispositivos de armazenamento de energia é limitada no Sistema Elétrico Brasileiro. Entretanto, dispositivos de armazenamento de energia em redes isoladas são vistos como economicamente viáveis pela EPE [14], dado o elevado custo de geração térmica nessas localidades e têm sido utilizados com bastante eficácia em outros sistemas isolados [1] [5] [10]. Assim, com a interrupção da interligação Brasil Venezuela, o estado de Roraima passou a operar de forma isolada sendo um sistema elétrico com potencial para avaliação da rede de transmissão com armazenamento de energia.

$\mathrm{Na}$ definição das características do sistema elétrico de Roraima, no Capítulo 5, todos os detalhes serão apresentados e explicitados promovendo a melhor compreensão da viabilidade do uso de sistemas de armazenamento de energia. 


\section{3}

\section{Controle de Frequência}

\section{1.}

\section{Introdução}

Neste capítulo apresentam-se os fundamentos do controle de frequência, com a formulação da equação de oscilação [16], ou equação swing, expondo cada etapa da regulação de frequência [17] com as definições e características típicas de controle de frequência.

\section{2.}

\section{Fundamentos do Controle de Frequência}

Um sistema elétrico hipotético opera em regime permanente com seus geradores síncronos em velocidade síncrona, por exemplo, $60 \mathrm{~Hz}$, a mesma estabelecida no Sistema Elétrico Brasileiro. Durante a condição de operação normal, o sistema elétrico se encontra em uma condição de equilíbrio estático, onde o torque mecânico das turbinas $T_{m}$ entregue aos geradores é equivalente ao torque elétrico entregue a rede $T_{e}$, ou seja, de acordo com a carga do sistema $\left(T_{m}=T_{e}\right)$. Na ocorrência de variações da carga deste sistema, esse equilíbrio é quebrado e a energia relativa a essa diferença se manifesta como um torque acelerante/desacelerante $T_{a}\left(T_{a}=T_{m}-T_{e}\right)$ condizente com a energia cinética das máquinas rotativas, induzindo uma aceleração ou desaceleração dos rotores das turbinas. 


\subsection{1.}

\section{Equação de Oscilação}

O torque de aceleração pode ser escrito como a Equação 3.1 onde $J$ é o momento de inércia do conjunto turbina-gerador e $\omega_{m}$ é a velocidade angular mecânica do rotor:

$$
T_{a}=J \frac{d \omega_{m}}{d t}=T_{m}-T_{e}
$$

Assim, enquanto a diferença entre o torque mecânico e o torque elétrico for nula, a velocidade angular do rotor será constante no tempo. A energia cinética é descrita pela Equação 3.2 onde $\omega_{0 m}$ é a velocidade angular mecânica nominal do rotor:

$$
\text { Energia }_{\text {cinética }}=\frac{1}{2} J \omega_{0 m}^{2}
$$

A representação da energia cinética das máquinas rotativas é geralmente expressa para as análises de sistemas de potência através da constante de inércia $H$, onde $S_{\text {base }}$ é a potência aparente nominal da unidade geradora:

$$
H=\frac{\text { Energia }_{\text {cinética }}}{V A_{\text {base }}}=\frac{\frac{1}{2} J \omega_{0 m}^{2}}{S_{\text {base }}}
$$

A inércia de uma unidade geradora ou de um conjunto de maquinas rotativas, nesse caso chamada de inércia equivalente (somatório de todas as constantes de inércia), pode ser interpretada como uma resistência a mudanças de velocidade, ou seja, quanto maior for a massa girante de uma máquina síncrona e consequente energia cinética, maior será a sua constante de inércia. Assim, sistemas que apresentem constante de inércia equivalente elevada estão menos sujeitos a grandes desvios de frequência.

Colocando o momento de inércia em evidência na Equação 3.3 teremos:

$$
J=\frac{2 H}{\omega_{0 m}^{2}} S_{\text {base }}
$$


Substituindo na Equação 3.1 e considerando que $T_{\text {base }}=S_{\text {base }} / \omega_{0 m}$, temse a Equação 3.7 em p.u.:

$$
\begin{gathered}
\frac{2 H}{\omega_{0 m}^{2}} S_{\text {base }} \frac{d \omega_{m}}{d t}=T_{m}-T_{e} \\
2 H \frac{d}{d t}\left(\frac{\omega_{m}}{\omega_{0 m}}\right)=\frac{T_{m}-T_{e}}{S_{\text {base }} / \omega_{0 m}} \\
2 H \frac{d \bar{\omega}_{r}}{d t}=\bar{T}_{m}-\bar{T}_{e}
\end{gathered}
$$

Da Equação 3.7 acima, onde $\omega_{r}$ é a velocidade angular elétrica do rotor em radianos por segundo e $p_{f}$ é o número de polos da máquina síncrona, podese escrever que:

$$
\bar{\omega}_{r}=\frac{\omega_{m}}{\omega_{0 m}}=\frac{\omega_{m} / p_{f}}{\omega_{0} / p_{f}}=\frac{\omega_{r}}{\omega_{0}}
$$

Assumindo que o rotor gira em velocidade síncrona e que $\delta$ é a posição angular ou o ângulo do rotor com relação a uma referência $\delta_{0}$, tem-se:

$$
\delta=\omega_{r} t-\omega_{0} t+\delta_{0}
$$

Derivando a Equação 3.9 acima:

$$
\begin{gathered}
\frac{d \delta}{d t}=\omega_{r}-\omega_{0}=\Delta \omega_{r} \\
\frac{d^{2} \delta}{d t^{2}}=\frac{d \omega_{r}}{d t}=\frac{d\left(\Delta \omega_{r}\right)}{d t}=\omega_{0} \frac{d \bar{\omega}_{r}}{d t}=\omega_{0} \frac{d\left(\Delta \bar{\omega}_{r}\right)}{d t}
\end{gathered}
$$

Substituindo $d \bar{\omega}_{r} / d t$ na Equação 3.7, tem-se: 


$$
\frac{2 H}{\omega_{0}} \frac{d^{2} \delta}{d t^{2}}=\bar{T}_{m}-\bar{T}_{e}
$$

Muitas vezes é desejável incluir um componente do torque de amortecimento, não contabilizado no cálculo do torque separadamente

$$
T_{D}=\frac{K_{D}}{\omega_{0}} \frac{d \delta}{d t}
$$

Assim, a equação de oscilação considerando a componente de amortecimento:

$$
\frac{2 H}{\omega_{0}} \frac{d^{2} \delta}{d t^{2}}=\bar{T}_{m}-\bar{T}_{e}-\frac{K_{D}}{\omega_{0}} \frac{d \delta}{d t}
$$

Esta formulação foi proposta em [16] sendo uma referência bibliográfica consolidada na literatura dos sistemas elétricos de potência.

\section{3.}

\section{Regulação de Frequência}

O comportamento da carga instantânea durante todas as horas do dia está intrinsecamente associado às atividades da população atendida pelo sistema local. As alterações a cada momento exigem um controle de frequência adequado que permita operar o sistema com equilíbrio entre a carga e a geração.

Manter o equilíbrio entre a carga e geração de um sistema elétrico de potência é uma tarefa primordial para os Operadores de Sistemas Elétricos ao redor do mundo. O desequilíbrio e consequentes variações de frequência sustentadas podem impor prejuízos em processos industriais e desgastes excessivos em unidades rotativas reduzindo a vida útil desses equipamentos.

Entretanto, mesmo que sejam realizadas previsões de carga assertivas e programações horárias de geração, sempre haverá incertezas associadas para 
operação do sistema. Essas incertezas estão atreladas ao erro da previsão de carga, erro da previsão de geração de fontes intermitentes, como eólica e solar, perda intempestiva de geração, entre outras.

Logo o controle de frequência é fundamental para se manter o equilíbrio de um sistema elétrico de potência.

\subsection{1.}

\section{Regulação Primária}

A regulação primária de frequência pode ser apresentada pelo diagrama esquemático da Figura 3.1, onde a diferença entre o torque mecânico $T_{m}$ e 0 torque elétrico $T_{e}$ de um conjunto turbina-gerador atendendo uma carga $P_{c a r g a}$, pode ser controlado por um regulador de velocidade, aumentando ou reduzindo a potência mecânica $P_{m}$ em função da potência elétrica $P_{e}$.

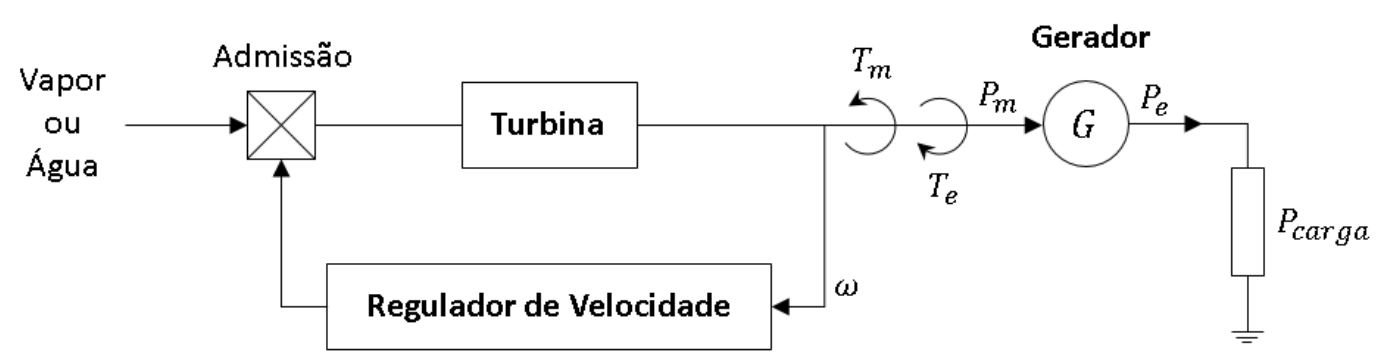

Figura 3.1 - Diagrama esquemático típico de regulação de frequência.

Para estudos de controle de frequência é mais usual a utilização da relação de potência elétrica e potência mecânica ao invés de torque. Essa relação apresentada na Equação 3.14 advém da mecânica clássica apresentada no Apêndice $A$, onde $P$ é a potência que pode ser elétrica ou mecânica:

$$
P=\frac{d W}{d t}=T \omega_{r}
$$

Considerando um pequeno desvio da condição inicial, representados por $P_{0}, T_{0}$ e $\omega_{0}$ tem-se: 


$$
\begin{gathered}
P=P_{0}+\Delta P \\
T=T_{0}+\Delta T \\
\omega_{r}=\omega_{0}+\Delta \omega_{r}
\end{gathered}
$$

Explicitando a Equação 3.14 e desconsiderando a parcela da multiplicação dos desvios, tem-se que:

$$
\begin{gathered}
P_{0}+\Delta P=\left(T_{0}+\Delta T\right)\left(\omega_{0}+\Delta \omega_{r}\right) \\
P_{0}+\Delta P=T_{0} \omega_{0}+T_{0} \Delta \omega_{r}+\Delta T \omega_{0}+\Delta T \Delta \omega_{r} \\
\Delta P=T_{0} \Delta \omega_{r}+\Delta T \omega_{0}
\end{gathered}
$$

Portanto:

$$
\Delta P_{m}-\Delta P_{e}=\left(T_{m 0}-T_{e 0}\right) \Delta \omega_{r}+\left(\Delta T_{m}-\Delta T_{e}\right) \omega_{0}
$$

Em regime normal de operação, o torque elétrico e o torque mecânico são iguais $\left(T_{m 0}=T_{e 0}\right)$ e a velocidade angular é unitária em p.u. $\left(\omega_{0}=1\right)$, assim, para pequenos desvios de frequência:

$$
\Delta P_{m}-\Delta P_{e}=\Delta T_{m}-\Delta T_{e}
$$

Enfim, dado um desbalanço entre a potência elétrica injetada na rede e a potência mecânica da turbina, ações de regulação de velocidade serão necessárias para conter este desequilíbrio. Nos itens seguintes serão tratadas as características de regulação primária de frequência.

\subsubsection{1.}

\section{Regulação Própria do Sistema Elétrico}

Em geral, cargas distintas são atendidas em um sistema de potência. Nos casos de cargas resistivas, a variação da frequência não causa alteração na potência elétrica, somente nas perdas na transmissão causadas pelo efeito pelicular. Já nos casos de cargas compondo motores de indução, em função da 
alteração da velocidade desses motores com a variação da frequência, a potência elétrica desse tipo de carga também varia. Essa relação pode ser escrita pela Equação 3.19, onde $\Delta P_{L}$ é a parcela de variação de carga insensível à variação da frequência, $D \Delta \omega_{r}$ é parcela de variação de carga sensível à variação da frequência e $D$ é o coeficiente de amortecimento da carga:

$$
\Delta P_{e}=\Delta P_{L}+D \Delta \omega_{r}
$$

Valores típicos do coeficiente de amortecimento $(D)$ em sistemas de potência são pequenos, em geral em torno de 1 a $2 \%$ [16], o que significa que uma alteração de 1\% na frequência causaria uma alteração em torno de 1 a $2 \%$ na carga verificada em regime permanente, essa relação pode ser escrita pela Equação 3.20 , onde $\Delta P_{D}$ é a variação de carga resultante da variação de frequência $\Delta f$ :

$$
D=\frac{\Delta P_{D}}{\Delta f}
$$

Para qualquer desvio de frequência, seja ocasionado por uma perda de um bloco de geração ou por uma redução repentina de carga no sistema, haverá alteração da carga devido ao seu coeficiente de amortecimento.

\subsubsection{2.}

\section{Regulador de Velocidade Isócrono}

Supondo que um pequeno sistema possua somente uma máquina síncrona que regule frequência através do seu regulador de velocidade. Neste caso, pode-se adotar um controlador que elimine completamente a diferença de velocidade angular $\Delta \omega$ em casos de variação de potência elétrica $P_{e}$, de tal forma que enquanto o rotor não estiver girando em velocidade síncrona nominal $\omega_{r e f}$, ou seja, retornando a frequência para os valores originais, haverá atuação do bloco integrador acionando a válvula de admissão de energia primária, seja água ou vapor, aumentando ou reduzindo a potência mecânica $P_{m}$ na turbina, conforme o diagrama da Figura 3.2. Para este tipo, denomina-se Regulador de Velocidade Isócrono e o seu comportamento pode ser visto na Figura 3.3. 


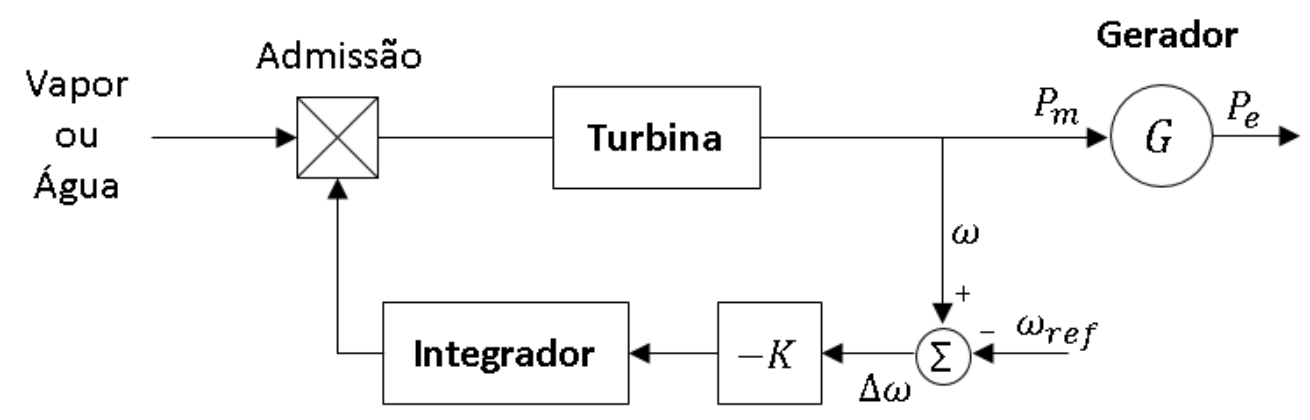

Figura 3.2 - Diagrama esquemático de um regulador de velocidade isócrono.

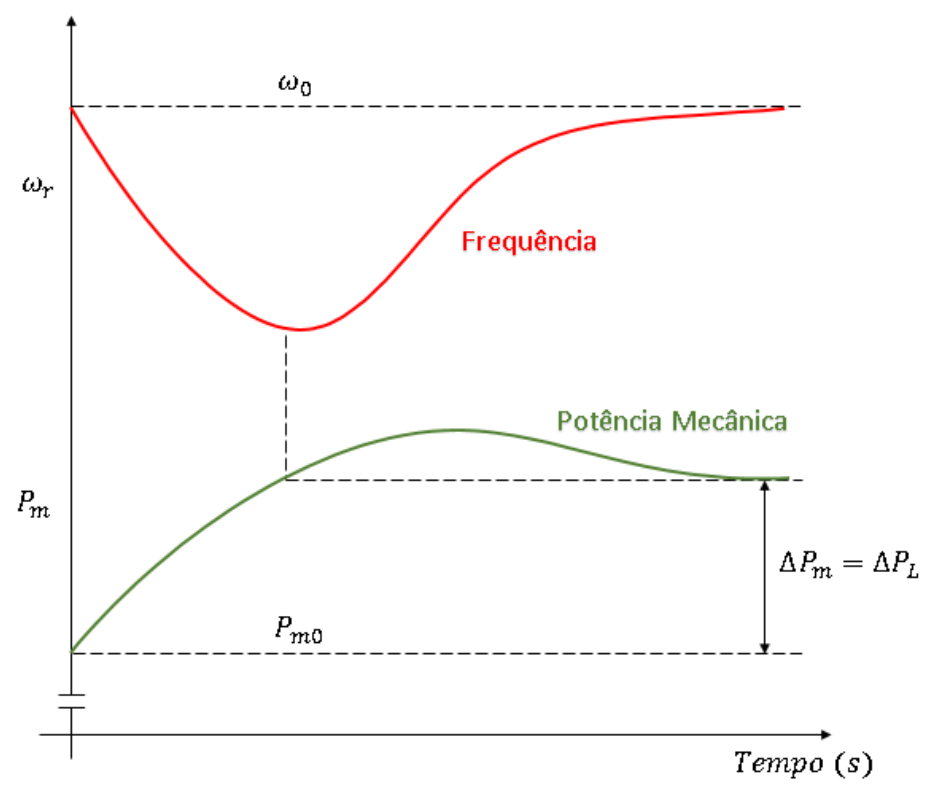

Figura 3.3 - Resposta no tempo de uma unidade geradora com regulador de velocidade isócrono [16].

Quando há outras máquinas síncronas regulando a frequência do sistema elétrico, este tipo de regulador de velocidade pode levar o sistema à instabilidade já que a repartição da responsabilidade de ajustar a frequência acaba sendo conflituosa quando há mais de um regulador de velocidade isócrono. Pode se chegar ao caso de uma unidade tender ao seu despacho máximo enquanto outra unidade geradora tende ao seu despacho mínimo, caracterizando uma relação de oposição. 
Assim, por mais que seja interessante minimizar o desvio de frequência até chegar ao valor nominal, a utilização de reguladores de velocidade isócronos acarreta sérios problemas no comportamento dinâmicos dos sistemas de potência interligados.

\subsubsection{3.}

\section{Regulador de Velocidade com Queda de Velocidade}

Como foi explicitado no item anterior, há dificuldade de se dividir as responsabilidades na regulação de frequência quando se tem mais de uma unidade geradora com regulador de velocidade isócrono. Para contornar essa questão é adicionada uma realimentação em paralelo $R$ ao bloco integrador que resultará em um desvio de frequência aceitável, conforme o diagrama da Figura 3.4, ou seja, à medida que a unidade geradora responde ao desbalanço entre a carga e a geração, o regulador de velocidade admite uma queda de velocidade, permitindo uma pequena diferença entre a frequência nominal do sistema e a frequência atingida após o desequilíbrio proporcional ao montante de desbalanço inicial, conforme visto na Figura 3.5.

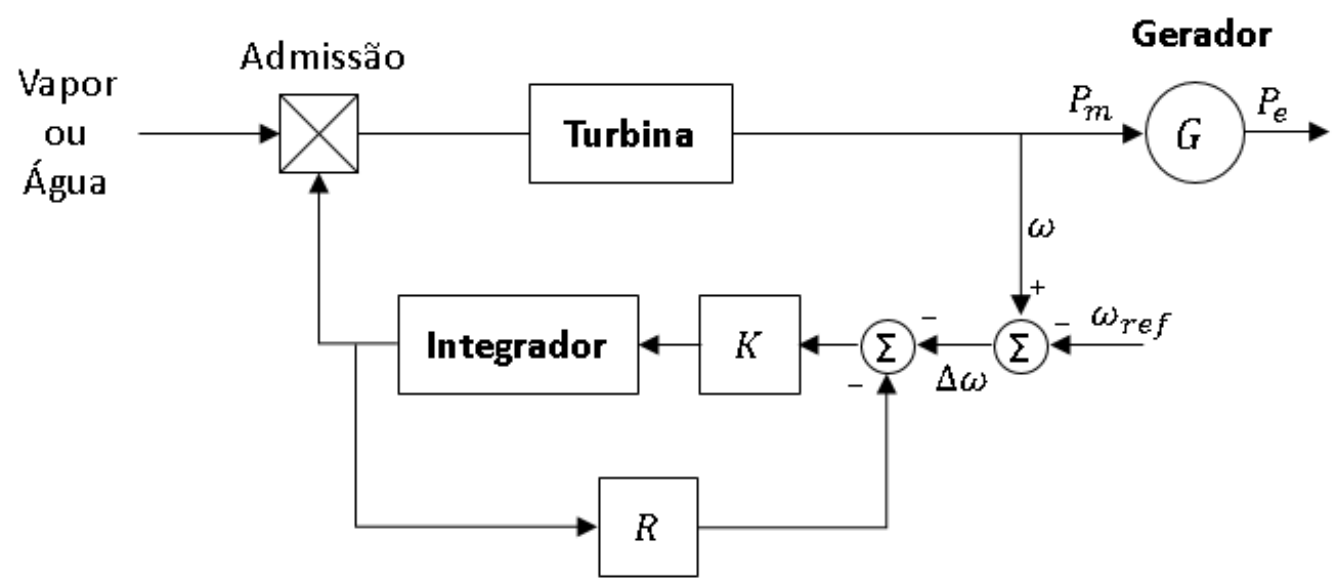

Figura 3.4 - Diagrama esquemático de um regulador de velocidade com queda de velocidade. 


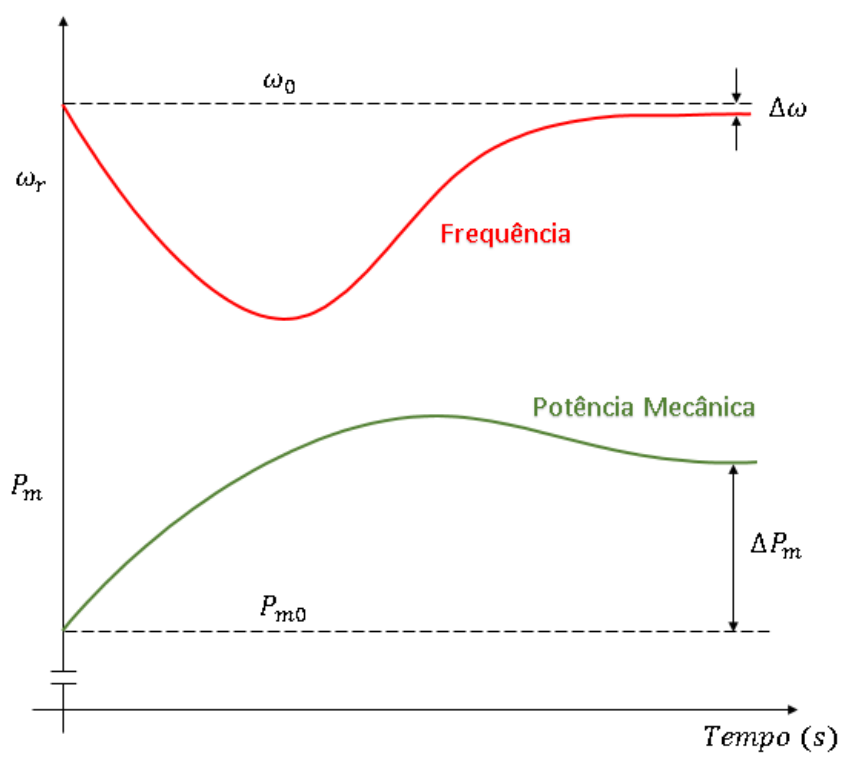

Figura 3.5 - Resposta no tempo de uma unidade geradora com regulador de velocidade com queda de velocidade [16].

Essa constante de regulação $R$, conhecida como estatismo permanente, pode ser definida conforme a Equação 3.21, onde $\Delta f$ é a variação de frequência após o distúrbio em relação ao valor nominal e $\Delta P_{i}$ é a variação de potência elétrica de uma unidade geradora $i$ após o distúrbio:

$$
R_{i}=\frac{\Delta f}{\Delta P_{i}}
$$

Para exemplificar esta relação, duas unidades geradoras conectadas ao mesmo sistema elétrico de potência com estatismos distintos, sendo $R_{1}>R_{2}$, geram as potências $P_{1}$ e $P_{2}$. Após a ocorrência de um aumento de carga repentino, haverá então um desbalanço entre a geração e a carga, com redução da velocidade dos rotores e consequentemente da frequência do sistema. Assim, os reguladores de velocidade dessas unidades atuarão no sentido de aumentar a velocidade dos rotores, aumentando a potência de cada gerador $P_{1}^{\prime}$ e $P_{2}^{\prime}$ até que se chegue a um novo ponto de equilíbrio com valor de frequência $f^{\prime}$. O montante de geração acrescido em cada unidade geradora é uma relação proporcional com o estatismo de seus reguladores de velocidade. Esta relação pode ser vista na equação 3.22 e vista pela Figura 3.6. 


$$
\begin{gathered}
\Delta P_{1}=P_{1}^{\prime}-P_{1}=\frac{\Delta f}{R_{1}} \\
\Delta P_{2}=P_{2}^{\prime}-P_{2}=\frac{\Delta f}{R_{2}} \\
\frac{\Delta P_{1}}{\Delta P_{2}}=\frac{R_{2}}{R_{1}}
\end{gathered}
$$
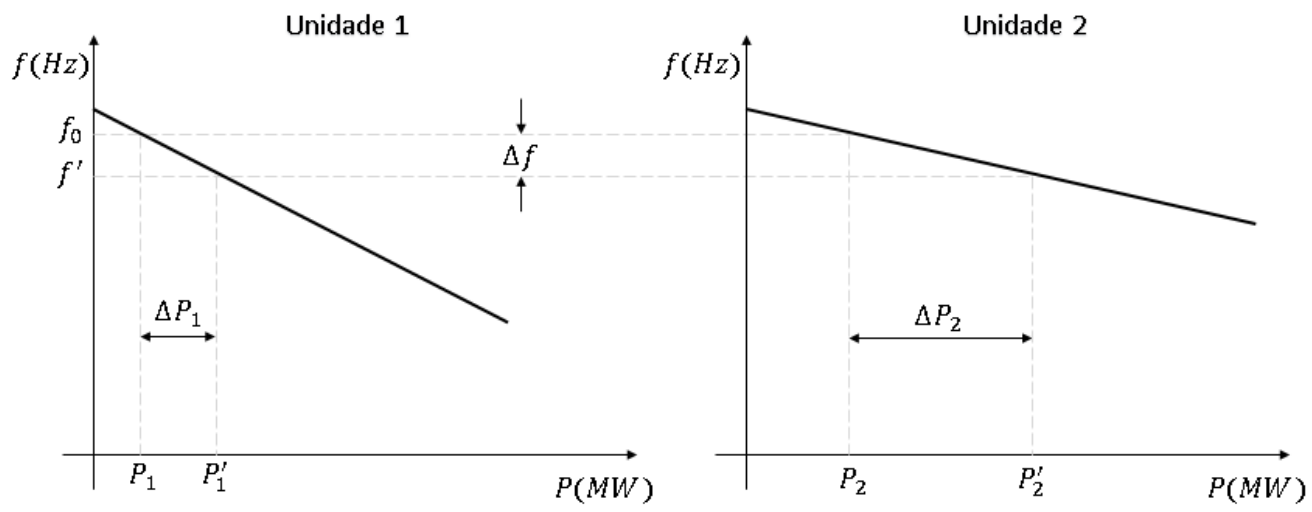

Figura 3.6 - Compartilhamento de carga por duas unidades geradoras com regulador de velocidade com queda de velocidade [16].

Logo, quanto menor for o estatismo de uma unidade geradora, maior será a contribuição desta máquina síncrona compensando um desbalanço entre carga e geração no sistema elétrico de potência. Portanto, o uso de reguladores de velocidade com queda de velocidade impede os conflitos entre unidades geradoras citados nos casos de utilização de reguladores de velocidade isócronos. Entretanto, como consequência da utilização de queda de velocidade, a frequência não retorna ao seu valor nominal, permanecendo em regime permanente com um desvio $\Delta f_{r p}$.

\subsubsection{4.}

\section{Esquema Regional de Alívio de Carga}

O corte de carga por subfrequência, conhecido no Brasil como Esquema Regional de Alívio de Carga (ERAC), é um sistema de proteção sensível à taxa de variação da frequência ou a um limite mínimo de frequência absoluta que atua no sentido de reduzir os montantes de carga atendidos pelo sistema elétrico, para impedir que a perda de grandes blocos de geração causem colapso de frequência. 
Esse montante de redução de carga é feito com a abertura dos disjuntores dos alimentadores de diversas subestações do sistema, previamente estabelecido, e em diferentes estágios, de tal forma que se reduza o desequilíbrio entre a geração e a carga na ocorrência de um grande distúrbio de déficit de geração. Este esquema de proteção é primordial para recomposição da frequência evitando-se atingir um valor de frequência mínima que levaria o sistema ao colapso. Mesmo dispondo desse esquema, a utilização de reguladores de velocidade com queda de velocidade não permite que os valores da frequência do sistema retornem ao valor nominal. Assim, na composição da estrutura de regulação da frequência em um sistema elétrico de potência, é necessário compor um segundo estágio de regulação, conhecido por Regulação Secundária.

\subsection{2.}

\section{Regulação Secundária}

Como foi explicitado anteriormente, mesmo com a Regulação Primária retornando a valores aceitáveis de frequência, ainda se mantém um pequeno desvio de frequência que imputa a necessidade de uma nova etapa de regulação de frequência que vá retornar com a frequência para o valor nominal, dado que mesmo que sejam pequenos esses desvios, podem proporcionar problemas nos sistemas elétricos de potência.

A estratégia de controle para a regulação secundária de frequência tem como objetivo anular o erro de frequência causado por um desbalanço de potência no sistema. Portanto torna-se necessário a inclusão de uma malha com controlador integrador adicional que acompanhe o erro de frequência resultante e atue no regulador de velocidade proporcionando aumento da potência injetada a partir de um determinado tempo.

O comportamento estático da unidade geradora permanece com a mesma inclinação sugerida na Figura 3.6. Entretanto, considerando esta nova etapa de regulação da frequência, pode-se interpretar como um deslocamento vertical na curva $(P \times f)$, para cima ou para baixo, dependendo do sinal do desvio de frequência, conforme a Figura 3.7. 


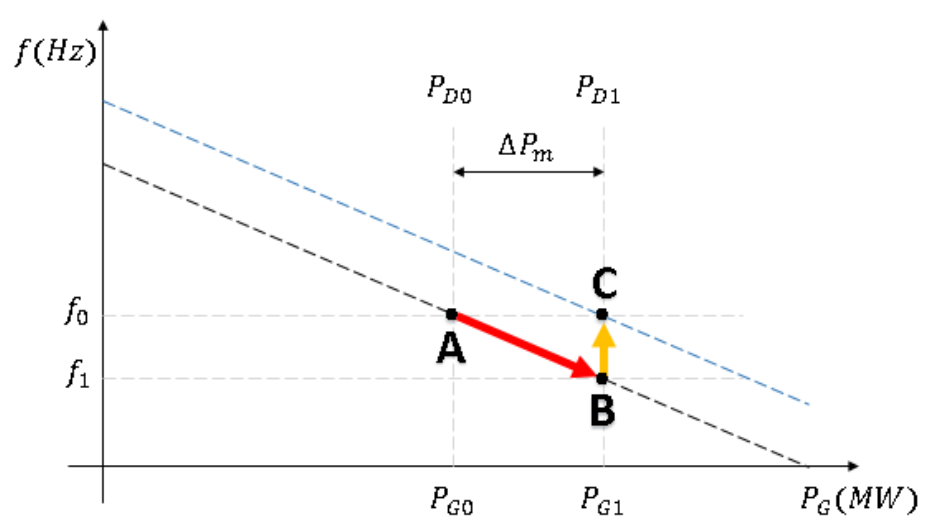

Figura 3.7 - Comportamento de uma unidade geradora considerando atuação da Regulação Primária e da Regulação Secundária. Adaptada de [17].

O gráfico $(P \times f)$ apresenta o comportamento de uma única unidade geradora operando no ponto $\mathrm{A}$, que após uma variação de carga atendida $\Delta P_{D}$, aumentando de $P_{D 0}$ para $P_{D 1}$, aumenta também a velocidade do rotor e a potência gerada em função da regulação primária, passando de $P_{G 0}$ para $P_{G 1}$, de forma que $P_{G 1}=P_{D 1}$ com uma frequência menor $f_{1}$, representado como ponto $\mathrm{B}$. O controle secundário atua para que a frequência retorne ao valor nominal inicial $f_{0}$, correspondente ao ponto $\mathrm{C}$.

Esta representação pode se estender para diversas máquinas que fariam a composição de uma área de controle, que por definição é uma área do sistema elétrico de potência onde unidades geradoras apresentam comportamentos coerentes respondendo às variações de carga, e que possuam um equilíbrio entre a carga e a geração. Quando este equilíbrio não é possível, deve-se de manter uma folga nos limites de interligação entre áreas de controle, para que possa haver auxílio mútuo.

Cada área de controle tem um estatismo equivalente, decorrente das unidades geradoras sincronizadas, e as ações de regulação de frequência secundária são repartidas entre as máquinas que participam desta etapa de controle.

Para avaliação do comportamento dinâmico proposta nesta dissertação, não foram previstas simulações considerando a Regulação Secundária, visto que os resultados das análises serão avaliados no período transitório da resposta inercial e da regulação primária. 
Portanto, o comportamento de unidades geradoras considerando armazenamento de energia, atuação de ERAC, da Regulação Primária e da Regulação Secundária pode ser visto na Figura 3.8.

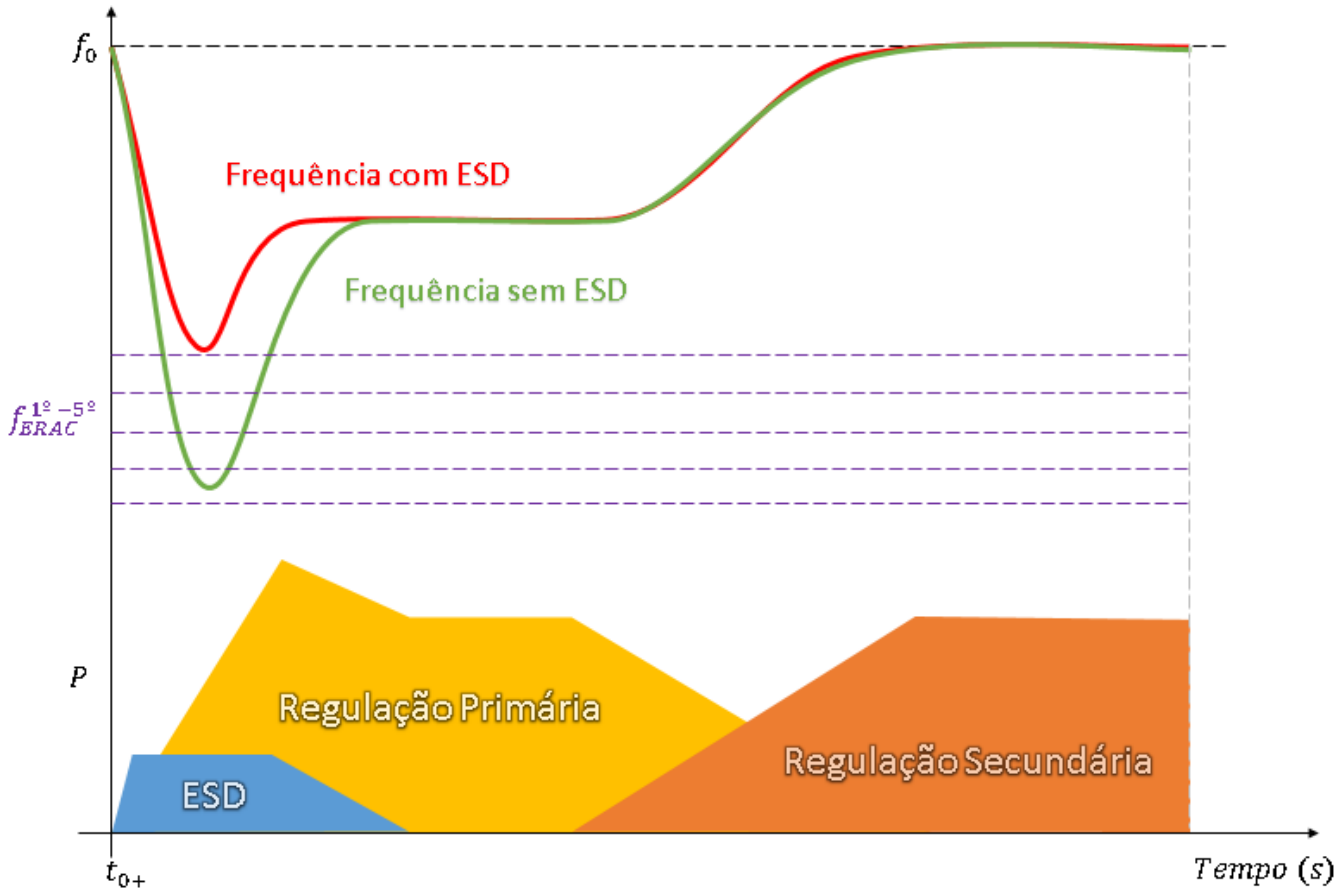

Figura 3.8 - Comportamento de diversas unidades geradoras considerando atuação da Regulação Primária e da Regulação Secundária. 


\section{4 \\ Modelagem Dinâmica dos Dispositivos de Armazenamento de Energia}

\section{1.}

\section{Introdução}

Neste capítulo, apresenta-se o modelo dinâmico dos dispositivos de armazenamento de energia que foram utilizados nas simulações no domínio do tempo. Foi estabelecido um modelo típico que representa de forma adequada o comportamento transitório dos ESD na rede de transmissão conectada.

\section{2.}

\section{Modelo Dinâmico do ESD}

Os dispositivos de armazenamento de energia são compostos por elementos armazenadores que se conectam ao sistema elétrico através de um conversor do tipo Voltage Source Converter (VSC), conforme a estruturação básica apresentada na Figura 4.1. O VSC é capaz de controlar a injeção de potência ativa e reativa no sistema em função das grandezas que se deseja controlar, como potência ativa, potência reativa, tensão e frequência. 


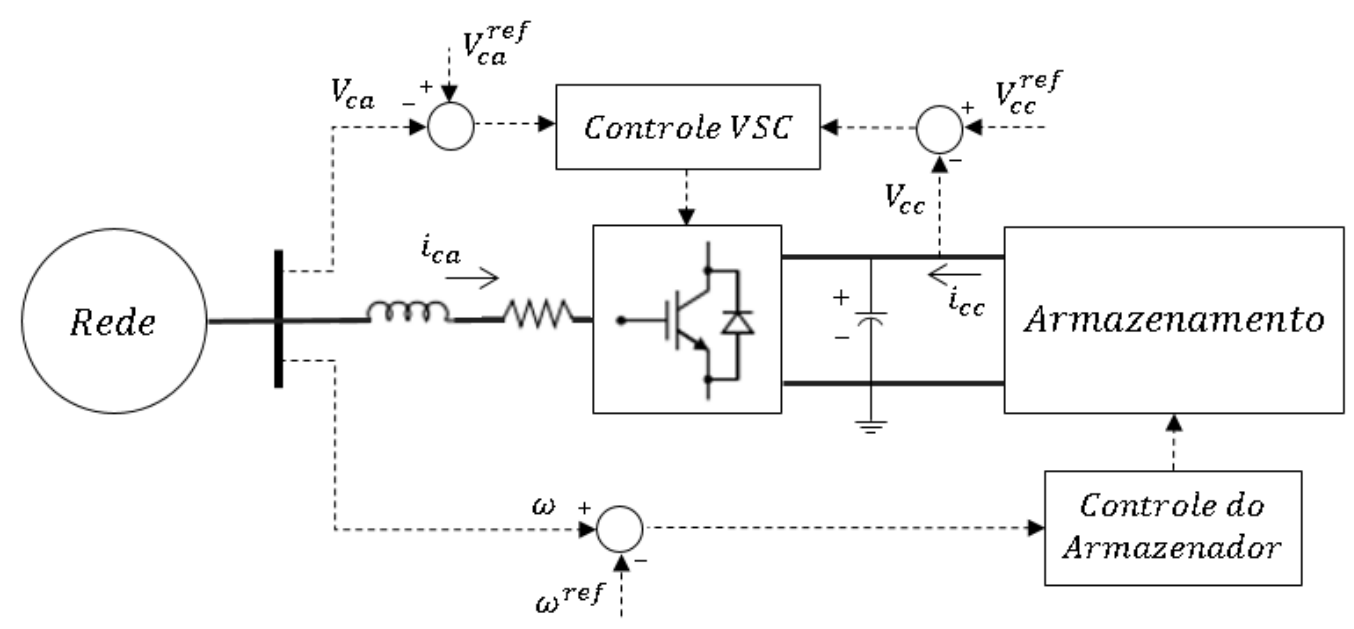

Figura 4.1 - Estrutura de um Sistema de Armazenamento de Energia

A Figura 4.2 apresenta a configuração usual de um VSC com um transformador no lado da corrente alternada (CA), um conversor bidirecional e um capacitor no lado da corrente contínua (CC) mantendo o nível de tensão $V_{c c}$. Esta tensão em CC é convertida em formato de onda CA através dos inversores eletrônicos de potência utilizando a lógica de controle adequada.

\section{Corrente Alternada Corrente Contínua}

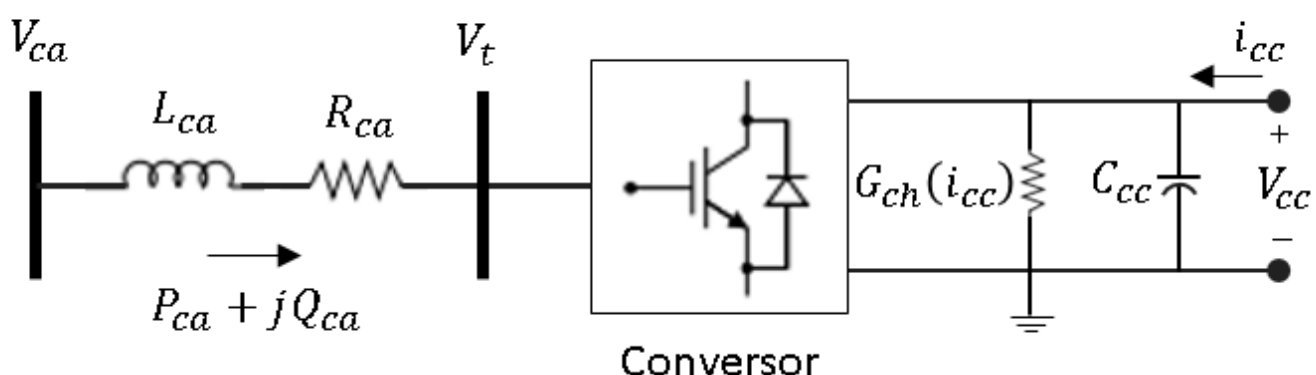

Figura 4.2 - Esquema de um Voltage Source Converter (VSC)

Onde $Z_{c a}=R_{c a}+j L_{c a}$ é a impedância agregada do transformador com o conversor e $S_{c a}=P_{c a}+j Q_{c a}$ é a potência aparente que pode ser consumida ou injetada pelo elemento armazenador.

O balanço de potência entre o lado CC e CA pode ser escrito com a potência do lado CA: 


$$
P_{c a}+V_{c c} i_{c c}-P_{\text {perdas }}-\frac{1}{2} C_{c c} \frac{d\left(V_{c c}^{2}\right)}{d t}=0
$$

Onde as perdas nos circuitos e no transformador e na comutação do conversor são apresentadas por:

$$
P_{\text {perdas }}=\frac{3}{2} R_{c a} i_{c a}^{2}+G_{c h}\left(i_{c c}\right) V_{c c}^{2}
$$

A variação de energia no capacitor é apresentada por:

$$
E_{c a p}=\frac{1}{2} C_{c c} \frac{d\left(V_{c c}^{2}\right)}{d t}
$$

A condutância de chaveamento é obtida a partir de uma dada condutância constante $G_{0}$, e o quadrado da razão entre a corrente atual e a corrente nominal, como segue:

$$
G_{c h}\left(i_{c c}\right)=G_{0}\left(\frac{i_{c c}}{i_{c c}^{n o m}}\right)^{2}
$$

Contudo, para as análises de estabilidade transitória dessa dissertação, a estrutura dos sistemas de armazenamento de energia foi representada nas simulações através de um modelo de fonte de corrente controlada. O modelo apresentado é uma adaptação do modelo simplificado descrito em [18] que foi uma evolução de outros modelos simplificados [19]. Foram feitas adequações de acordo com as necessidades do sistema ao qual ele foi conectado.

Uma característica importante dos modelos simplificados propostos nessas referências é que a dinâmica do ESD é representada considerando apenas o controle da potência ativa e reativa injetada na rede. Nestes casos, a dinâmica do próprio elemento armazenador e as perdas não são consideradas, devido à dificuldade de se representar as dinâmicas do lado CC e os chaveamentos do VSC em ferramentas que possuem apenas a sequência positiva.

Como essas simplificações não impactam de forma significativa as análises transitórias e as análises do comportamento dinâmico do sistema, 
optou-se por adotar uma adaptação do modelo simplificado que se adequasse as necessidades do sistema analisado.

Assim, foram considerados controladores que realizam o controle de tensão terminal e da frequência do sistema. Dessa forma, os dispositivos de armazenamento de energia podem contribuir para uma maior penetração de fontes renováveis, evitando o corte total das cargas do estado nos casos de redução abrupta de geração, mantendo parcialmente o atendimento local. Como citado em [20], o ESD “...pode fornecer uma rápida mudança de potência ativa e reativa em ambas as direções, fornecendo controle nos quatro quadrantes do plano $P Q . "$

\subsection{1.}

\section{Controle de Potência Ativa}

No controle de potência ativa, o modelo simulado utiliza um controlador do tipo proporcional-integral (PI) para tratar dos desvios de frequência da rede. Como adaptação do modelo simplificado, é considerado um estatismo baseado na realimentação de potência elétrica para permitir a participação do ESD na regulação primária com as demais usinas do sistema. O diagrama de blocos do controle de potência ativa pode ser visto pela Figura 4.3.

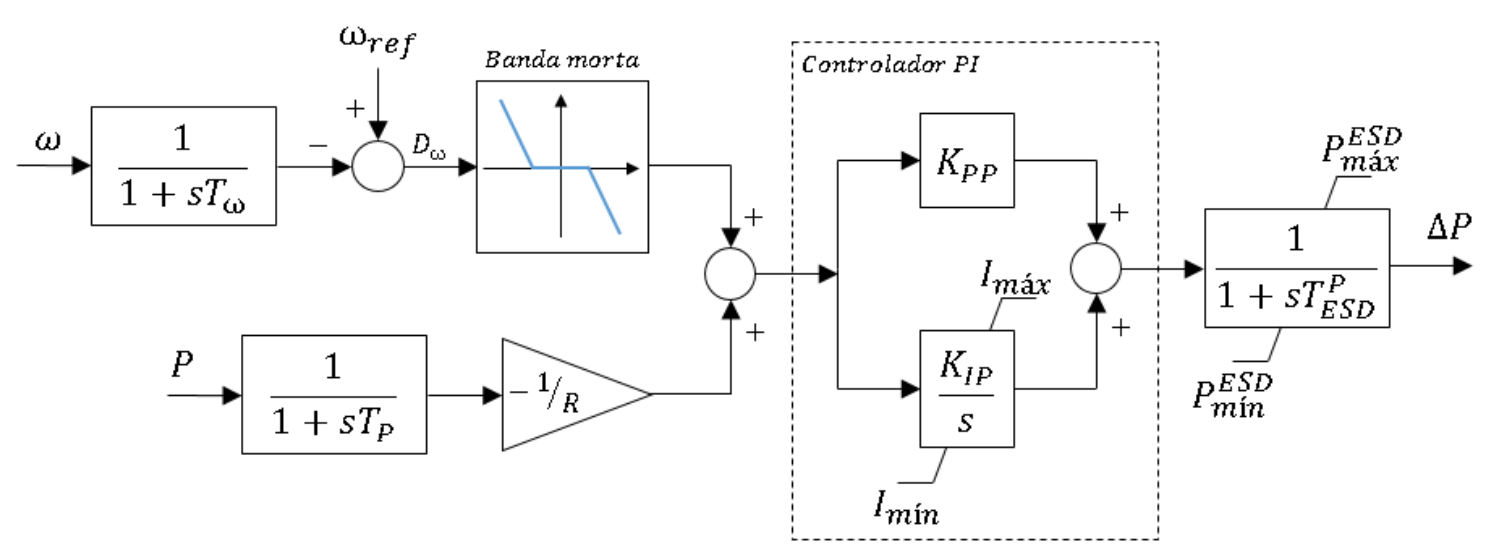

Figura 4.3 - Diagrama de Blocos do Controle de Potência Ativa do Modelo de ESD. 
Os blocos de atraso de medição podem ser vistos com as constantes de tempo $T_{\omega}$ e $T_{P}$. A diferença $D_{\omega}$ entre a frequência de referência $\omega_{\text {ref }}$ e a frequência do sistema $\omega$ respeita a limitação de uma banda morta, onde se busca atuar apenas para desvios relevantes de frequência, que caracterizam uma perturbação sistêmica. Para pequenos desvios de frequência inerentes à operação do sistema, não se deve atuar o controle de potência ativa do ESD. Esta banda morta não deve existir para sistemas elétricos isolados que não contenham unidades geradoras que possam executar o controle de frequência, assim o ESD seria o único elemento para regulação de frequência. Essa condição de operação pode provocar uma redução da vida útil de seus componentes.

$\mathrm{Na}$ realimentação de potência elétrica é dimensionada a energia de regulação $-1 / R$ através de um ganho, que faz com que os dispositivos de armazenamento de energia participem do controle de frequência primário juntamente com outras unidades geradoras do sistema. Quanto menor for o estatismo, menor será o desvio de frequência passado o período transitório da perturbação.

A soma desses desvios supracitados adentra ao controlador PI, que possui uma limitação da corrente de forma a proteger o controle do conversor VSC, resultando em um sinal de aumento ou redução de potência ativa injetada no sistema pelo ESD. O conversor VSC é representado através de um bloco de atraso com constante de tempo $T_{E S D}^{P}$. Este bloco de atraso também limita a potência ativa injetada pelo ESD entre $P_{\min }^{E S D}$ e $P_{m a ́ x}^{E S D}$ protegendo o conjunto armazenador-conversor.

\subsection{2.}

\section{Controle de Potência Reativa}

Os ESD também dispõem de capacidade de controle de potência reativa ou da tensão terminal. Como adaptação do modelo simplificado, é considerado um seletor que pode alternar entre o controle da tensão terminal do ESD ou da potência reativa que se deseja injetar ou absorver da rede. O modelo adotado utiliza um controlador do tipo proporcional-integral (PI) para realizar o controle da tensão, conforme apresentado na Figura 4.4. 


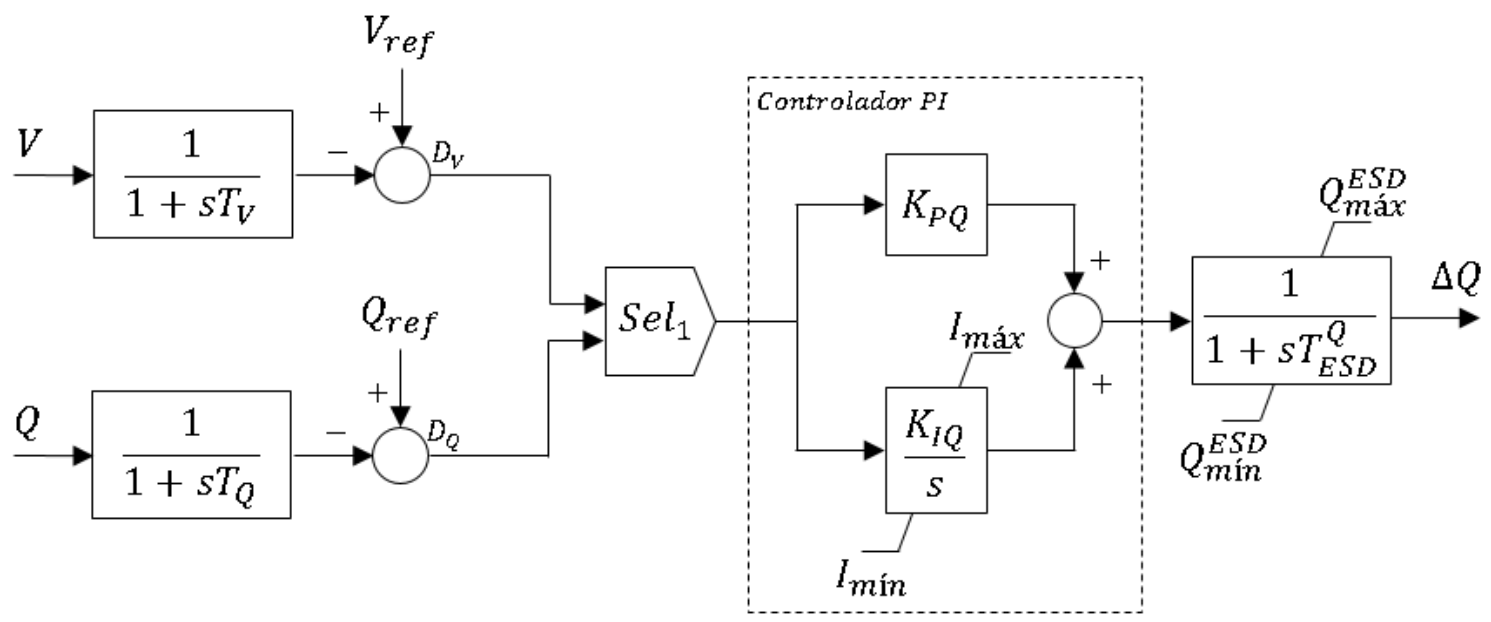

Figura 4.4 - Diagrama de Blocos do Controle de Potência Reativa do Modelo de ESD.

Os blocos de atraso de medição podem ser vistos com as constantes de tempo $T_{V}$ e $T_{Q}$. Através do seletor $\operatorname{Sel}_{1}$, o conversor pode controlar a diferença $D_{V}$ entre a tensão de referência $V_{\text {ref }}$ e a tensão terminal do elemento armazenador $V$ ou a diferença $D_{Q}$ entre a potência reativa de referência $Q_{r e f}$ e a potência reativa injetada ou absorvida pelo elemento armazenador $Q$.

A escolha pelo controle de potência reativa pode ser prudente para os empreendedores que possuam ESD caso não haja incentivo financeiro para controle de tensão local. Nesse caso, os armazenadores poderiam operar com um fator de potência que reduzissem as perdas elétricas ao invés de suportarem o controle de tensão sistêmico.

Os desvios supracitados, seja tensão terminal ou potência reativa, adentra ao controlador PI, que possui uma limitação de forma a proteger o controle do conversor VSC, resultando em um sinal de aumento ou redução de potência reativa absorvida ou injetada no sistema pelo ESD. O conversor VSC é representado através de um bloco de atraso com constante de tempo $T_{E S D}^{Q}$. Este bloco de atraso também limita a potência reativa absorvida ou injetada pelo ESD entre $Q_{\text {mín }}^{E S D}$ e $Q_{\text {máx }}^{E S D}$ protegendo o conjunto armazenador-conversor. 


\section{3.}

\section{Modelagem dos Demais Elementos do Sistema de Roraima}

Para os demais elementos do sistema elétrico de Roraima foram considerados modelos típicos de unidades geradoras advindo da base de dados de transitórios eletromecânicos do ONS [21], de usinas existentes que mais se aproximavam dos parâmetros elétricos estabelecidos para esse sistema.

O Apêndice $B$ contém todos os parâmetros de fluxo de potência e o Apêndice $\mathrm{C}$ contém a definição dos modelos e os parâmetros de cada elemento da rede que foram utilizados, incluindo definição das proteções e da modelagem de carga.

Com o conhecimento dos fundamentos de controle de frequência e com a modelagem estabelecida neste capítulo, é possível realizar todas as simulações para avaliação do comportamento dinâmico de um sistema elétrico com penetração de fontes de energia renováveis considerando dispositivos de armazenamento de energia. 


\section{5}

\section{Simulações e Resultados}

\section{1. \\ Introdução}

As características do sistema elétrico de Roraima serão apresentadas neste Capítulo $5 \mathrm{com}$ a definição da metodologia aplicada, estabelecendo a contingência mais impactante para as simulações dinâmicas. De posse dos resultados das simulações, será realizada uma análise do comportamento dinâmico desse sistema elétrico com penetração de fontes intermitentes, considerando a utilização de dispositivos de armazenamento de energia.

A construção de um mapa com os resultados dessas simulações dinâmicas pode ser um componente decisor no processo de planejamento de um sistema de transmissão isolado. Outro mapa pode ser elaborado, a partir da decisão do planejador, onde se avaliam os riscos assumidos no processo de programação da operação e na própria operação em tempo real.

\section{2.}

\section{Características do Sistema Elétrico}

O sistema elétrico do estado de Roraima é predominantemente atendido por um circuito simples de 230 kV oriundo da interligação Brasil - Venezuela, e o restante por pequenas usinas térmicas locais movidas a diesel. Além disso, um sistema de subtransmissão em $69 \mathrm{kV}$ atende todo o território estadual. A fragilidade dessa interligação expõe toda a carga do estado que vivenciou diversos blecautes nos últimos anos. Atualmente, por questões governamentais, esse sistema elétrico opera de modo isolado do Sistema Interligado Nacional (SIN), dependendo apenas da geração térmica local para atendimento à carga. $A$ Figura 5.1 apresenta o diagrama geoelétrico do estado de Roraima. 


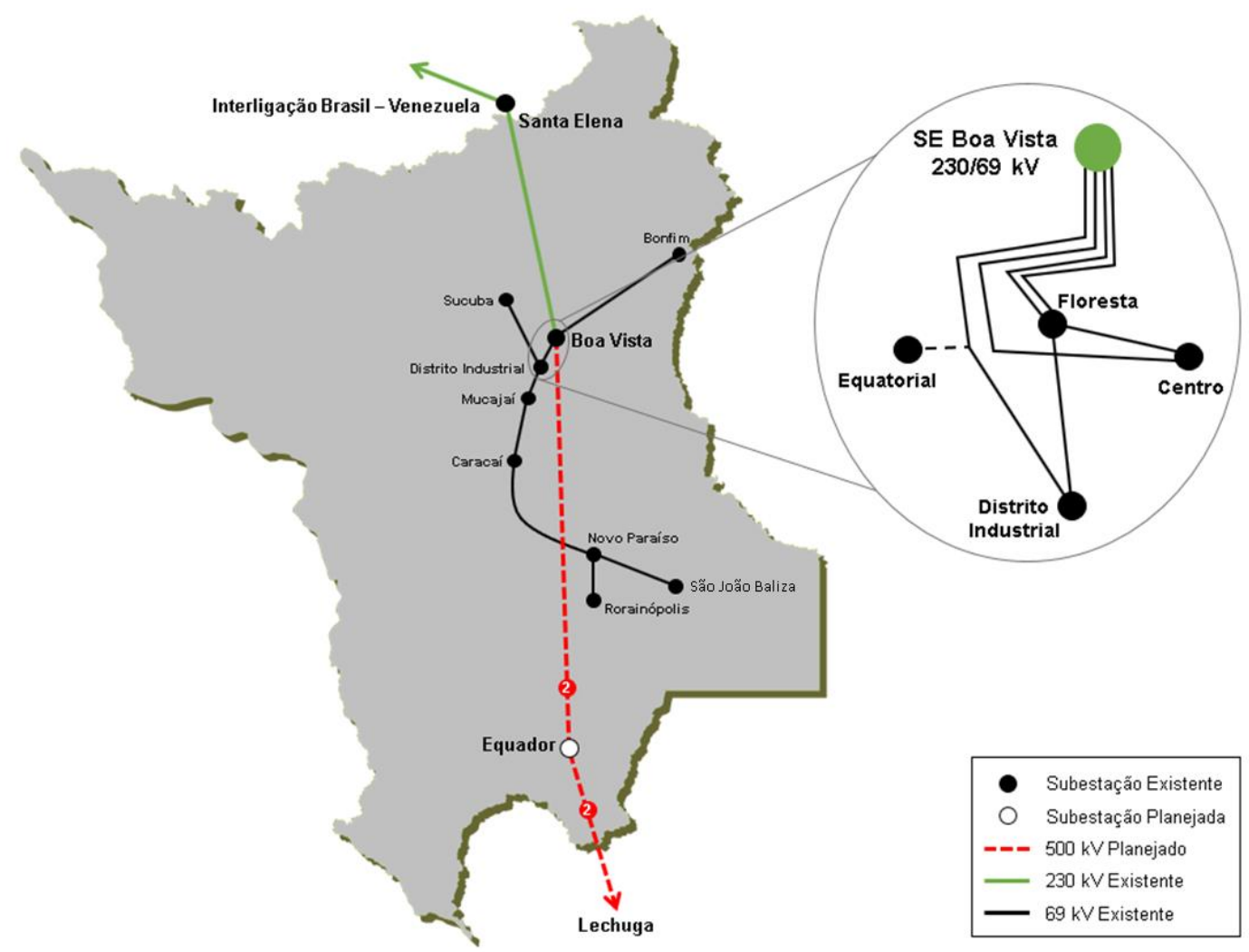

Figura 5.1 - Diagrama geoelétrico do estado de Roraima.

Por questões políticas e econômicas, o governo da Venezuela interrompeu o fornecimento de energia para o Brasil solicitando o desligamento da interligação. Com isso, foi determinado pelo Comitê de Monitoramento do Setor Elétrico (CMSE) que o estado de Roraima seria operado de maneira isolada, atendida somente pelo parque gerador térmico local. Esta decisão, por si só, não eliminou as interrupções completas de carga neste sistema.

Em fevereiro de 2019, o Ministério de Minas e Energia (MME), através da Portaria ํo 134 [22], alterou alguns dispositivos da Portaria ํo 512 de dezembro de 2018 [23], estabelecendo as diretrizes para realização do Leilão exclusivo para o estado de Roraima definindo, através da Nota Técnica [24], as margens para escoamento de geração em cada área elétrica, e com requisitos técnicos mínimos para participação do processo licitatório. Sabe-se que todo o parque gerador térmico local não atende aos requisitos mínimos, sendo necessária a remoção de todas as usinas térmicas hoje em operação [24]. Sabe-se também, que há possibilidade de contratação de energia renovável complementar com objetivo de reduzir custos operacionais. A fonte renovável mais promissora para 
esta região seria advinda de painéis fotovoltaicos próximos aos centros de carga. Portanto, quanto maior for a penetração de usinas fotovoltaicas, menor será o custo da operação.

A solução estrutural, estudada pela Empresa de Pesquisa Energética (EPE), contempla um circuito duplo de mesma torre interligando em $500 \mathrm{kV}$ a subestação Boa Vista com a subestação Lechuga, próximo à cidade de ManausAM. Essa linha de transmissão enfrenta diversos problemas socioambientais e atualmente está sem previsão para entrada em operação.

Contudo, em 31 de maio de 2019, ocorreu o Leilão de Geração no 01/2019ANEEL, os quais foram vencedores do certame, os empreendimentos listados na Tabela 5.1 a seguir. Foram 9 empreendimentos contratados, totalizando 294 MW de potência para o sistema isolado de Roraima. Dentre os vencedores, há projetos a gás natural, óleo diesel e biomassa, além de soluções híbridas, combinando biocombustíveis, solar fotovoltaica e baterias [25].

Tabela 5.1 - Empreendimentos de Geração Vencedores no Leilão de Geração no 01/2019-

ANEEL.

\begin{tabular}{c|c|c}
\hline \hline Usina & Potência Instalada (MW) & Subestação \\
\hline \hline UTE Jaguatirica II & 126,290 & Boa Vista 230 kV \\
\hline UTE Palmaplan Energia 2 & 11,490 & Rorainópolis 34,5 kV \\
\hline UTE Monte Cristo Sucuba & 42,255 & Sucuba 69 kV \\
\hline UTE Bonfim & 10,000 & Bonfim 69 kV \\
\hline UTE Cantá & 10,000 & Bonfim 69 kV \\
\hline UTE Pau Rainha & 10,000 & Boa Vista $69 \mathrm{kV}$ \\
\hline UTE Santa Luz & 10,000 & Boa Vista 69 kV \\
\hline Híbrido Forte de São Joaquim & 56,218 & São João Baliza 69 kV \\
\hline UTE BBF Baliza & 17,616 & \\
\hline \hline TOTAL & 293,869 & \\
\hline \hline
\end{tabular}

Portanto, este será o parque gerador para o sistema de Roraima operar de forma isolada do SIN até que seja construída a solução estrutural. Desta forma, será realizada uma análise contemplando modelos típicos e parâmetros aproximados das unidades geradoras vencedoras do leilão de geração para avaliação do comportamento dinâmico deste sistema isolado. Destaca-se que mesmo após a entrada em operação da LT 500 kV Boa Vista - Equador Lechuga, considerando a "desinterligação" entre Brasil e Venezuela, os ESD 
podem contribuir para a segurança do sistema de Roraima na ocorrência da contingência dupla desses circuitos.

\section{3.}

\section{Metodologia Aplicada}

A metodologia utilizada nesta dissertação baseia-se na substituição gradual do despacho da geração térmica local prevista no Leilão de Geração do estado de Roraima por geração fotovoltaica. Para cada patamar de penetração de energia renovável, diferentes valores de ESD serão analisados através da realização de simulações dinâmicas no domínio do tempo. Os estudos se concentrarão em contingências que provoquem reduções abruptas da geração fotovoltaica que podem ser decorrentes de sombra nos painéis. Como ainda não se tem critérios definidos para sombreamento de painéis fotovoltaicos, adotou-se o posicionamento conservativo de simular essa contingência de perda de geração em degrau. A redução de geração solar instantânea também pode ser simulada como a perda do transformador elevador entre a planta solar e o sistema de subtransmissão.

Nesses eventos, observa-se uma redução significativa da frequência, sendo necessária uma resposta rápida dos controles para evitar blecautes ou cortes parciais de cargas. Nesse trabalho serão avaliadas condições com e sem o Esquema Regional de Alívio de Carga (ERAC). Os casos simulados serão classificados segundo os critérios de estabilidade eletromecânica estabelecidos pelo Submódulo 3.6 dos Procedimentos de Rede do ONS [26], para que se encontre uma relação entre a penetração de geração fotovoltaica e o dimensionamento de ESD.

As análises de desempenho dinâmico desse sistema foram realizadas por meio de simulações computacionais no domínio do tempo no programa Organon, utilizando dados de usinas térmicas do SIN com características equivalentes às vencedoras do leilão de geração, respeitando os requisitos mínimos citados em [24]. Para as usinas fotovoltaicas foi utilizado o modelo da planta São Pedro em operação no SIN [21], e um modelo dinâmico típico para os dispositivos de armazenamento de energia, apresentado no Capítulo 4 desta dissertação. 
Essas simulações transitórias foram limitadas em 15 segundos, pois o objetivo das análises está na etapa de atuação da regulação primária discutida no Capítulo 3.

\subsection{1.}

\section{Método de Definição da Contingência Mais Severa}

Para definição da contingência mais severa de um sistema isolado, do ponto de vista de estabilidade dinâmica da frequência, deve-se considerar as características do parque gerador e da rede de transmissão ou subtransmissão que atendem às cargas. Para o sistema de transmissão, fica estabelecido o critério de atendimento à contingência de um elemento da rede sem ocorrência de corte de carga descontrolado. Conhecendo as características do parque gerador, deve-se levar em conta a perda de unidades de maior capacidade nominal de potência nos casos de usinas hidrelétricas e termelétricas. Para as usinas renováveis como solar e eólica, deve-se considerar a perda do maior conversor ou do transformador elevador que conecta a planta renovável à rede elétrica.

Outra avaliação a ser feita diz respeito à imprevisibilidade da fonte renovável, quando uma sombra pode reduzir abruptamente a geração solar ou uma alteração rápida de ventos podem interromper o fornecimento de energia advindo de unidades eólicas.

Para essa análise, é dada atenção ao efeito de sombreamento provocado nos painéis fotovoltaicos avaliados em [27] e [28], que mostrou que "os sombreamentos causados por nuvens móveis podem ter um efeito importante na operação e eficiência geral das usinas fotovoltaicas". Nesta análise, concluiu-se que na média o sombreamento reduz em cerca de $60 \%$ a intensidade luminosa do sol. Porém, em $0,08 \%$ dos casos, podem apresentar reduções superiores a $90 \%$ e em $3,9 \%$ dos casos podem apresentar reduções superiores a $80 \%$.

Para o sistema Roraima isolado, mesmo com a possibilidade de baixa penetração de usinas fotovoltaicas, a redução de potência por efeito de sombreamento pode ser superior à perda da maior máquina, e também superior à perda de um elemento do sistema de transmissão que modificaria o equilíbrio carga-geração desse sistema isolado. Assim, ficou definido que independente da penetração de usinas fotovoltaicas, a contingência mais severa para o sistema Roraima será o efeito sombreamento. Nesta avaliação, serão considerados os 
montantes de $95 \%, 80 \%$, 65\% e $40 \%$ de redução de potência injetada pelos painéis fotovoltaicos para cada montante de penetração simulado. Neste contexto, estipula-se usar níveis de ESD variando de 5 em $5 \%$ da geração total para comparação dos resultados. Nessas condições, foram considerados cortes parciais de carga através do ERAC, e também, relés de subfrequência para desconexão de banco de capacitores, a fim de evitar sobretensões excessivas decorrentes desses cortes de carga.

\section{4 .}

\section{Análise do Sistema Isolado de Roraima}

$\mathrm{Na}$ construção dos casos de referência para análise, foi considerada a projeção da demanda máxima com 233,97 MW e 94,77 Mvar, sendo aproximadamente $80 \%$ da demanda na capital e o restante no interior. Apesar do baixo valor de fator de potência indutivo, atualmente essa rede é bem compensada com equipamentos shunts. Os barramentos de carga estão listados na Tabela 5.2.

Tabela 5.2 - Carga por Barramento do Sistema Isolado de Roraima.

\begin{tabular}{c|c|c|c|c}
\hline \multirow{2}{*}{ Nome da Subestação } & \multirow{2}{*}{ Nome da Barra } & \multicolumn{3}{|c}{ Carga por Barramento } \\
\cline { 3 - 5 } & & P (MW) & Q (Mvar) & FP \\
\hline \hline Mucajaí & MUCAJA-RR013 & 3,553 & 1,055 & 0,959 \\
\hline Caracaí & CARACA-RR013 & 4,997 & 1,492 & 0,958 \\
\hline Nova Paraíso & NPARAI-RR013 & 5,681 & 1,691 & 0,958 \\
\hline Rorainópolis & RORAIN-RR013 & 5,168 & 1,539 & 0,958 \\
\hline Bonfim & BONFIM-RR013 & 7,011 & 2,090 & 0,958 \\
\hline Sucuba & SUCUBA-RR013 & 6,688 & 1,995 & 0,958 \\
\hline São João Baliza & SJBALI-RR013 & 5,425 & 1,615 & 0,958 \\
\hline Distrito Industrial & D.INDUUTE000 & 34,550 & 14,730 & 0,920 \\
\hline Equatorial & EQUATO-RR013 & 50,040 & 21,320 & 0,920 \\
\hline Centro & CENTRO-RR013 & 55,530 & 23,660 & 0,920 \\
\hline \hline Floresta & FLORESUTE000 & 55,330 & 23,580 & 0,920 \\
\hline \hline
\end{tabular}


Para a realização desse estudo, todo o parque gerador foi constituído por usinas térmicas e fotovoltaicas que se referenciaram nas unidades geradoras vencedoras do leilão de geração [25] e nos requisitos mínimos citados [24]. A saber, tendo potência aparente mínima de 10 MVA e constante de inércia mínima de 1,6 segundos para as usinas conectadas nos barramentos classificados como Capital, e potência aparente mínima de 3,5 MVA e constante de inércia mínima de 1,25 segundos para as usinas conectadas nos barramentos classificados como Interior, que contemplam área Sucuba, área Bonfim e área Sul.

Todas as usinas térmicas possuem regulação de velocidade e participam da regulação primária de frequência. $\mathrm{Na}$ Tabela 5.3 consta a capacidade instalada das usinas de acordo com montantes de geração vencidos no certame, dentro das margens que foram estabelecidas pela nota técnica [24] através da análise de fluxo de potência, da disponibilidade física para conexão de novos empreendimentos e também, de violação do nível de curto circuito em barramentos candidatos. Cabe ressaltar que não foi encontrada na base de dados de transitórios eletromecânicos [21] uma usina térmica com constantes de inércia que cumprisse o requisito de constante de inércia mínima na Capital, sendo suavemente adaptada sempre mantendo a posição conservativa.

Tabela 5.3 - Capacidade Instalada das Usinas do Sistema Isolado de Roraima.

\begin{tabular}{c|c|c|c|c|c}
\hline \hline \multirow{2}{*}{ Área } & Usina & Unidade(s) & $\mathbf{P ( M W )}$ & Total (MW) & H (s) \\
\hline \hline \multirow{3}{*}{ Bonfim } & UTE Bonfim & 1 & 16,00 & 16,00 & 1,25 \\
\cline { 2 - 6 } & UTE Cantá & 1 & 16,00 & 16,00 & 1,25 \\
\hline \multirow{3}{*}{ Sucuba } & UTE Monte Cristo Sucuba & 13 & 3,25 & 42,25 & 1,25 \\
\cline { 2 - 6 } & UTE Palmaplan & 3 & 3,25 & 9,75 & 1,25 \\
\cline { 2 - 6 } & UTE Baliza 1 & 1 & 16,00 & 16,00 & 1,25 \\
\hline \multirow{5}{*}{ Capital } & UTE Baliza 2 & 2 & 3,25 & 6,50 & 1,25 \\
\cline { 2 - 6 } & UTE Pau Rainha & 1 & 16,00 & 16,00 & 1,6 \\
\cline { 2 - 6 } & UTE Santa Luz & 1 & 16,00 & 16,00 & 1,6 \\
\cline { 2 - 6 } & UTE Jaguatirica II - vapor & 1 & 45,60 & 45,60 & 2,971 \\
\cline { 2 - 6 } & UTE Forte de São Joaquim & 4 & 16,00 & 64,00 & 1,6 \\
\cline { 2 - 6 } & UFV Forte de São Joaquim & 27 & 1,00 & 27,00 & \\
\hline \hline
\end{tabular}


A usina fotovoltaica pode controlar a potência ativa, potência reativa, tensão e frequência. Para as simulações dinâmicas realizadas, os inversores da planta solar operam controlando a tensão terminal e com modo de controle de potência ativa constante, assim como acontece com as plantas fotovoltaicas atualmente conectadas no SIN. Desta forma, não participam da regulação primária de frequência desta rede. O modelo de usina fotovoltaica utilizado foi a UFV São Pedro da base de dados de transitórios eletromecânicos do ONS [21].

Na composição do despacho, foram consideradas as usinas térmicas do interior com prioridade, dado que essas usinas tem a constante de inércia inferior, representaram a menor constante de inércia equivalente possível e desta forma a análise foi conservativa. As plantas fotovoltaicas e o ESD foram consideradas no barramento de $69 \mathrm{kV}$ da SE Boa Vista, entendendo também que esta decisão seria conservativa. Com uma melhor distribuição geográfica tanto dos painéis fotovoltaicos quanto dos ESD, o sistema tende a se comportar dinamicamente melhor. $\mathrm{Na}$ premissa de que as plantas solares podem estar geograficamente separadas, atenua de maneira significativa a possibilidade de redução instantânea de geração por ocorrência de sombreamento dos painéis fotovoltaicos.

Foram considerados os valores de $0 \%, 10 \%, 20 \%, 30 \%, 40 \%, 50 \%$ e $60 \%$ de penetração de usinas fotovoltaicas, conforme a Tabela 5.4 e para cada nível de penetração, variou-se o ESD em $0 \%, 5 \%, 10 \%, 15 \%, 20 \%, 25 \%$ e $30 \%$, conforme a Tabela 5.5. Esses valores são percentuais da geração total do sistema isolado de Roraima que é a soma da carga total com as perdas elétricas. No aumento da penetração de usinas fotovoltaicas foram sendo substituídas das máquinas com maior constante de inércia para as máquinas com menor constante de inércia, sempre garantindo um posicionamento conservativo. 
Tabela 5.4 - Despacho de cada usina por patamar de penetração de UFV no Sistema Isolado de Roraima.

\begin{tabular}{|c|c|c|c|c|c|c|c|c|}
\hline \multirow{2}{*}{ Nome da Usina } & \multirow{2}{*}{$\begin{array}{l}\text { Nome da } \\
\text { Barra }\end{array}$} & \multicolumn{7}{|c|}{ Penetração de UFV (MW) } \\
\hline & & $0 \%$ & $10 \%$ & $20 \%$ & $30 \%$ & $40 \%$ & $50 \%$ & $60 \%$ \\
\hline UTE Bonfim & $\begin{array}{l}\text { BONFI- } \\
\text { UTE069 }\end{array}$ & 16,00 & 16,00 & 16,00 & 16,00 & 10,25 & 9,92 & 7,00 \\
\hline UTE Cantá & $\begin{array}{l}\text { CANTA- } \\
\text { UTE069 }\end{array}$ & 16,00 & 16,00 & 16,00 & 16,00 & 10,25 & 9,92 & 0,00 \\
\hline $\begin{array}{c}\text { UTE Monte Cristo } \\
\text { Sucuba }\end{array}$ & $\begin{array}{l}\text { MCSUC- } \\
\text { UTE069 }\end{array}$ & 42,25 & 42,25 & 42,25 & 42,25 & 39,00 & 16,00 & 4,75 \\
\hline UTE Palmaplan & $\begin{array}{l}\text { PALMA- } \\
\text { UTE069 }\end{array}$ & 9,75 & 9,75 & 9,75 & 9,75 & 9,75 & 9,75 & 9,75 \\
\hline UTE Baliza 1 & $\begin{array}{l}\text { BALZ1- } \\
\text { UTE069 }\end{array}$ & 16,00 & 16,00 & 16,00 & 16,00 & 10,25 & 9,92 & 9,00 \\
\hline UTE Baliza 2 & $\begin{array}{l}\text { BALZ2- } \\
\text { UTE069 }\end{array}$ & 6,50 & 6,50 & 6,50 & 6,50 & 6,50 & 6,50 & 6,50 \\
\hline UTE Pau Rainha & $\begin{array}{l}\text { P.RAI- } \\
\text { UTE069 }\end{array}$ & 13,75 & 16,00 & 9,50 & 4,50 & 0,00 & 0,00 & 0,00 \\
\hline UTE Santa Luz & $\begin{array}{l}\text { STALU- } \\
\text { UTE069 }\end{array}$ & 13,75 & 16,00 & 9,50 & 0,00 & 0,00 & 0,00 & 0,00 \\
\hline $\begin{array}{c}\text { UTE Jaguatirica II } \\
\text { - gás }\end{array}$ & $\begin{array}{l}\text { JAG.G- } \\
\text { UTE230 }\end{array}$ & 60,00 & 60,00 & 60,00 & 60,00 & 60,00 & 60,00 & 60,00 \\
\hline $\begin{array}{c}\text { UTE Jaguatirica II } \\
\text { - vapor }\end{array}$ & $\begin{array}{l}\text { JAG.V- } \\
\text { UTE230 }\end{array}$ & 0,00 & 0,00 & 0,00 & 0,00 & 0,00 & 0,00 & 0,00 \\
\hline $\begin{array}{c}\text { UTE Forte de São } \\
\text { Joaquim }\end{array}$ & $\begin{array}{l}\text { S.JOA- } \\
\text { UTE069 }\end{array}$ & 50,00 & 21,50 & 9,50 & 0,00 & 0,00 & 0,00 & 0,00 \\
\hline $\begin{array}{c}\text { UFV Forte de São } \\
\text { Joaquim }\end{array}$ & $\begin{array}{l}\text { S.JOA- } \\
\text { UFV069 }\end{array}$ & 0,00 & 24,00 & 27,00 & 27,00 & 27,00 & 27,00 & 27,00 \\
\hline $\begin{array}{c}\text { ESS Forte de São } \\
\text { Joaquim }\end{array}$ & $\begin{array}{l}\text { S.JOA- } \\
\text { ESS069 }\end{array}$ & 0,00 & 0,00 & 0,00 & 0,00 & 0,00 & 0,00 & 0,00 \\
\hline UFV Boa Vista & $\begin{array}{l}\text { SOLAR- } \\
\text { UFV000 }\end{array}$ & 0,00 & 0,00 & 22,00 & 46,00 & 71,00 & 95,00 & 120,00 \\
\hline ESS Boa Vista & $\begin{array}{l}\text { BATERIA-- } \\
000\end{array}$ & 0,00 & 0,00 & 0,00 & 0,00 & 0,00 & 0,00 & 0,00 \\
\hline \multicolumn{2}{|c|}{ TOTAL } & 244,00 & 244,00 & 244,00 & 244,00 & 244,00 & 244,00 & 244,00 \\
\hline
\end{tabular}


Tabela 5.5 - Capacidade Nominal dos Dispositivos de Armazenamento de Energia.

\begin{tabular}{c|c}
\hline \hline ESD & $\begin{array}{c}\text { Capacidade } \\
\text { Nominal (MW) }\end{array}$ \\
\hline \hline 0\% da Geração Total & 0 \\
\hline $5 \%$ da Geração Total & 12 \\
\hline $10 \%$ da Geração Total & 24 \\
\hline $15 \%$ da Geração Total & 37 \\
\hline 20\% da Geração Total & 49 \\
\hline $25 \%$ da Geração Total & 61 \\
\hline $30 \%$ da Geração Total & 73 \\
\hline \hline
\end{tabular}

Foram então elaborados 7 casos de referência para análise conforme demonstra a Tabela 5.5. Exceto o primeiro caso, que serviu de partida para os demais, em todos os outros 6 casos foram consideradas 7 variações distintas da potência nominal dos ESD em percentual da geração total, conforme a Tabela 5.6, e também, a variação da contingência considerada que é a redução de geração fotovoltaica em 4 patamares, totalizando 168 casos de simulação.

Tabela 5.6 - Casos de referência para análise dinâmica do Sistema Isolado de Roraima.

\begin{tabular}{|c|c|c|c|c|c|}
\hline \multirow{2}{*}{ Caso } & \multirow{2}{*}{ Título } & \multicolumn{4}{|c|}{ Redução de UFV (MW) } \\
\hline & & $40 \%$ & $65 \%$ & $80 \%$ & $95 \%$ \\
\hline 1 & 0\% Penetração de Fotovoltaicas (0 MW) & - & - & - & - \\
\hline 2 & $10 \%$ Penetração de Fotovoltaicas (24 MW) & 10 & 16 & 19 & 23 \\
\hline 3 & $20 \%$ Penetração de Fotovoltaicas (49 MW) & 20 & 32 & 39 & 47 \\
\hline 4 & $30 \%$ Penetração de Fotovoltaicas (73 MW) & 29 & 47 & 58 & 69 \\
\hline 5 & 40\% Penetração de Fotovoltaicas (98 MW) & 39 & 64 & 78 & 93 \\
\hline 6 & 50\% Penetração de Fotovoltaicas (122 MW) & 49 & 79 & 98 & 116 \\
\hline 7 & 60\% Penetração de Fotovoltaicas (147 MW) & 59 & 96 & 118 & 140 \\
\hline
\end{tabular}




\subsection{1.}

\section{Resultados das Simulações Dinâmicas}

Diante dos casos analisados, foram elaborados gráficos que apresentam a relação do aumento gradual da penetração de usinas fotovoltaicas com o aumento gradual da capacidade nominal dos ESD. Para cada condição, ficou estabelecido que os casos poderiam: ser estáveis (i.e., o sistema isolado de Roraima se mantém íntegro); apresentar cortes parciais de carga em até 5 estágios; ou apresentar instabilidade ou violação de critérios do ponto de vista de estabilidade de frequência. Para a construção de cada gráfico, foi determinado um montante fixo de redução de geração com intuito de promover a similaridade das análises. Os resultados das simulações considerando a redução de $40 \%$ da geração fotovoltaica estão apresentados na Figura 5.2, considerando a redução de $65 \%$ da geração fotovoltaica estão apresentados na Figura 5.3, considerando a redução de $80 \%$ da geração fotovoltaica estão apresentados na Figura $5.4 \mathrm{e}$ por fim, considerando a redução de $95 \%$ da geração fotovoltaica estão apresentados na Figura 5.5.

Com os resultados desses gráficos, denominado Mapa de Decisão para o Planejamento, pode-se chegar a uma decisão de planejamento com base nos riscos que se deseja correr na operação do sistema e quanto se tem de interesse em promover a penetração de fontes intermitentes, neste caso, fotovoltaicas.

Para redução de $40 \%$ da geração fotovoltaica

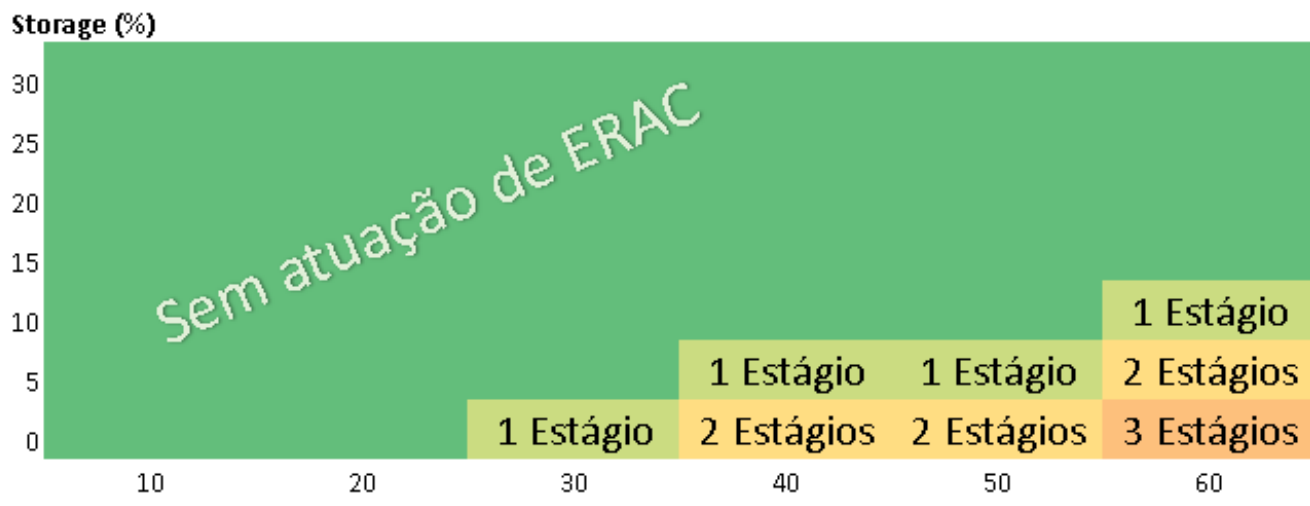


Para reduçăo de $65 \%$ da geraçã̃o fotovoltaica

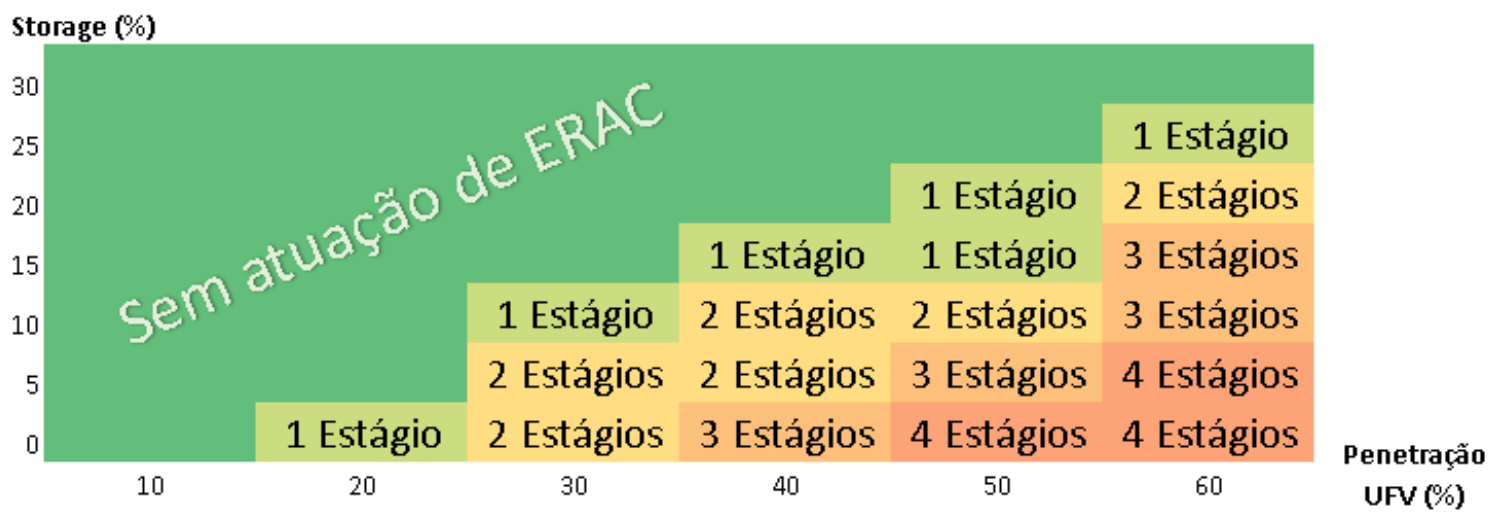

Figura 5.3 - Resultados das simulações considerando a redução de $65 \%$ da geração fotovoltaica.

Para redução de $80 \%$ da geração fotovoltaica

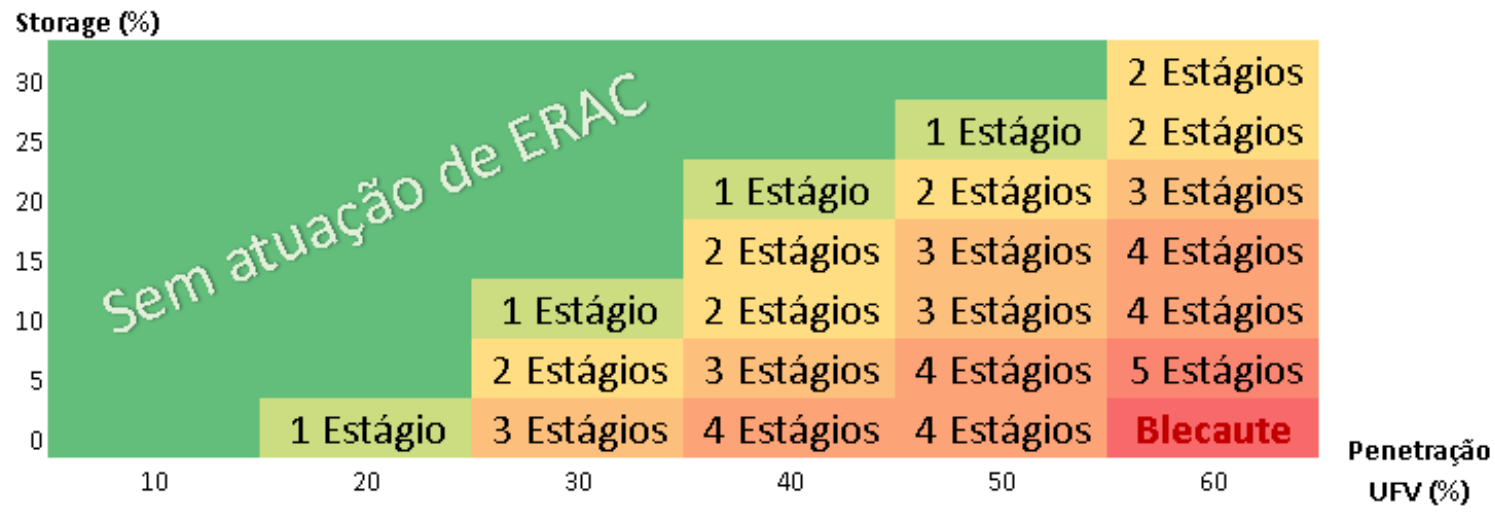

Figura 5.4 - Resultados das simulações considerando a redução de $80 \%$ da geração fotovoltaica. 
Para redução de $95 \%$ da geração fotovoltaica

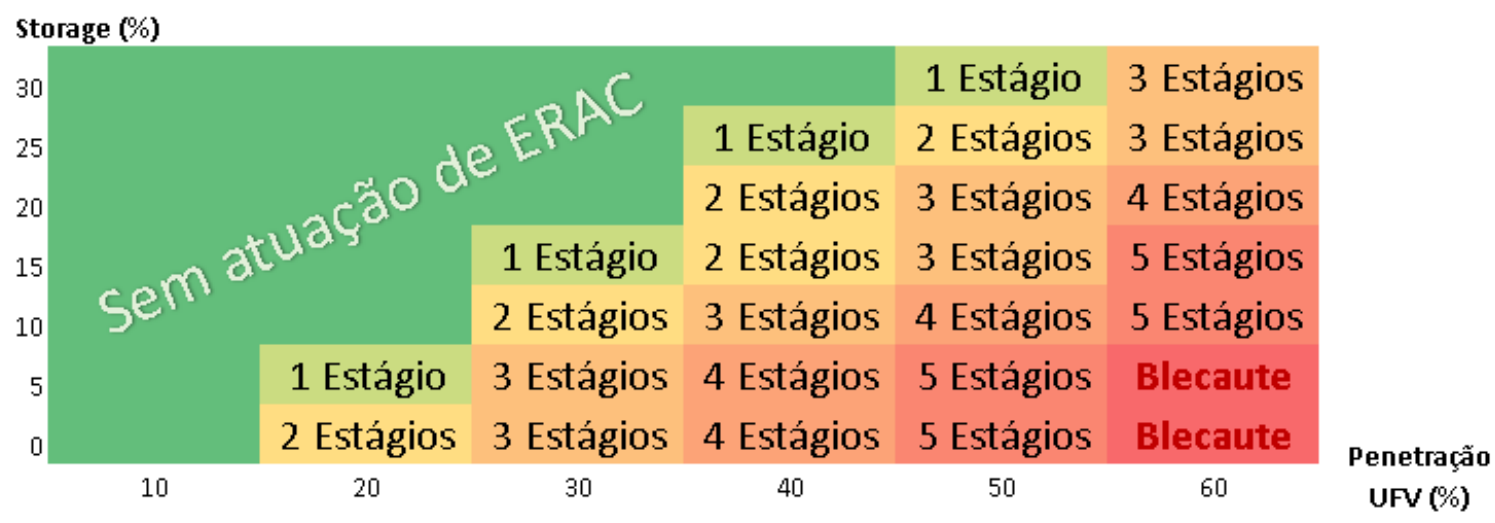

Figura 5.5 - Resultados das simulações considerando a redução de 95\% da geração fotovoltaica.

Como esperado, o aumento da capacidade nominal dos ESD apresenta uma relação direta com a estabilidade de frequência do sistema isolado de Roraima. Entretanto, o crescimento da proporção de geração de usinas fotovoltaicas pode provocar o corte total das cargas do estado, mesmo considerando a utilização de armazenamento. Nota-se também que a redução do montante de geração contingenciado por sombreamento dos painéis fotovoltaicos atenua a possibilidade de blecaute.

De forma a minimizar qualquer possibilidade de blecaute, a decisão de planejamento de um ESD correspondente a 10\% da geração total do sistema (24 MW) permitiria uma penetração de até $60 \%$ de usinas fotovoltaicas $147 \mathrm{MW}$ neste sistema isolado. Nota-se que um montante mais reduzido de ESD, com $5 \%$ da geração total do sistema (12 MW), também poderia ser dimensionado para penetração de até $60 \%$ de usinas fotovoltaicas, considerando um risco aproximado de $5 \%$ de ocorrer blecaute. A Figura 5.6 apresenta as possibilidades de penetração com relação à redução abrupta de geração fotovoltaica considerando um ESD correspondente a $15 \%$ da geração total do sistema (37 MW), a Figura 5.7 considerando um ESD correspondente a $10 \%$ da geração total do sistema (24 MW) e a Figura 5.8 considerando um ESD correspondente a 5\% da geração total do sistema (12 MW). 
Para cada um desses gráficos, denominado Mapa de Decisão para a Operação, já considerando o montante de armazenamento determinado pelo processo de planejamento, pode-se acompanhar em tempo real quais são os riscos associados a cada contingência de geração por percentual de penetração de fontes renováveis.

Considerando BESS de $15 \%$ da carga

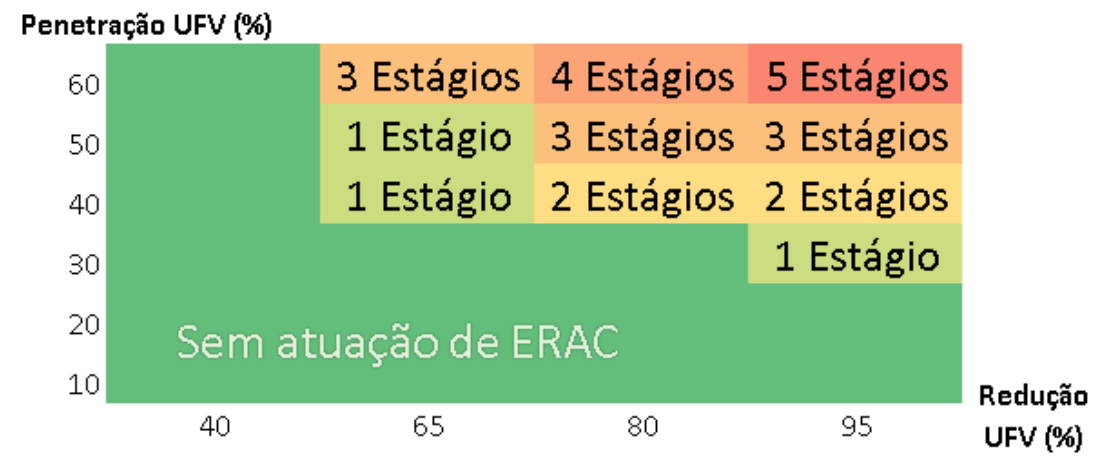

Figura 5.6 - Resultado das simulações considerando um ESD de 15\% da geração total do sistema.

Considerando BESS de $10 \%$ da carga

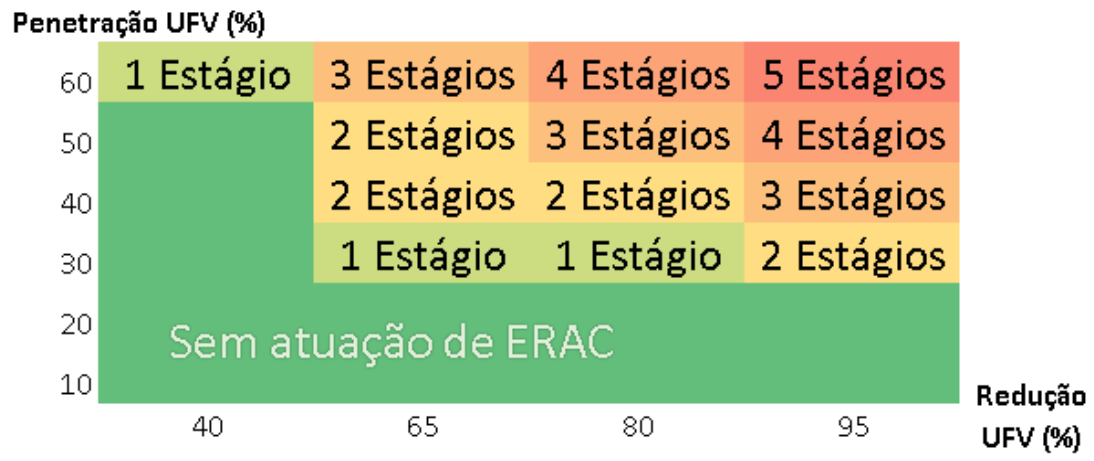

Figura 5.7 - Resultado das simulações considerando um ESD de 10\% da geração total do sistema. 


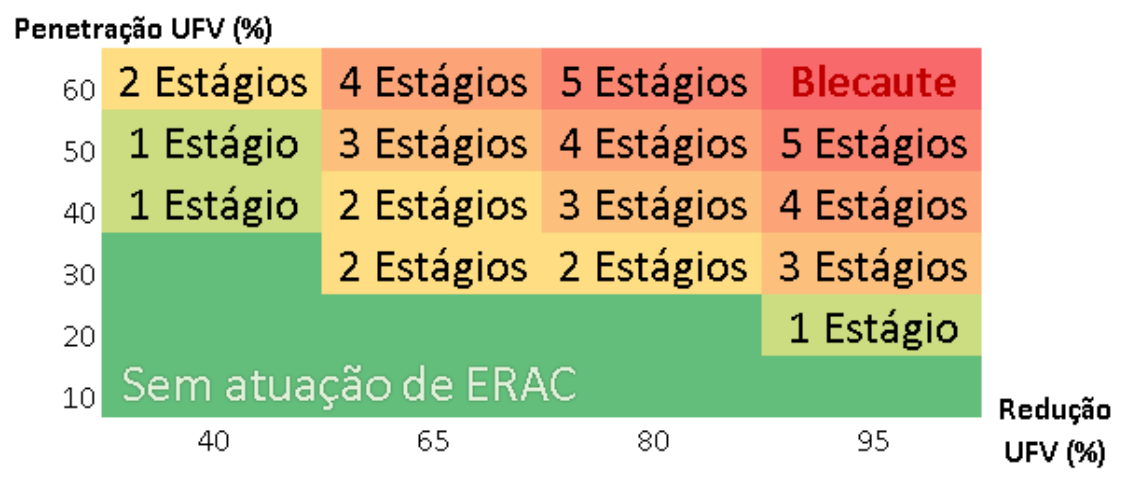

Figura 5.8 - Resultado das simulações considerando um ESD de 5\% da geração total do sistema.

\subsubsection{1.}

\section{Simulações com $60 \%$ de Penetração de Fotovoltaicas e $10 \%$ de ESD}

Diante dos resultados, pode-se visualizar as diferenças de frequência para cada nível de redução de geração fotovoltaica, considerando a hipótese de 10\% de ESD e $60 \%$ de penetração de fotovoltaica pelo gráfico apresentado na Figura 5.9. Notadamente, quanto maior for a contingência de redução de geração fotovoltaica, menor será a frequência do sistema e consequentemente, mais estágios de ERAC serão necessários, como foi consolidado anteriormente na Figura 5.7.

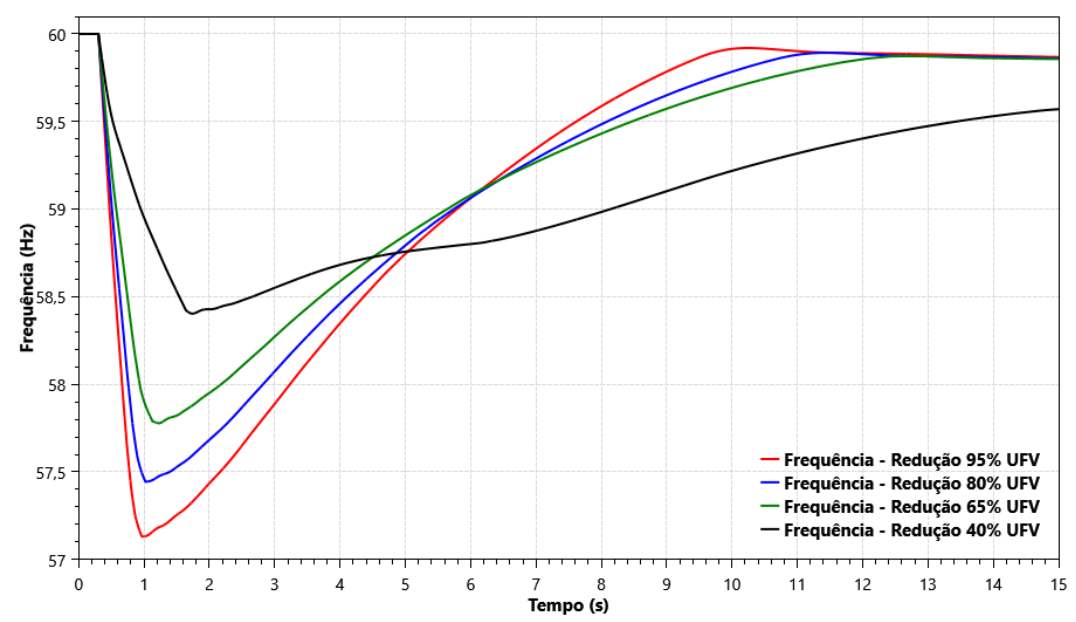

Figura 5.9 - Frequência do Sistema para Reduções de Geração Fotovoltaicas Distintas Considerando um ESD de $10 \%$ da Geração Total do Sistema e $60 \%$ de Penetração de Usinas Fotovoltaicas. 
É possível verificar que apenas a regulação primária considerando o estatismo das máquinas síncronas, ou seja, reguladores de velocidade com queda de velocidade, não são capazes de retornar com a frequência para o valor nominal. No caso de redução de $95 \%$ da geração de usinas fotovoltaicas, os 5 estágios de ERAC são fundamentais na resposta transitória para evitar que a frequência alcance valores inferiores a $57 \mathrm{~Hz}$, limite mínimo estabelecido para unidades geradoras térmicas pelos Procedimentos de Rede [26]. Para o caso de redução de $40 \%$ da geração de usinas fotovoltaicas, com a menor taxa de variação de frequência, o único estágio de ERAC atua um pouco depois conforme visto na Figura 5.10, mantendo ainda um pequeno desbalanço entre carga e geração que faz com que os reguladores de velocidade recuperem mais lentamente a frequência do sistema.

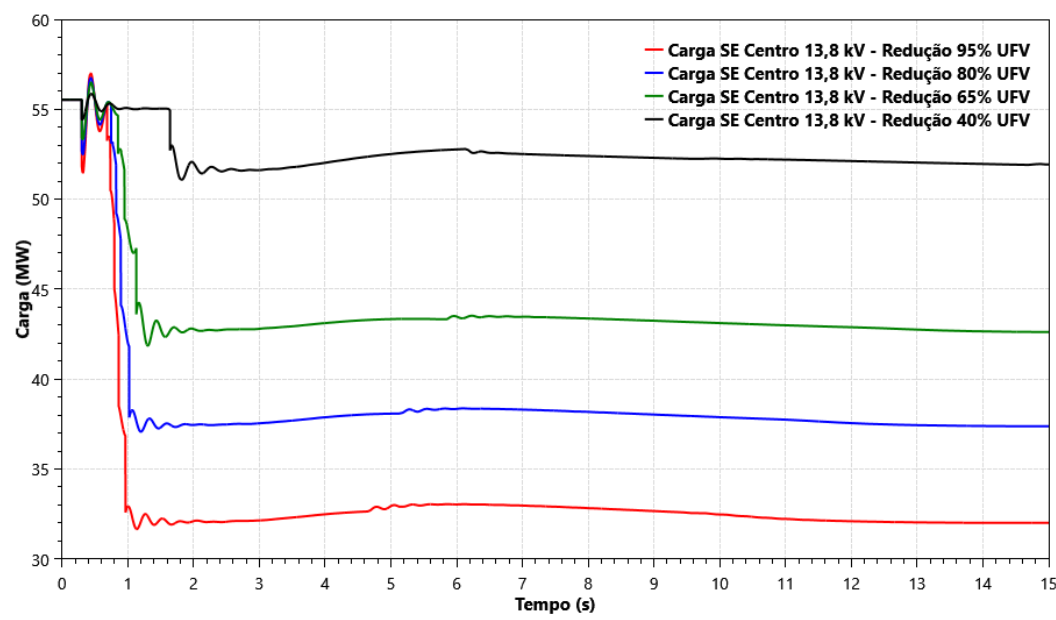

Figura 5.10 - Carga na Subestação Centro 13,8 kV para Reduções de Geração Fotovoltaicas Distintas Considerando um ESD de 10\% da Geração Total do Sistema e 60\% de Penetração de Usinas Fotovoltaicas.

Pode-se comparar a injeção de potência ativa do ESD com 10\% da geração total para cada redução de geração fotovoltaica, mantendo o nível de penetração em 60\%. Para todos os casos, como visto na Figura 5.11, o ESD atinge o valor máximo considerando uma sobrecarga admissível. 


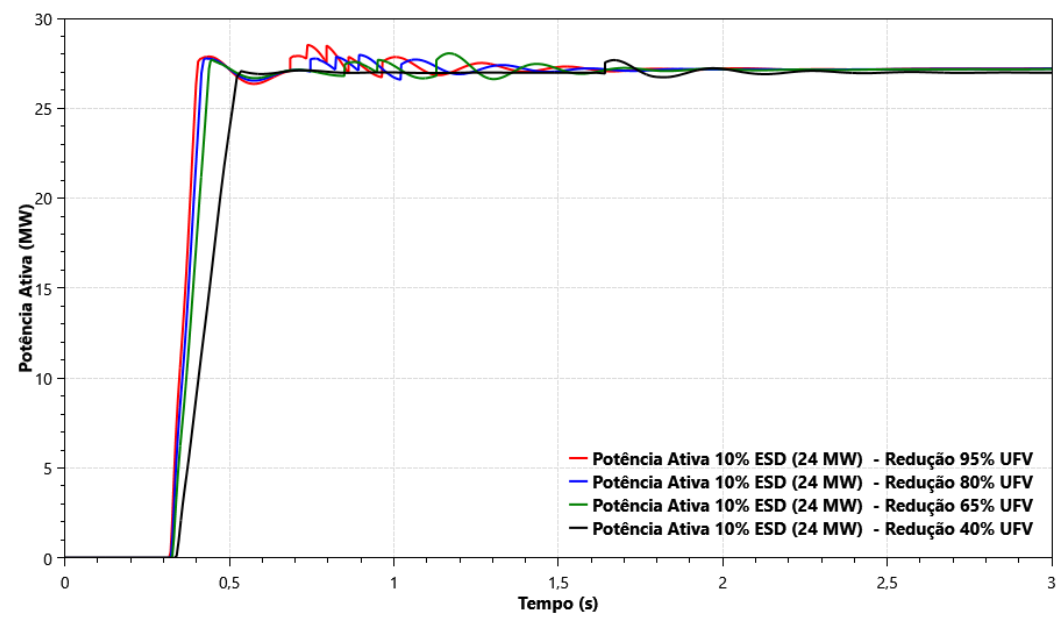

Figura 5.11 - Potência Ativa do ESD para Reduções de Geração Fotovoltaicas Distintas Considerando um ESD de 10\% da Geração Total do Sistema e 60\% de Penetração de Usinas Fotovoltaicas.

Para avaliação das tensões do sistema utilizou-se a tensão no barramento de $69 \mathrm{kV}$ da SE Boa Vista para representar a variação significativa, principalmente no período transitório pós-distúrbio. Fica evidente pela Figura 5.12 que quanto maior a redução de geração fotovoltaica, maior será a oscilação das tensões em todos os barramentos do sistema. Nesta ocasião, há atuação de relés sensíveis a variação da frequência que atuam no sentido de desligar equipamentos shunts da rede, possibilitando controle de tensão em valores permissíveis. Para o exemplo gráfico da tensão da SE Boa Vista, entre 4 e 7 segundos, há uma perda do controle da tensão em função do limite de absorção dos elementos armazenadores, como pode ser visto na Figura 5.13, sem prejuízos para a tensão em regime permanente. 


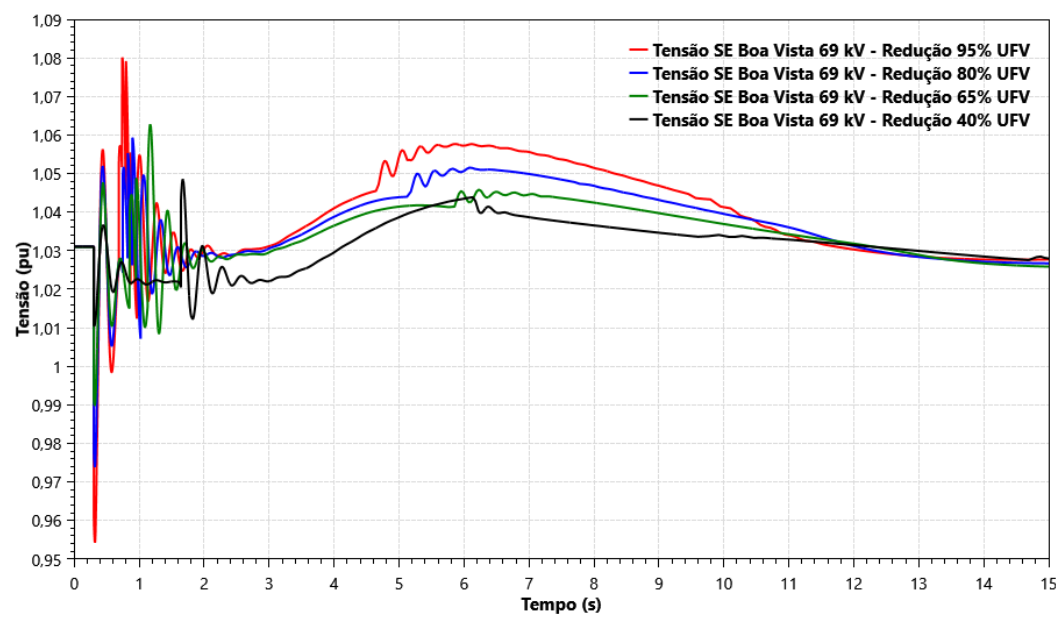

Figura 5.12 - Tensão no Barramento de 69 kV na Subestação Boa Vista para Reduções de Geração Fotovoltaicas Distintas Considerando um ESD de 10\% da Geração Total do Sistema e $60 \%$ de Penetração de Usinas Fotovoltaicas.

Outro fator importante para o controle de tensão é a capacidade das unidades síncronas, das unidades fotovoltaicas e dos ESD injetarem e absorverem potência reativa. O ESD contribui tanto para injetar potência reativa no início do período transitório, onde as unidades síncronas ainda estão respondendo com aumento da potência injetada, quanto para absorver potência reativa quando há excedente de potência reativa do sistema com carregamentos reduzidos, decorrente das atuações de ERAC, como pode ser visto em Figura 5.13. Também são consideradas sobrecargas para a injeção e absorção de potência reativa. Essas sobrecargas podem ser simultâneas com as sobrecargas de potência ativa em função da capacidade dos conversores usualmente suportarem até $100 \%$ de sobrecarga em poucos segundos. Neste caso, é prudente considerar $10 \%$ de sobrecarga para potência ativa e reativa. 


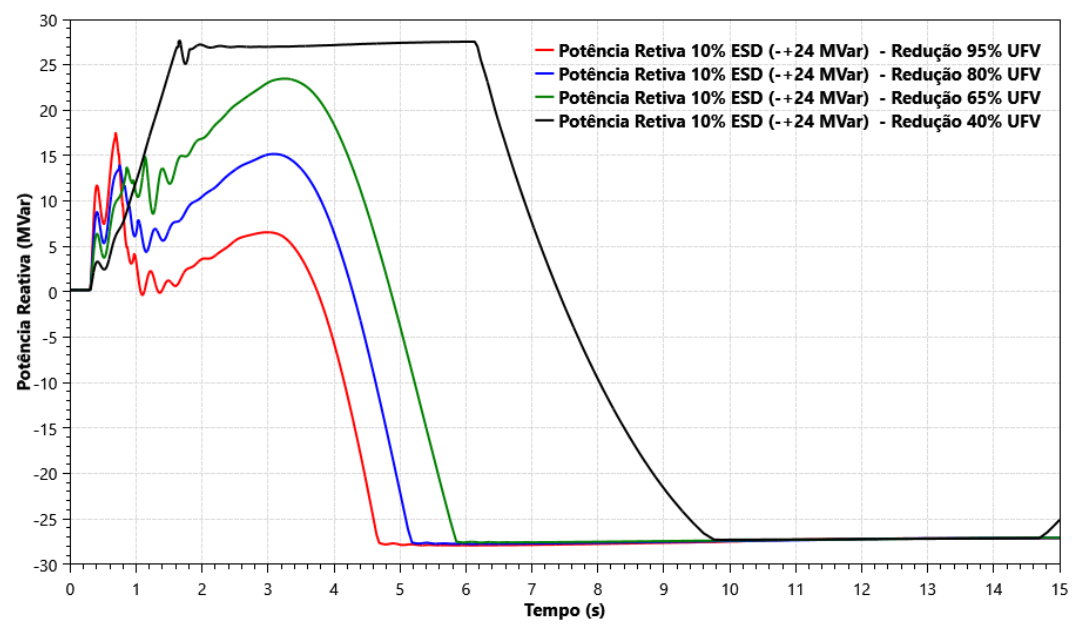

Figura 5.13 - Potência Reativa do ESD para Reduções de Geração Fotovoltaicas Distintas Considerando um ESD de 10\% da Geração Total do Sistema e 60\% de Penetração de Usinas Fotovoltaicas.

Pela metodologia, as contingências simuladas foram reduções abruptas da geração fotovoltaica, em degrau, conforme pode ser visto pela Figura 5.14. Para este caso, com $60 \%$ de penetração de usinas fotovoltaicas resultando em 147 MW de potência injetada, cada contingência reduz um percentual desse montante.

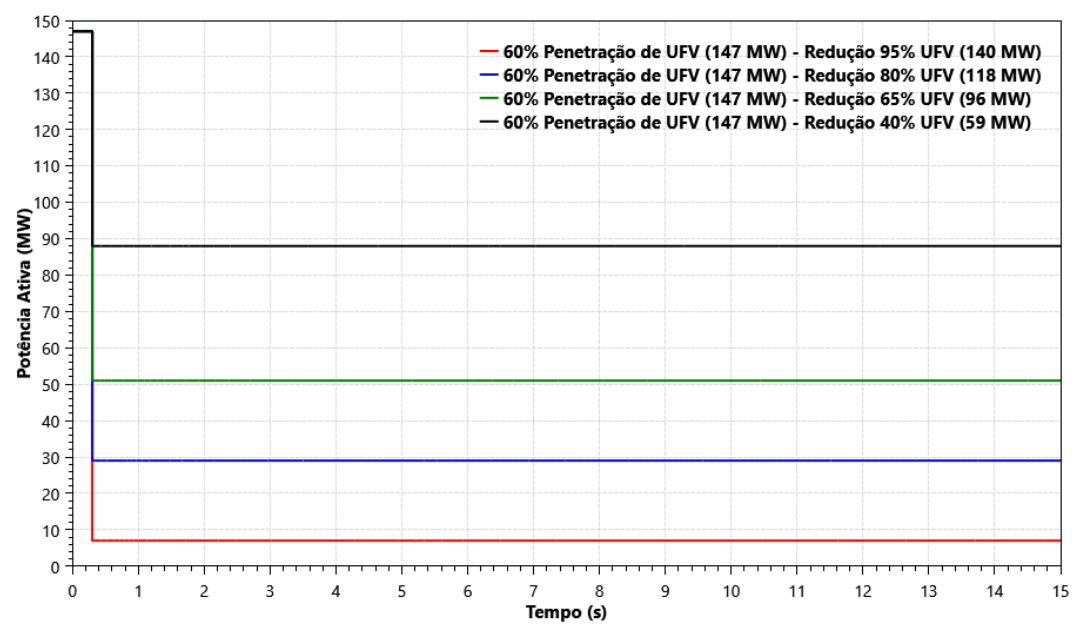

Figura 5.14 - Contingência Simulada para Reduções de Geração Fotovoltaicas Distintas Considerando um ESD de $10 \%$ da Geração Total do Sistema e $60 \%$ de Penetração de Usinas Fotovoltaicas. 
Como foi apresentada no Capítulo 3, uma variação na potência elétrica resulta em uma potência acelerante, aumentando a velocidade síncrona dos rotores das turbinas e, consequentemente, aumentando a potência mecânica das unidades geradoras. Utilizou-se somente a UTE Bonfim para representar graficamente este conceito como pode ser visto na Figura 5.15 e na Figura 5.16.

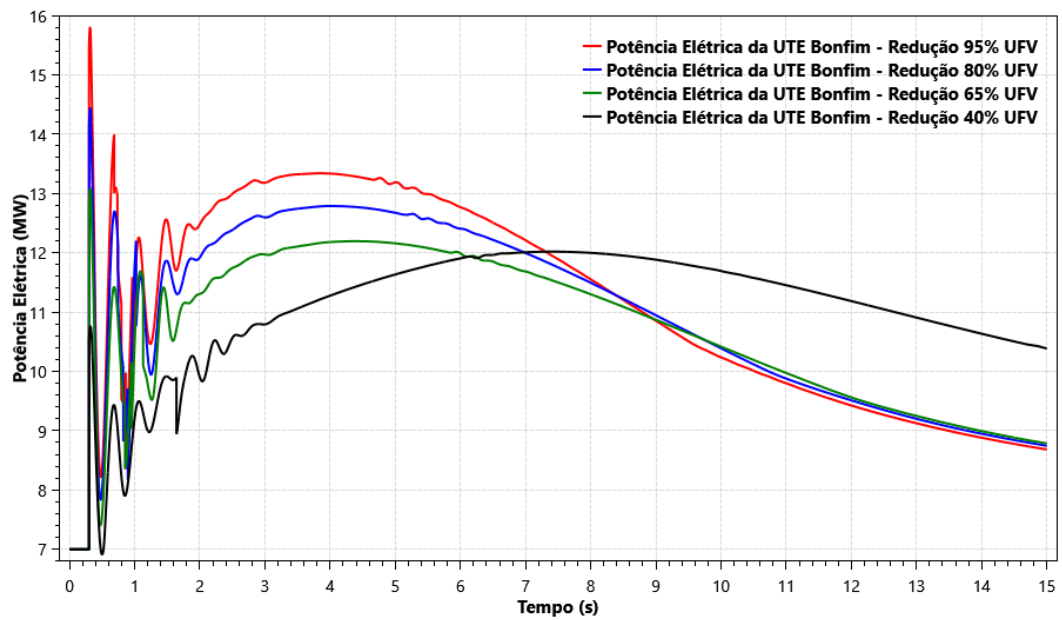

Figura 5.15 - Potência Elétrica da UTE Bonfim para Reduções de Geração Fotovoltaicas Distintas Considerando um ESD de 10\% da Geração Total do Sistema e 60\% de Penetração de Usinas Fotovoltaicas.

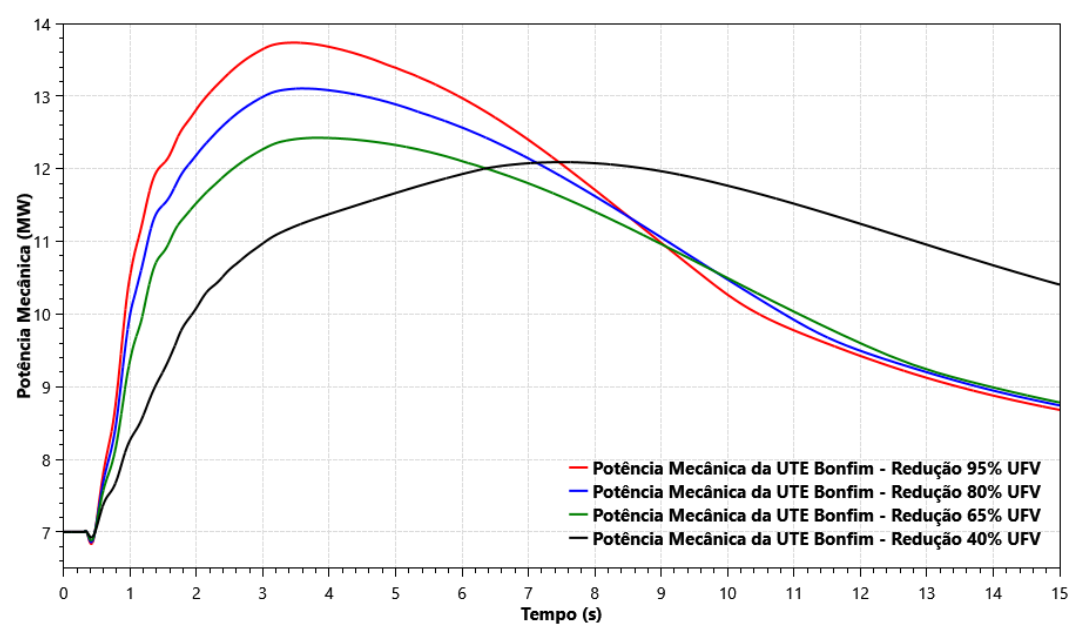

Figura 5.16 - Potência Mecânica da UTE Bonfim para Reduções de Geração Fotovoltaicas Distintas Considerando um ESD de $10 \%$ da Geração Total do Sistema e $60 \%$ de Penetração de Usinas Fotovoltaicas. 
Finalizando as análises das simulações dinâmicas considerando a hipótese de $10 \%$ de ESD e $60 \%$ de penetração de fotovoltaica, apresenta-se na Figura 5.17 a variação de frequência para todas as unidades geradoras sincronizadas na redução de $95 \%$ de geração fotovoltaica, a maior perturbação simulada.

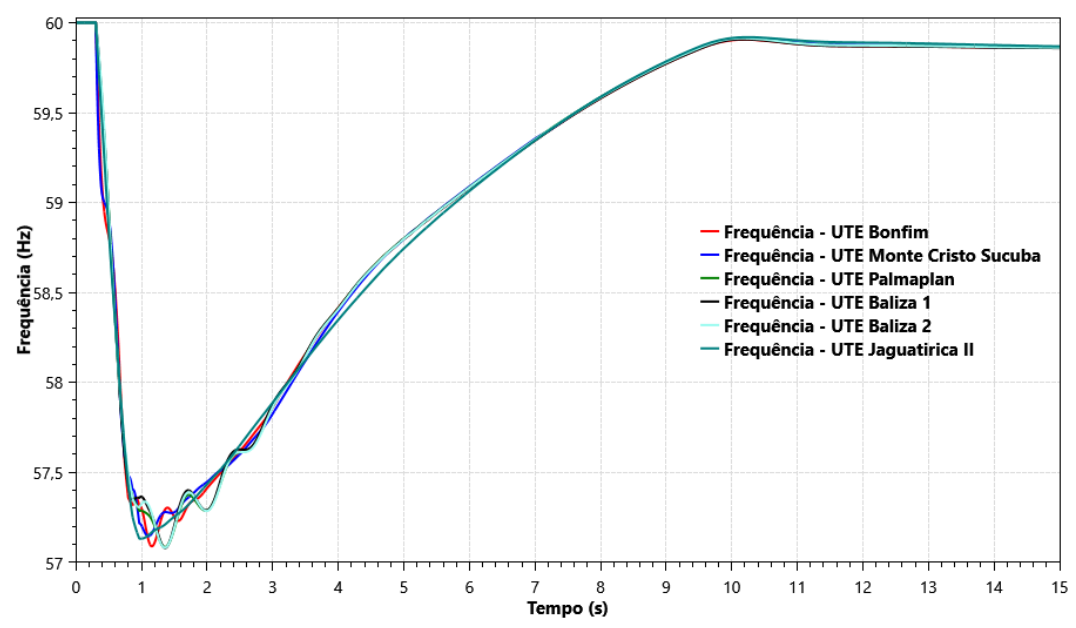

Figura 5.17 - Frequência de Todas as Unidades Geradoras do Sistema para 95\% de Redução de Geração Fotovoltaicas Considerando um ESD de 10\% da Geração Total do Sistema e $60 \%$ de Penetração de Usinas Fotovoltaicas.

Nota-se que não houve um descolamento dos desvios de frequência das máquinas sincronizadas, tendo as unidades geradoras localizadas no interior do estado apresentando comportamentos semelhantes. Cabe ressaltar que foram considerados estabilizadores (Power System Stabilizer - PSS) em todas as usinas térmicas da região para não haver perda de sincronismo entre as máquinas síncronas da capital e as máquinas síncronas do interior.

\subsubsection{2.}

\section{Simulações com 60\% de Penetração de Fotovoltaicas e 95\% de Redução de Geração Fotovoltaica}

Com objetivo de visualizar o ganho efetivo com o aumento da capacidade nominal do ESD para controle de frequência, é apresentada a Figura 5.18 que promove a comparação dos desvios de frequência para cada valor de ESD. Neste caso, foi considerada a penetração de $60 \%$ de usinas fotovoltaicas com a contingência de $95 \%$ de redução de geração. Como visto, quanto maior for a 
capacidade de injeção de potência ativa por parte do ESD menor será o desvio de frequência no período transitório do sistema isolado. Nessas condições, a contingência de redução de geração sem ESD levaria o sistema ao colapso e um montante de armazenamento de $5 \%$ da geração total não seria suficiente para restabelecer o sistema para uma condição aceitável, violando a frequência mínima de $57 \mathrm{~Hz}$, causando desligamentos em cascata e colapso.

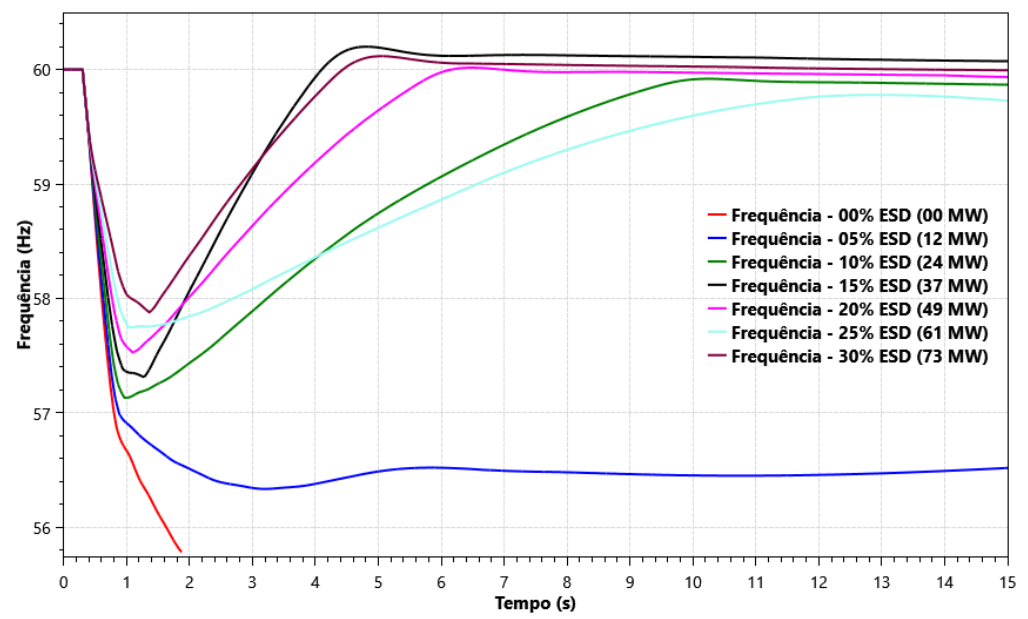

Figura 5.18 - Frequência do Sistema para Redução de 95\% de Geração Fotovoltaicas e 60\% de Penetração de Usinas Fotovoltaicas Considerando Valores Distintos de ESD.

Aproximando o gráfico para o momento da perturbação como na Figura 5.19 é possível concluir que a taxa de variação da frequência é inversamente proporcional à potência ativa injetada pelos ESD. Assim, um relé capaz de atuar no corte de carga por taxa de variação da frequência pode ser mais efetivo do que atuar somente por valores de frequência absoluta, ou seja, este relé acionaria os estágios de ERAC antes mesmo de se alcançar valores reduzidos de frequência absoluta. 


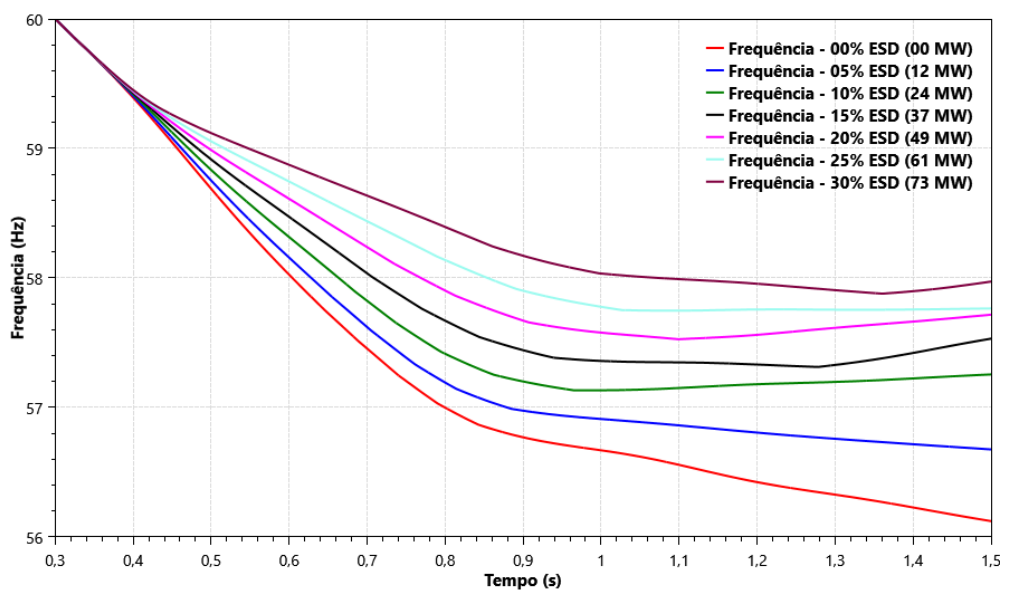

Figura 5.19 - Frequência do Sistema no Momento da Perturbação para Redução de $95 \%$ de Geração Fotovoltaicas e 60\% de Penetração de Usinas Fotovoltaicas Considerando Valores Distintos de ESD.

Para este mesmo caso é possível ver pela Figura 5.20 o comportamento semelhante do ESD com valores distintos, sempre no sentido de fornecer potência ativa para equilibrar o balanço carga e geração.

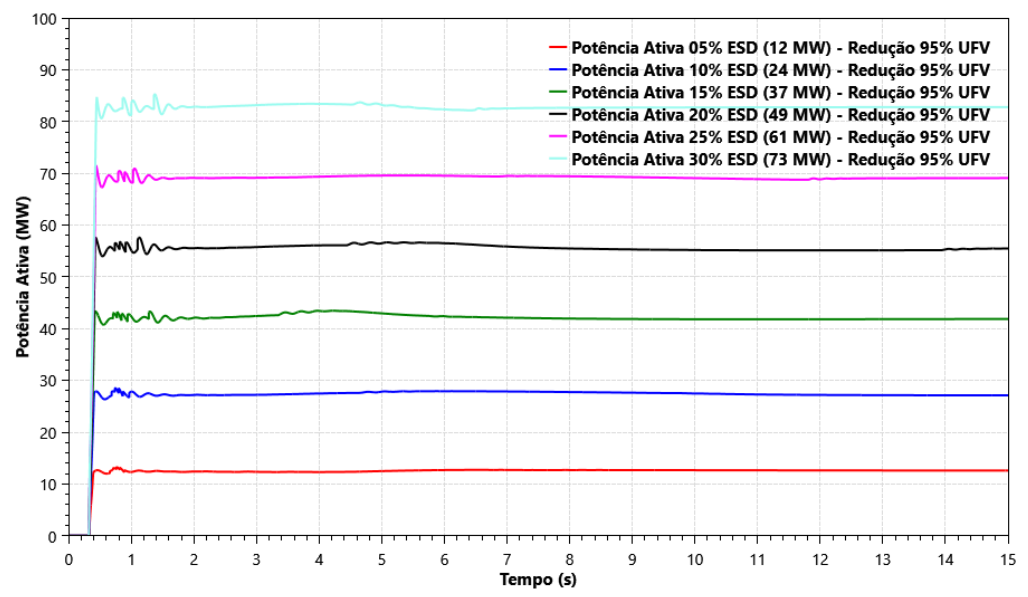

Figura 5.20 - Potência Ativa de ESD para Redução de 95\% de Geração Fotovoltaicas e 60\% de Penetração de Usinas Fotovoltaicas Considerando Valores Distintos de ESD.

Cabe ressaltar que nessas análises transitórias, presumiu-se que os controles dos elementos armazenadores de energia adotavam estratégias no sentido de sempre disponibilizar o montante máximo e mínimo, de potência ativa 
e de potência reativa, a ser utilizado em benefício do sistema. Assim, não foram consideradas as quantidades de carga armazenada nos dispositivos de armazenamento de energia.

\subsubsection{3.}

\section{Simulações com 10\% de ESD e 95\% de Redução de Geração}

\section{Fotovoltaica}

Para visualizar como se comporta o sistema com a variação da penetração de usinas fotovoltaicas considerando a capacidade nominal do ESD em $10 \%$ da geração total simulando a contingência de 95\% de redução de geração tem-se a Figura 5.21. Como visto, quanto maior for a penetração de usinas fotovoltaicas maior será o déficit de geração na redução de $95 \%$ da geração e consequentemente menor será a frequência após a perturbação. Com 10\% e com $20 \%$ de penetração de unidades fotovoltaicas não houve atuação de nenhum estágio de ERAC após a contingência.

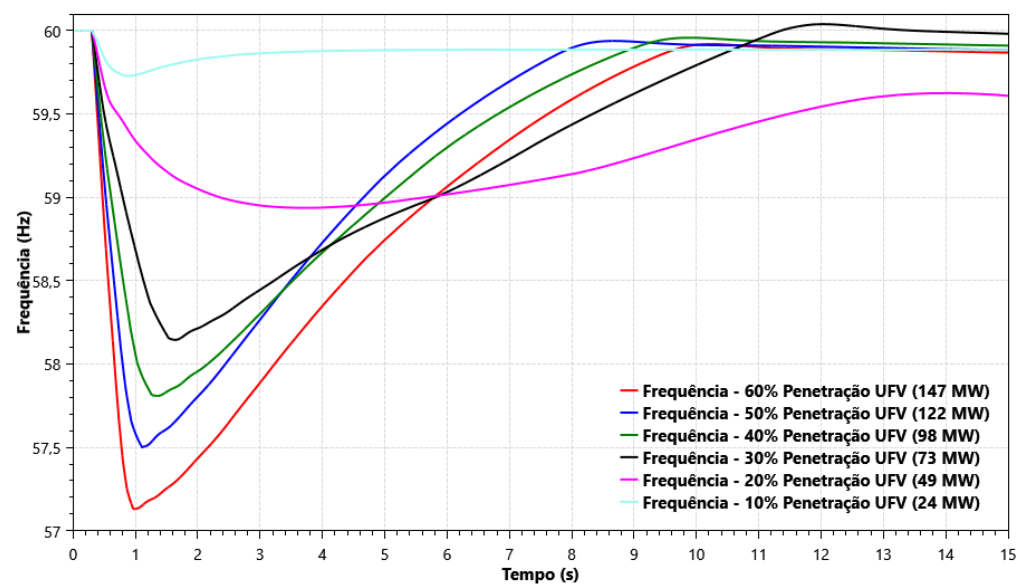

Figura 5.21 - Frequência do Sistema para Redução de 95\% de Geração Fotovoltaicas e 10\% de ESD Considerando Valores Distintos de Penetração de Usinas Fotovoltaicas.

Apresentando graficamente a consolidação feita pela Figura 5.5, temos a Figura 5.22 que dimensiona os estágios de ERAC na subestação Centro ocasionados pela redução de $95 \%$ da geração fotovoltaica do sistema em cada 
montante de penetração. Nota-se que com $10 \%$ e com $20 \%$ de penetração de unidades fotovoltaicas não houve atuação de nenhum estágio de ERAC tendo uma pequena oscilação do montante da potência consumida apenas pela modelagem da carga.

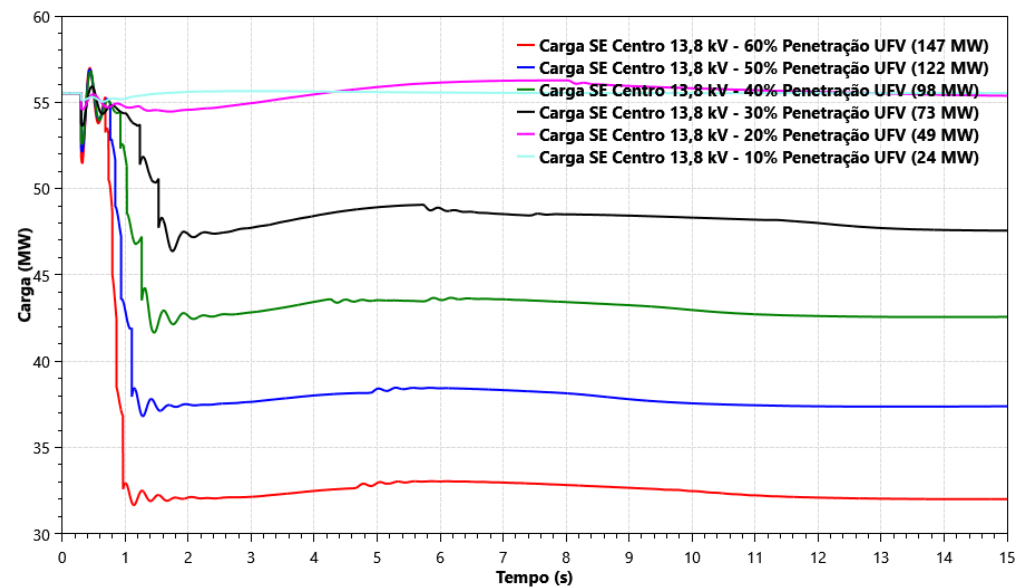

Figura 5.22 - Carga na Subestação Centro 13,8 kV para Redução de 95\% de Geração Fotovoltaicas e $10 \%$ de ESD Considerando Valores Distintos de Penetração de Usinas Fotovoltaicas.

Neste contexto, podemos avaliar a injeção de potência ativa pelo ESD para cada montante de penetração de usinas fotovoltaicas após a redução de $95 \%$ de geração. Visualizando a Figura 5.23 nota-se que a utilização de armazenamento é eficiente em todos os montantes de penetração de fotovoltaicas, ou seja, independente da quantidade de fontes renováveis, os ESD serão fundamentais para o controle de frequência local. Para o caso de $10 \%$ de penetração de usinas fotovoltaicas, a redução de $95 \%$ de geração tem como consequência uma excursão de frequência pequena sem atuação de ERAC, não sendo necessário utilizar toda a capacidade do ESD. 


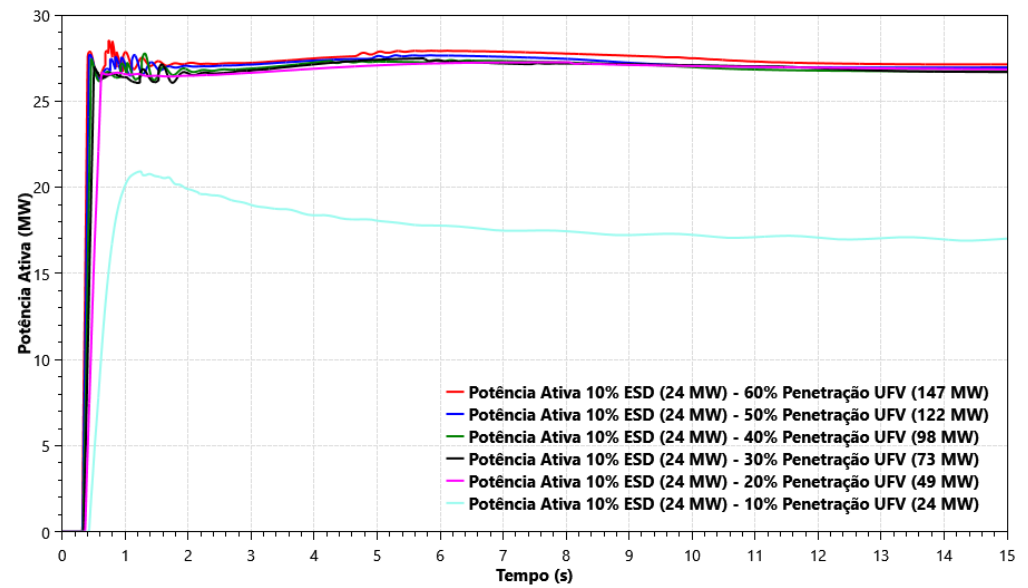

Figura 5.23 - Potência Ativa do ESD para Redução de 95\% de Geração Fotovoltaicas e 10\% de ESD Considerando Valores Distintos de Penetração de Usinas Fotovoltaicas.

\subsubsection{4.}

\section{Conclusões das Simulações Dinâmicas}

Como conclusão dessas simulações pode-se notar que o aumento da capacidade nominal dos ESD apresenta uma relação direta com a estabilidade de frequência do sistema isolado de Roraima e que sua utilização é eficiente para qualquer montante de penetração de usinas fotovoltaicas, reduzindo os desvios de frequência no período transitório após a perturbação fornecendo injeção de potência ativa.

Evidentemente, com o crescimento da proporção de geração de usinas fotovoltaicas, não se pode garantir apenas o corte parcial das cargas. Há risco de blecautes mesmo considerando a utilização de um montante de armazenamento pequeno. Percebe-se também que um menor valor da contingência de sombreamento dos painéis fotovoltaicos atenua o impacto da perturbação na frequência do sistema.

Notadamente, quanto maior for a redução de geração fotovoltaica, maior será a oscilação das tensões em todos os barramentos do sistema e menor será a frequência do sistema. Como consequência, deve haver maior disponibilidade de controle de potência reativa e mais estágios de ERAC serão necessários. 


\section{Conclusões}

O crescimento de geração de energia renovável ganha cada vez mais espaço no cenário mundial, com a substituição de geradores síncronos convencionais por fontes renováveis intermitentes menos custosas, aumentando a eficiência econômica na geração do sistema elétrico. Para os sistemas isolados, operar com baixa constante de inércia equivalente e alta penetração de fontes intermitentes são grandes desafios a serem contornados.

A produção crescente no segmento de armazenamento de energia vem promovendo a redução de seus custos, tornando-a competitiva para utilização nos sistemas elétricos de potência, que estão prestando cada vez mais serviços em diversas aplicações práticas.

Assim, soluções utilizando dispositivos de armazenamento de energia podem ser aplicadas no sentido de permitir aumento na participação de fontes renováveis de forma segura e robusta. Esses dispositivos podem ser fundamentais em sistemas isolados com grande penetração de fontes intermitentes, onde se pode controlar a tensão terminal e a frequência do sistema, utilizando os quatro quadrantes do plano $P Q$, permitindo assim uma operação mais segura e menos custosa com a produção de energia renovável.

Pelas análises dinâmicas realizadas foi possível constatar que a utilização de armazenamento de energia pode promover um aumento significativo na penetração de usinas renováveis intermitentes, como eólica e solar fotovoltaica, em sistemas de potência isolados. Desta forma, com o aumento da capacidade nominal dos ESD, apresenta-se uma relação direta com a estabilidade de frequência do sistema elétrico, sendo sua utilização eficiente para qualquer montante de penetração de usinas fotovoltaicas, reduzindo os desvios de frequência no período transitório com fornecimento de injeção de potência ativa.

$\mathrm{Na}$ metodologia utilizada nesta dissertação, a elaboração do Mapa de Decisão pode auxiliar no planejamento da expansão de parques geradores em sistemas isolados, quando se propõe saber qual seria o montante de penetração dessas novas fontes renováveis e qual seria o melhor dimensionamento de ESD que equilibrasse a relação custo-benefício e desempenho dinâmico. Nesta 
tomada de decisão, o órgão planejador permite ao operador realizar simulações dinâmicas para construção do Mapa de Decisão da operação, que irá auxiliar nos processos de programação da operação.

Utilizando o Mapa de Decisão, e com intuito de minimizar qualquer possibilidade de blecaute, a decisão de planejamento para o sistema Roraima simulado nesta dissertação foi por um dispositivo de armazenamento de energia correspondente a $10 \%$ da geração total do sistema, ou seja de $24 \mathrm{MW}$ de potência instalada, que permitiria uma penetração de até $60 \%$ de usinas fotovoltaicas neste sistema isolado, a saber $147 \mathrm{MW}$.

De posse desta escolha, obteve-se o Mapa de Decisão para ser utilizado no processo de programação e operação, onde para qualquer valor de penetração de usinas fotovoltaicas até $60 \%$ da geração total, não se teria colapso de frequência no sistema isolado de Roraima.

Como empreendimento vencedor no Leilão de Geração ํo 01/2019, o conjunto Híbrido Forte de São Joaquim apresentou no cadastramento da geração um conjunto de baterias com $10 \mathrm{MW}$ de potência instalada e $11 \mathrm{MWh}$ de energia onde será avaliado o impacto que a utilização desses armazenadores pode causar no sistema isolado de Roraima. Cabe ressaltar que existem aspectos regulatórios que devem ser discutidos para que haja disponibilidade de utilização desses dispositivos de armazenamento de energia pelo operador do sistema elétrico.

Portanto, como visto nesta dissertação, qualquer montante de armazenamento de energia pode ser eficiente no controle de frequência de um sistema isolado, atenuando os cortes parciais de carga em perturbações causadas por redução de geração. Sendo assim, promovem aumento na penetração de fontes renováveis garantindo a segurança o sistema.

\section{1}

\section{Trabalhos Futuros}

Análises adicionais podem ser desenvolvidas no sentido de incrementar a eficiência na decisão de planejamento, quando se considera otimização energética, garantindo o dimensionamento de armazenamento de energia que entrega o melhor equilíbrio entre a relação custo-benefício e o desempenho dinâmico. Assim, outros patamares de carga seriam avaliados reduzindo a possibilidade de operar com uma capacidade de armazenamento ociosa. 
Outros patamares de carga também podem ser utilizados na composição do Mapa de Decisão para programação e operação em tempo real, quando diversos cenários são estudados além das premissas conservativas no âmbito do planejamento. Pode-se assim construir áreas de segurança (Dynamic Security Assessment - DSA) através do programa Organon para acompanhamento em tempo real.

Outra proposição promissora seria considerar uma análise probabilística das contingências de perda de geração simuladas e quanto o posicionamento geográfico dos painéis fotovoltaicos dentro de um sistema elétrico pode atenuar as contingências de sombreamento simultâneo dos painéis fotovoltaicos ou as alterações abruptas nos ventos na geração eólica. Desta forma, como as contingências mais severas seriam reduzidas, um mesmo montante de armazenamento de energia aumentaria o potencial de penetração de energia renovável nos sistemas elétricos, mantendo a segurança dinâmica. 


\section{Referências bibliográficas}

[1] DELILLE, G.; FRANCOIS, B.; MALARANGE, G. Dynamic frequency control support by energy storage to reduce the impact of wind and solar generation on isolated power system's inertia. IEEE Trans. on Sustainable Energy, v. 3, n. 4, p. 931-939, 2012.

[2] BLOOMBERG NEF. Energy Storage Investments Boom As Battery Costs Halve in the Next Decade, 31 julho 2019. Disponível em: $<$ https://about.bnef.com/blog/energy-storage-investments-boom-batterycosts-halve-next-decade/>. Acesso em: 15 dezembro 2019.

[3] WANG, L. et al. Real-time coordinated voltage control of PV inverters and energy storage for weak networks with high PV penetration. IEEE Trans. on Power Systems, v. 33, n. 3, p. 3383-3395, 2018.

[4] DHINGRA, K.; SINGH, M. Frequency support in a micro-grid using virtual synchronous generator based charging station. IET Renewable Power Generation, v. 12, n. 9, p. 1034-1044, 2018.

[5] VASCONCELOS, $\mathrm{H}$. et al. Advanced control solutions for operating isolated power systems: examining the Portuguese islands. IEEE Electrification Magazine, v. 3, n. 1, p. 25-35, 2015.

SEPULVEDA RANGEL, C. A. et al. Methodology for ESS-type selection and optimal energy management in distribution system with DG considering reverse flow limitations and cost penalties. IET Generation, Transmission \& Distribution, v. 12, n. 5, p. 1164-1170, 2018.

[7] Al, X. et al. Multi-time-scale coordinated ramp-rate control for photovoltaic plants and battery energy storage. IET Renewable Power Generation, v. 2, n. 12, p. 1390-1397, 2018.

[8] SHI, Y. et al. Using battery storage for peak shaving and frequency regulation: joint optimization for superlinear gains. IEEE Trans. on Power Systems, v. 33, n. 3, p. 2882-2894, 2018. 
[9] OUDALOV, A.; CHARTOUNI, D.; OHLER, C. Optimizing a battery energy storage system for primary frequency control. IEEE Trans. on Power Systems, v. 22, n. 3, p. 1259-1266, 2007.

[10] MERCIER, P.; CHERKAOUI, R.; OUDALOV, A. Optimizing a battery energy storage system for frequency control application in an isolated power system. IEEE Trans. on Power Systems, v. 24, n. 3, p. 1469-1477, 2009.

[11] TAN, Y. et al. Enhanced frequency regulation using multilevel energy storage in remote area power supply systems. IEEE Trans. on Power Systems, v. 34, n. 1, p. 163-170, 2019.

[12] BHUIYAN, F. A.; YAZDANI, A. Energy storage technologies for grid-connected and off-grid power system applications. IEEE Electrical Power and Energy Conference. London, 2012.

[13] INTERNATIONAL ELECTROTECHNICAL COMMISSION (IEC). Electrical Energy Storage, 2011. Disponível em: <www.iec.ch/whitepaper/energystorage/>. Acesso em: 29 maio 2018.

[14] EPE. EPE-DEE-NT-098/2019-rO - Sistemas de Armazenamento em Baterias - Aplicações e Questões Relevantes para o Planejamento. Disponível em: <http://www.epe.gov.br/sites-pt/publicacoes-dadosabertos/publicacoes/PublicacoesArquivos/publicacao-441/EPE-DEE-NT098_2019_Baterias\%20no\%20planejamento.pdf>. Acesso em: 3 dezembro 2019.

[15] CRUZ, M. A. R. S. et al. Feasibility analysis of a wind pumped hydroelectric storage system on the Island of Brava. 9th International Renewable Energy Congress (IREC). Hammamet. 2018.

[16] KUNDUR, P. Power System Control and Stability. McGraw-Hill Inc., 1994.

[17] VIEIRA FILHO, X. Operação de Sistemas de Potência com Controle Automático de Geração. Editora Campus: Eletrobrás, 1984.

[18] ORTEGA, Á.; MILANO, F. Generalized model of VSC-based energy storage systems for transient stability analysis. IEEE Trans. Power Syst, v. 31, n. 5, p. 3369-3380, 2016.

[19] WU, J. et al. Feasibility Study of Segmenting Large Power System Interconnections With AC Link Using Energy Storage Technology. IEEE Transactions on Power Systems, v. 27, n. 3, p. 1245-1252, 2012.

[20] LOPES, J. P.; MOREIRA, C.; MADUREIRA, A. Defining control 
strategies for MicroGrids islanded operation. IEEE Transactions on Power Systems, v. 21, n. 2, p. 916-924, 2006.

[21] ONS. Base de Dados de Transitórios Eletromecânicos. Disponível em: $\quad$ <https://sintegre.ons.org.br/sites/8/93/Produtos/211/BD0319R2.zip>. Acesso em: 9 março 2019.

[22] MME. Portaria MME no 134/2019. Disponível em: $<$ http://www.in.gov.br/materia//asset_publisher/Kujrw0TZC2Mb/content/id/63364038/>. Acesso em: 14 fevereiro 2019

[23] MME. Portaria MME no 512/2018. Disponível em: < http://www.in.gov.br/materia//asset_publisher/Kujrw0TZC2Mb/content/id/56644411/>. Acesso em: 24 dezembro 2018.

[24] EPE/ONS. EPE-DEE-NT073/2017-rev2 / ONS NT 0143/2017 Definição das Características Elétricas para o Leilão de Suprimento a Roraima. Disponível em: < http://www.epe.gov.br/sites-pt/publicacoesdados-abertos/publicacoes/PublicacoesArquivos/publicacao340/Minuta\%20NT\%20Margens\%20para\%20RORAIMArev2_Sem\%20Assinatura.pdf>. Acesso em: 20 janeiro 2019.

[25] EPE. Resultado do Leilão para suprimento a Boa Vista e localidades conectadas. Disponível em: <http://www.epe.gov.br/pt/imprensa/noticias/resultado-do-leilao-de-roraima>. Acesso em: 31 maio 2019.

[26] ONS. Submódulo 3.6 - Requisitos técnicos mínimos para a conexão às instalações de transmissão. Disponível em: < http://www.ons.org.br/paginas/sobre-o-ons/procedimentos-derede/vigentes>. Acesso em: 20 agosto 2019.

[27] LAPPALAINEN, K.; VALKEALAHTI, S. Analysis of shading periods caused by moving clouds. Solar Energy, v. 135, p. 188-196, 2016.

[28] LAPPALAINEN, K.; VALKEALAHTI, S. Recognition and modelling of irradiance transitions caused by moving clouds. Solar Energy, v. 112, p. 5567, 2015. 
A

\section{Apêndice - Movimento Rotacional}

Neste apêndice apresentam-se as grandezas associadas ao movimento circular uniforme ou movimento rotacional, advindo da mecânica clássica.

Ângulo em radianos $(\mathrm{rad})$ :

Momento de Inércia em $\mathrm{kg} \cdot \mathrm{m}^{2}$ :

$$
J=\int r^{2} d m
$$

Velocidade Angular em $\mathrm{rad} / \mathrm{s}$ :

$$
\omega=\frac{d \theta}{d t}
$$

Aceleração Angular em $\mathrm{rad} / \mathrm{s}^{2}$ :

$$
\alpha=\frac{d \omega}{d t}
$$

Torque em N.m ou $J /$ rad:

$$
T=J \alpha
$$

Trabalho em J ou W.s:

$$
W=\int T d \theta
$$

Potência em $W$ :

$$
P=\frac{d W}{d t}=T \omega
$$


B

\section{Apêndice - Parâmetros do Caso de Referência}

Neste apêndice apresenta-se parâmetros do caso de referência elaborado no Anarede que serviu como base para elaboração de todos os outros casos de simulação dinâmica no Organon.

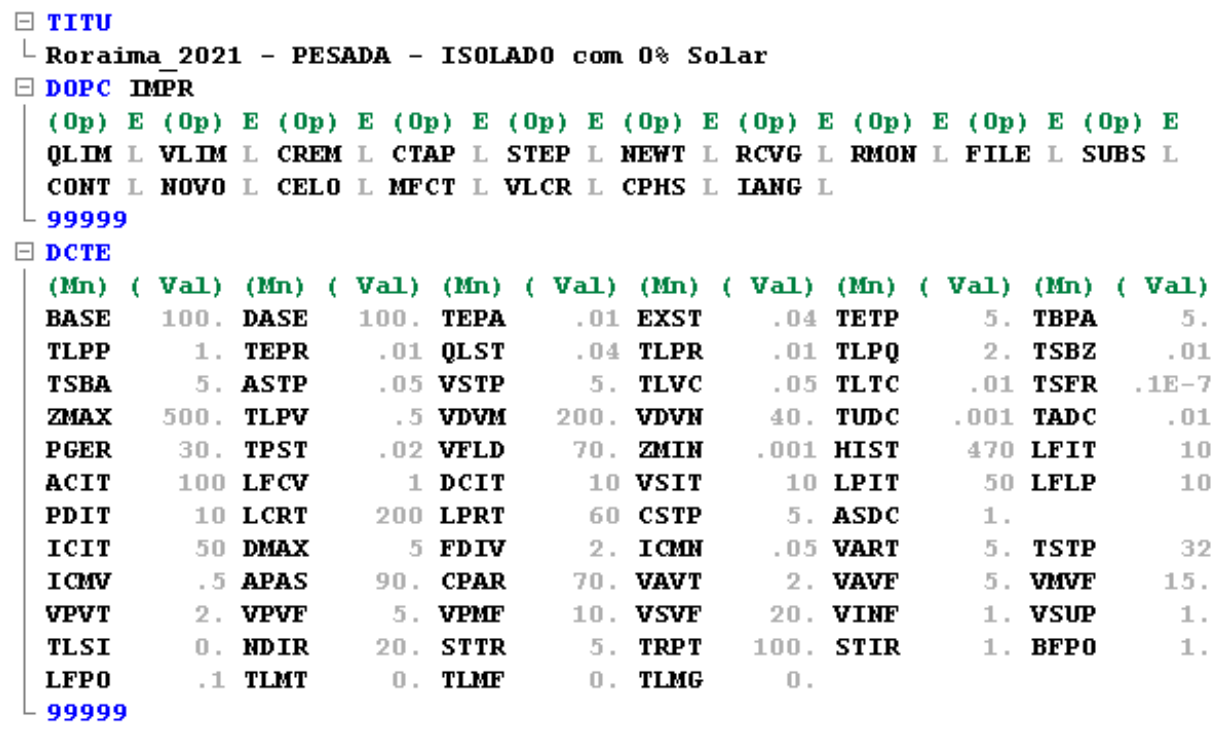

Figura B.1 - Parâmetros de Inicialização e Definição de Constantes do Caso de Referência. 


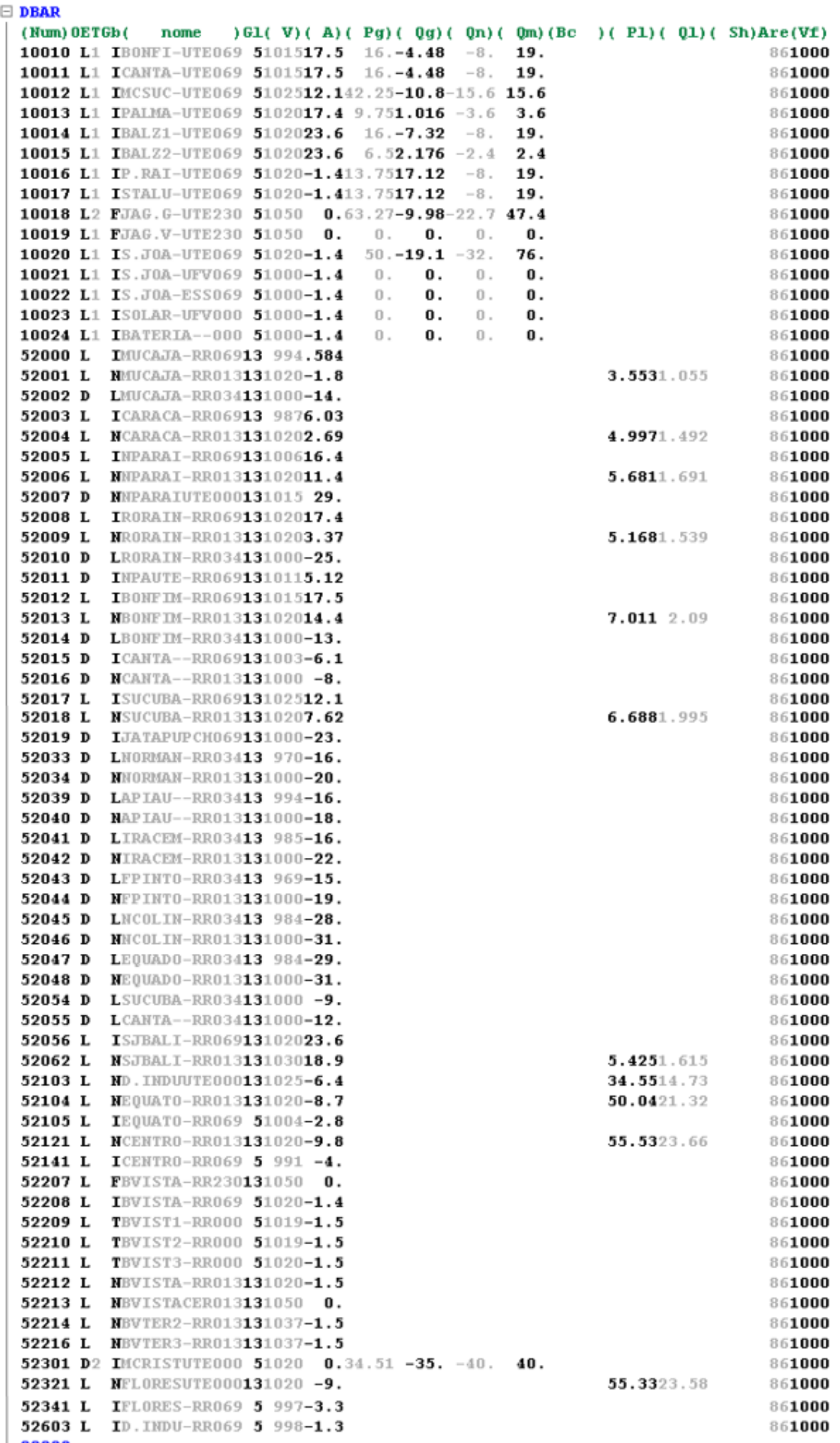

Figura B.2 - Parâmetros de Barramentos do Caso de Referência. 


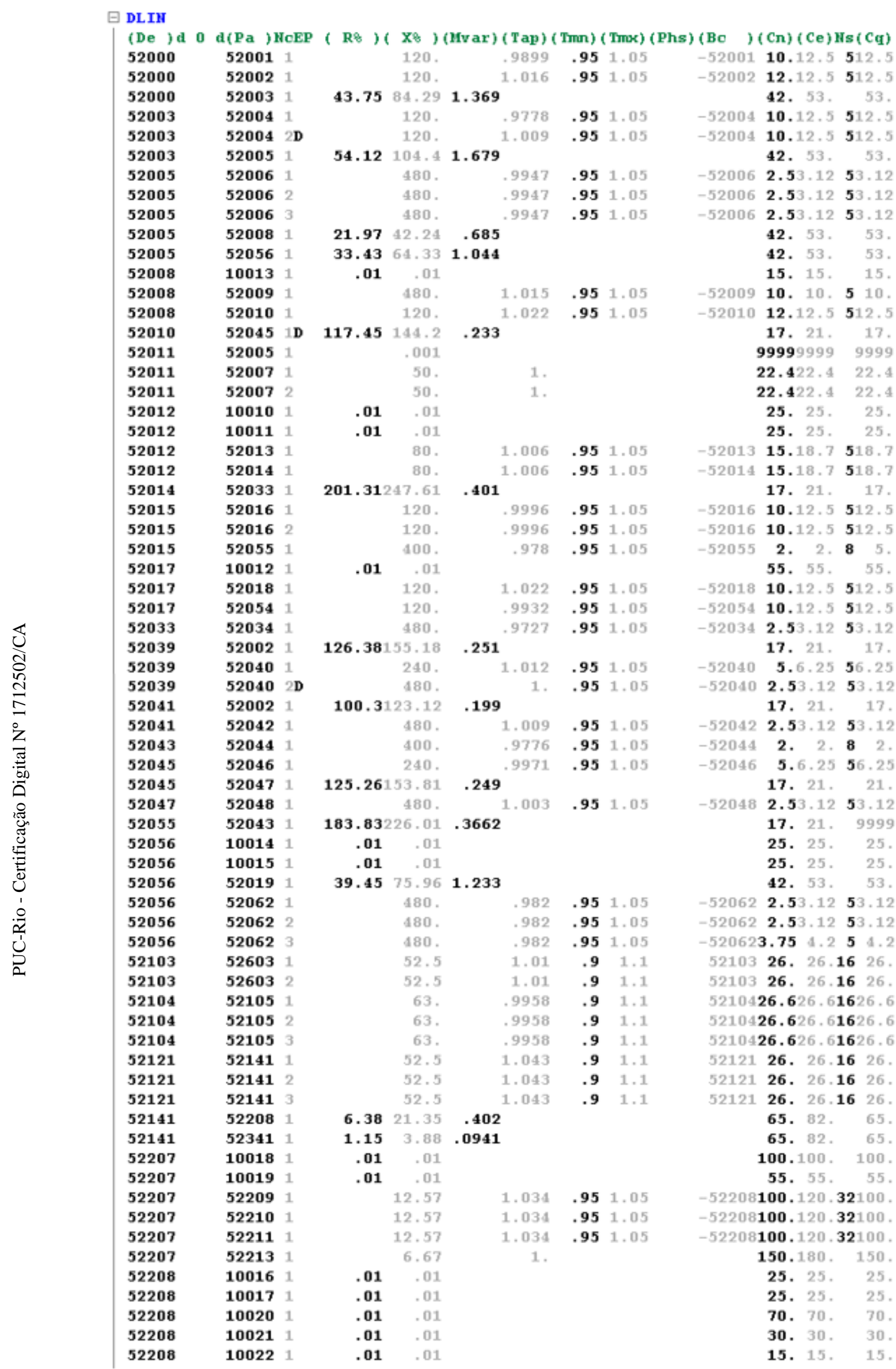




\begin{tabular}{|c|c|c|c|c|c|c|c|c|}
\hline 52208 & 10023 & 1 & .01 & 01 & & & & \\
\hline 52208 & 10024 & 1 & .01 & .01 & & & & \\
\hline 52208 & 52105 & 1 & 2.68 & 16.48 & .33 & & & \\
\hline 52208 & 52301 & 1 & .01 & .01 & & & & \\
\hline 52209 & 52208 & 1 & & -.34 & & 1. & & \\
\hline 52209 & 52214 & 1 & & 9.175 & & 1. & & \\
\hline 52210 & 52208 & 1 & & -.34 & & 1. & & \\
\hline 52210 & 52216 & 1 & & 9.175 & & 1. & & \\
\hline 52211 & 52208 & 1 & & -.34 & & 1. & & \\
\hline 52211 & 52212 & 1 & & -9.175 & & 1. & & \\
\hline 52321 & 52341 & 1 & & 52.5 & & 1.03 & .9 & 1.1 \\
\hline 52321 & 52341 & 2 & & 52.5 & & 1.03 & .9 & 1.1 \\
\hline 52321 & 52341 & 3 & & 52.5 & & 1.03 & .9 & 1.1 \\
\hline 52341 & 52208 & 1 & 4. 71 & 15.77 & .3219 & & & \\
\hline 52341 & 52208 & 2 & 2.4 & 14.71 & .29 & & & \\
\hline 52603 & 52000 & 1 & 27.18 & 52.29 & .848 & & & \\
\hline 52603 & 52012 & 1 & 59.511 & 114.89 & 1.869 & & & \\
\hline 52603 & 52015 & 1 & 21.18 & 40.73 & .66 & & & \\
\hline 52603 & 52017 & 1 & 30.65 & 58.96 & .956 & & & \\
\hline 52603 & 52105 & 1 & 1.19 & 7.32 & .14 & & & \\
\hline 52603 & 52208 & 1 & 4. 23 & .26 & .505 & & & \\
\hline 52603 & 52341 & 1 & 1.67 & 8.64 & .1687 & & & \\
\hline 99999 & & & & & & & & \\
\hline
\end{tabular}

120.120. 120 .

120.120. 120 .

99.125.99.

200.200. 200.

100.120. 100.

33. 40.33 .

100.120. 100.

33. 40.33 .

100.120. 100.

33. 40,33 .

$52321 \mathbf{2 6 . 6 2 6 . 6 1 6 2 6 . 6}$

$52321 \mathbf{2 6 . 6 2 6 , 6 1 6 2 6 . 6}$

$52321 \mathbf{2 6} . \mathbf{6} 26.6 \mathbf{1 6 2} 2.6$

65. 82, 65 .

99.125. 125 .

42. 53. 53.

42. 53. 53.

42. 53. 53 .

42. 53.53.

99.125. 99.

98.123, 123.

90.113. 113.

Figura B.3 - Parâmetros de Circuitos e Transformadores do Caso de Referência.

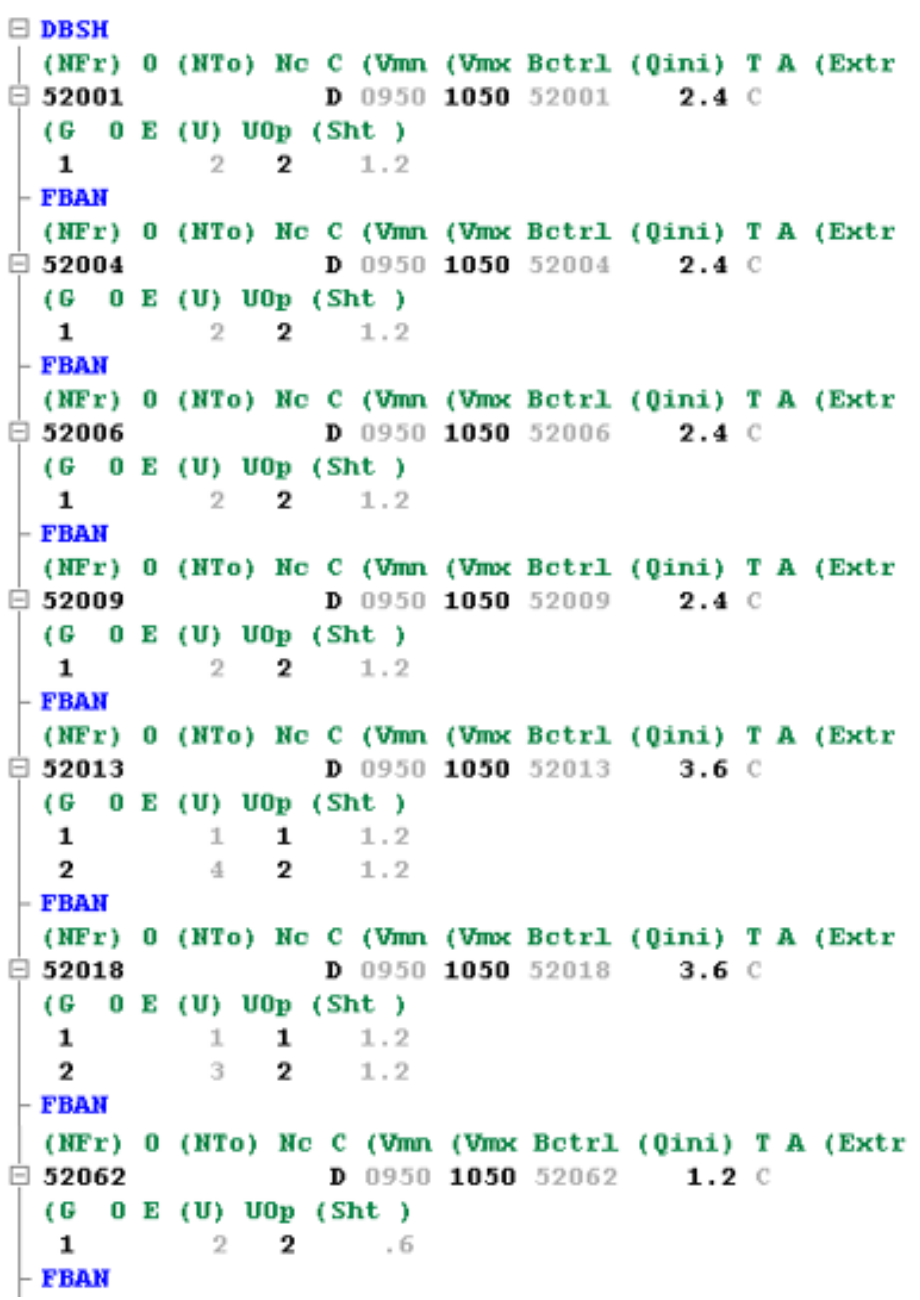




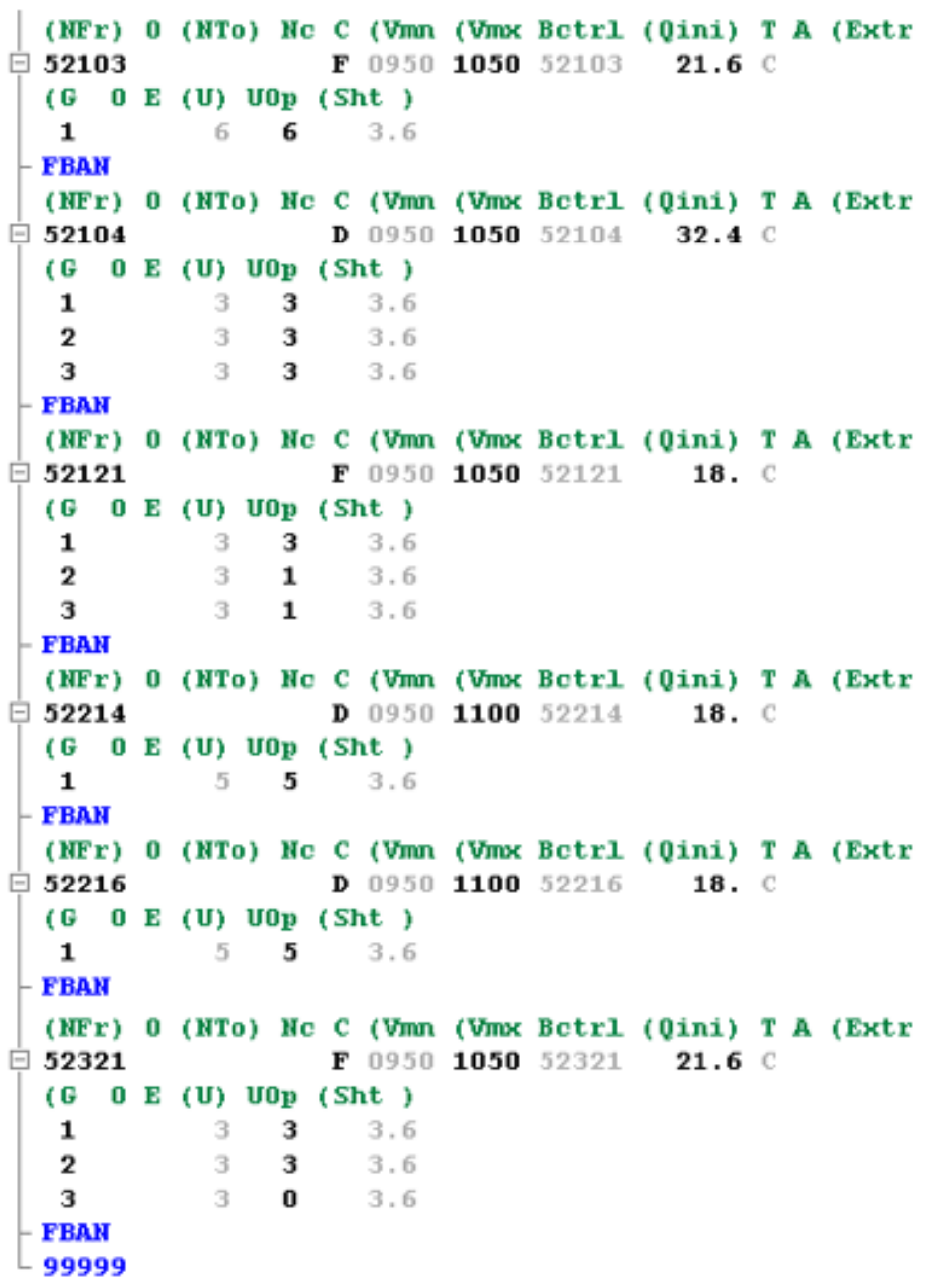

Figura B.4 - Parâmetros de Elementos Shunts de Barra do Caso de Referência. 


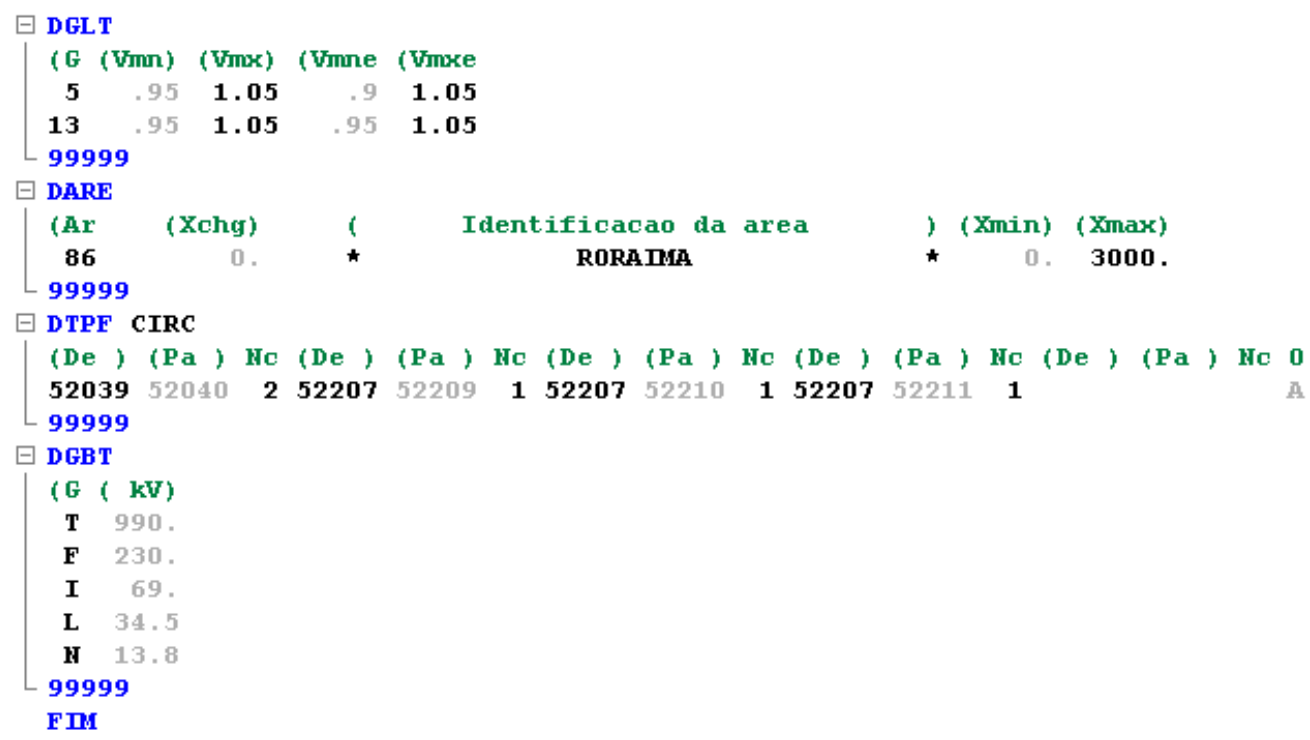

Figura B.5 - Parâmetros de Grupo Base e Grupo Limite de Barra, Definição de Área e Transformadores com o Tap Congelado no Caso de Referência. 
C

\section{Apêndice - Modelos do Sistema Roraima}

Neste apêndice apresenta-se os modelos e parâmetros de máquina síncrona, reguladores de velocidade e de tensão, além do modelo do estabilizador PSS e da modelagem de carga utilizadas em todos os casos simulados no Organon.

1. Modelo de máquina síncrona

a) Máquina síncrona com polos salientes - SM04
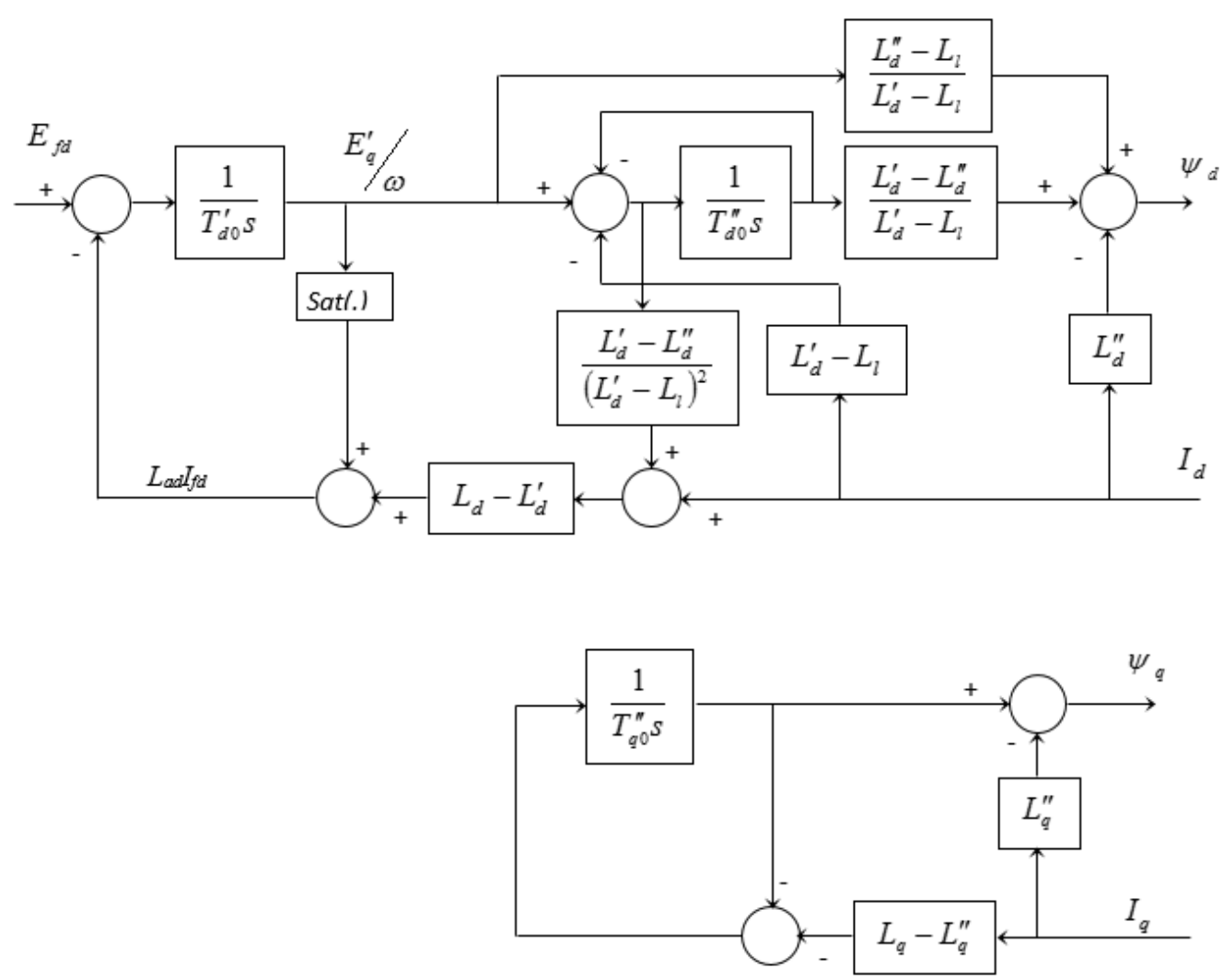

Figura C.1 - Diagrama de blocos do modelo de máquina síncrona com polos salientes SM04. 
O modelo de máquina síncrona com polos salientes SM04 da Figura C.1 foi utilizado na UTE Monte Cristo Sucuba, na UTE Palmaplan e na UTE Baliza 2 com os parâmetros da Tabela C.1.

Tabela C.1 - Parâmetros do modelo SM04 (UTE Monte Cristo Sucuba, UTE Palmaplan e UTE Baliza 2)

\begin{tabular}{|c|c|c|c|}
\hline Parâmetro & Descrição & Unidade & $\begin{array}{c}\text { Valor } \\
\text { Implementado }\end{array}$ \\
\hline$X_{d}$ & D axis reactance & pu & 2.072 \\
\hline$X_{d}^{\prime}$ & D axis transient reactance & pu & 0.300 \\
\hline$X_{d}^{\prime \prime}$ & D axis sub-transient reactance & pu & 0.220 \\
\hline$X_{q}$ & $\mathrm{Q}$ axis reactance & pu & 0.800 \\
\hline$X_{q}^{\prime}$ & $\mathrm{Q}$ axis transient reactance & pu & 0.000 \\
\hline$X_{q}^{\prime \prime}$ & $\mathrm{Q}$ axis sub-transient reactance & pu & 0.220 \\
\hline$R_{a}$ & Stator resistance $(\mathrm{pu})$ & pu & 0.00 \\
\hline Base & MVA base & MVA & 4.062 \\
\hline$X_{l}$ & Leakage reactance & $\mathrm{s}$ & 0.100 \\
\hline$X_{t}$ & Step-up transformer reactance & s & 0.00 \\
\hline$T_{d}^{\prime}$ & D axis transient time constant & $\mathrm{s}$ & 3.60 \\
\hline$T_{d}^{\prime \prime}$ & D axis sub-transient time constant & s & 0.030 \\
\hline$T_{q}^{\prime}$ & $\mathrm{Q}$ axis transient time constant & s & 0.000 \\
\hline $\mathrm{H}$ & Inertia constant & MW/MVA*s & 0.5 \\
\hline $\mathrm{D}$ & Damping & pu/pu & 0.05 \\
\hline$T_{q}^{\prime \prime}$ & Q axis sub-transient time constant & $\mathrm{s}$ & 1.250 \\
\hline$A_{g}$ & Saturation proportional coefficient & -- & 0.02988 \\
\hline$B_{g}$ & Saturation proportional coefficient & -- & 6.66282 \\
\hline
\end{tabular}


b) Máquina síncrona com polos lisos - SM05

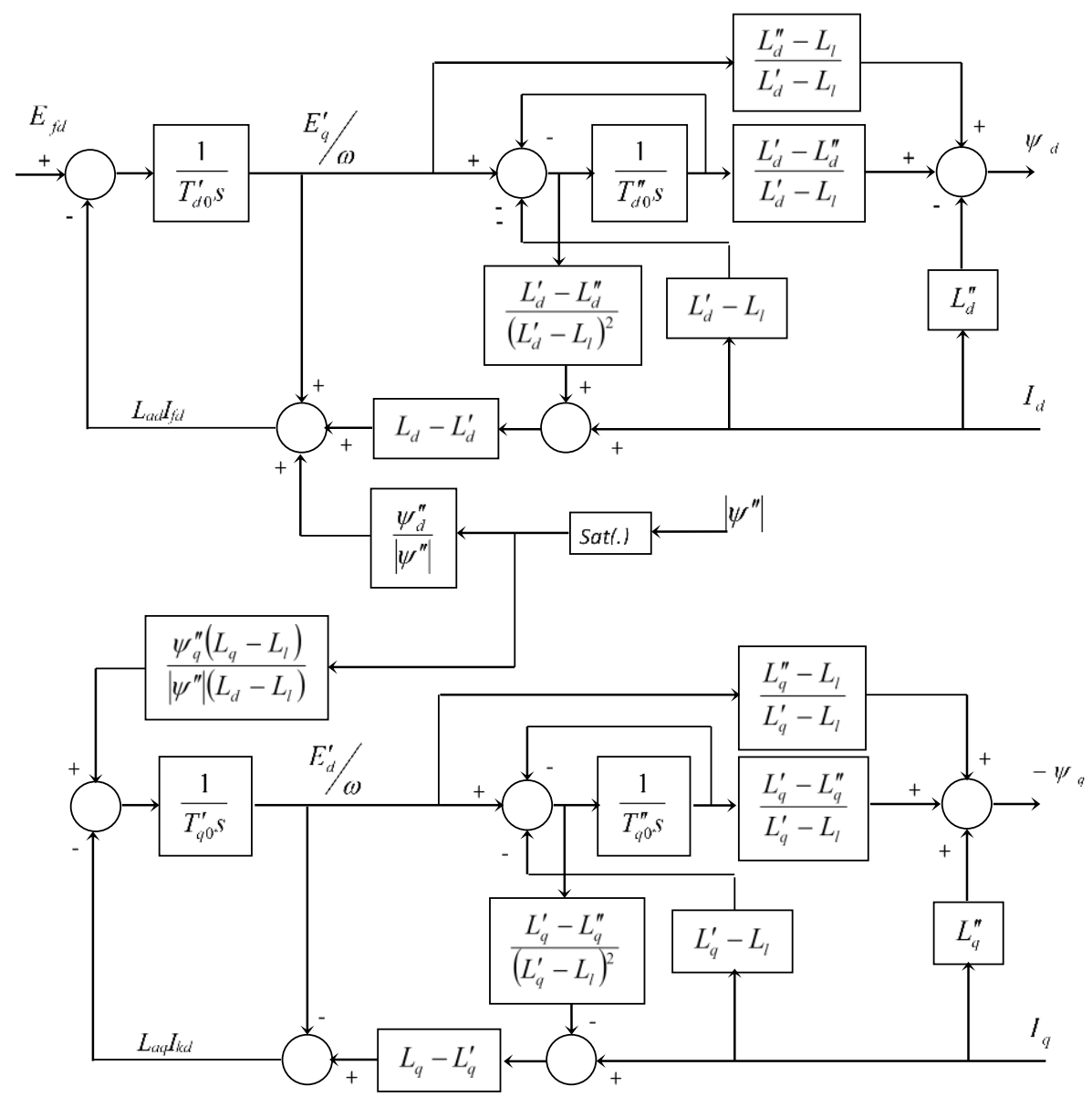

Figura C.2 - Diagrama de blocos do modelo de máquina síncrona com polos lisos - SD05.

O modelo de máquina síncrona com polos lisos SM05 da Figura C.2 foi utilizado na UTE Bonfim, na UTE Cantá, na UTE Baliza 1, na UTE Pau Rainha, na UTE Santa Luz e na UTE Forte de São Joaquim com os parâmetros da Tabela C.2. 
Tabela C.2 - Parâmetros do modelo SM05 (UTE Bonfim, UTE Cantá, UTE Baliza 1, UTE Pau Rainha, UTE Santa Luz e UTE Forte de São Joaquim)

\begin{tabular}{|c|c|c|c|}
\hline Parâmetro & Descrição & Unidade & $\begin{array}{c}\text { Valor } \\
\text { Implementado } \\
\end{array}$ \\
\hline$X_{d}$ & $\mathrm{D}$ axis reactance & pu & 1.463 \\
\hline$X_{d}^{\prime}$ & $\mathrm{D}$ axis transient reactance & pu & 0.370 \\
\hline$X_{d}^{\prime \prime}$ & D axis sub-transient reactance & pu & 0.260 \\
\hline$X_{q}$ & $Q$ axis reactance & pu & 0.804 \\
\hline$X_{q}^{\prime}$ & $\mathrm{Q}$ axis transient reactance & pu & 0.700 \\
\hline$X_{q}^{\prime \prime}$ & $\mathrm{Q}$ axis sub-transient reactance & pu & 0.260 \\
\hline$R_{a}$ & Stator resistance $(\mathrm{pu})$ & pu & 0.000 \\
\hline Base & MVA base & MVA & 17.80 \\
\hline$X_{l}$ & Leakage reactance & $\mathrm{s}$ & 0.100 \\
\hline$X_{t}$ & Step-up transformer reactance & s & 0.000 \\
\hline$T_{d}^{\prime}$ & D axis transient time constant & s & 6.535 \\
\hline$T_{d}^{\prime \prime}$ & D axis sub-transient time constant & $\mathrm{s}$ & 0.0430 \\
\hline$T_{q}^{\prime}$ & Q axis transient time constant & $\mathrm{s}$ & 2.000 \\
\hline $\mathrm{H}$ & Inertia constant & MW/MVA*s & 1.250 \\
\hline $\mathrm{D}$ & Damping & pu/pu & 0.00 \\
\hline$T_{q}^{\prime \prime}$ & Q axis sub-transient time constant & s & 0.158 \\
\hline$S_{1.0}$ & Saturation proportional coefficient & -- & 0.208225 \\
\hline$S_{1.2}$ & Saturation proportional coefficient & -- & 0.591511 \\
\hline
\end{tabular}

2. Regulador de Velocidade

a) Regulador de Velocidade - GOV08

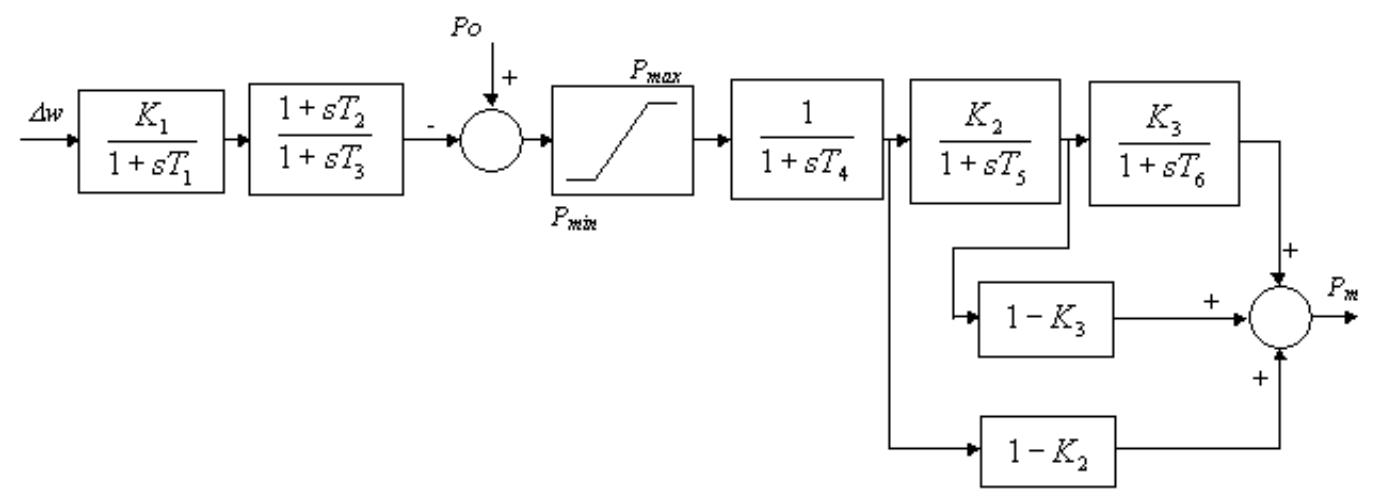

Figura C.3 - Diagrama de blocos do modelo de regulador de velocidade - GOV08. 
O modelo do regulador de velocidade GOV08 da Figura C.3 foi utilizado na UTE Jaguatirica II a vapor com os parâmetros da Tabela C.3.

Tabela C.3 - Parâmetros do modelo GOV08 (UTE Jaguatirica II vapor)

\begin{tabular}{c|c}
\hline \hline Parâmetro & $\begin{array}{c}\text { Valor } \\
\text { Implementado }\end{array}$ \\
\hline$T_{1}$ & 7.89 \\
\hline$T_{2}$ & 0.01 \\
\hline$T_{3}$ & 0.01 \\
\hline$T_{4}$ & 0.01 \\
\hline$T_{5}$ & 0.01 \\
\hline$T_{6}$ & 0.01 \\
\hline$K_{1}$ & 20.216 \\
\hline$K_{2}$ & 0.0 \\
\hline$K_{3}$ & 0.0 \\
\hline$P_{\max }$ & 1.2 \\
\hline$P_{\min }$ & 0.0 \\
\hline \hline
\end{tabular}

b) Regulador de Velocidade - GOV11

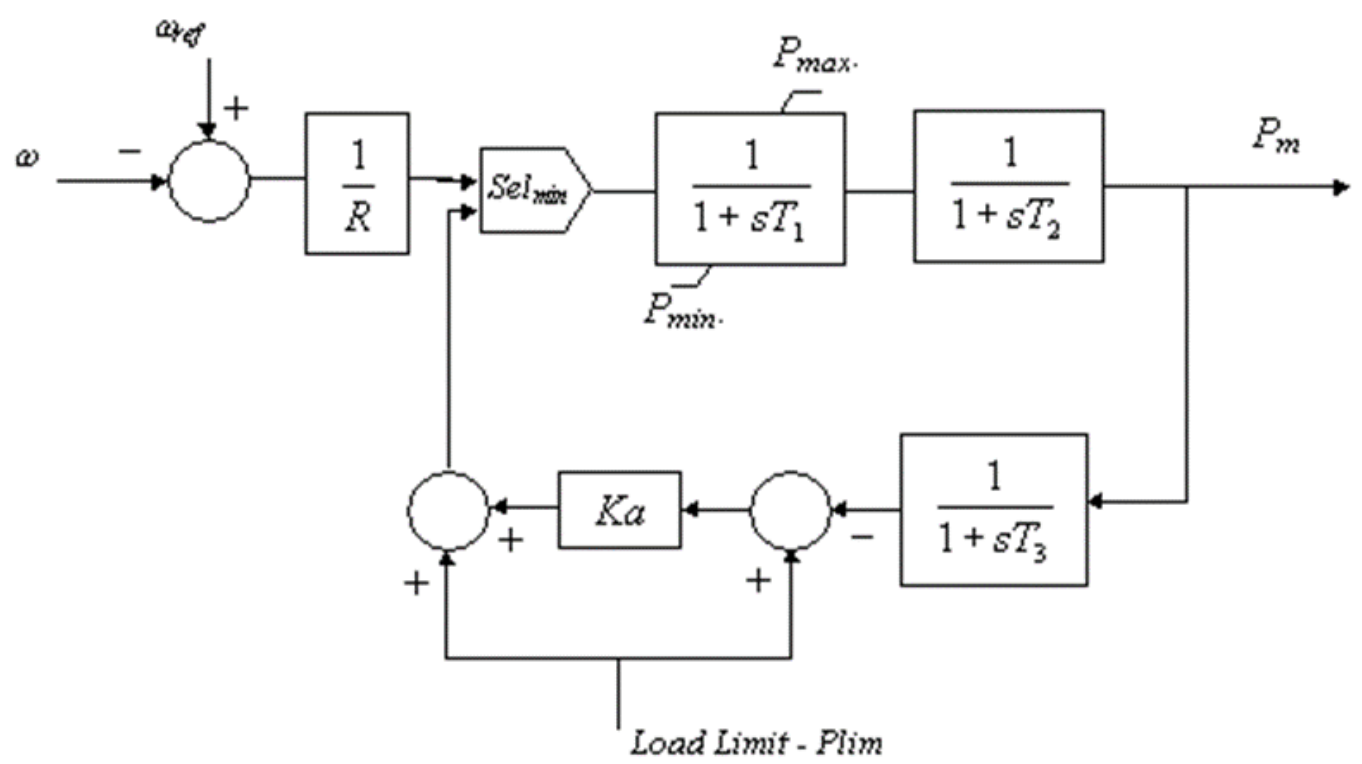

Figura C.4 - Diagrama de blocos do modelo de regulador de velocidade - GOV11. 
O modelo do regulador de velocidade GOV11 da Figura C.4 foi utilizado na UTE Jaguatirica II a gás com os parâmetros da Tabela C.4.

Tabela C.4 - Parâmetros do modelo GOV11 (UTE Jaguatirica II gás)

\begin{tabular}{c|c}
\hline \hline Parâmetro & $\begin{array}{c}\text { Valor } \\
\text { Implementado }\end{array}$ \\
\hline \hline$R$ & 0.03 \\
\hline$T_{1}$ & 0.02 \\
\hline$T_{2}$ & 0.4 \\
\hline$T_{3}$ & 0.2 \\
\hline$P_{\text {lim }}$ & 1.00 \\
\hline$K_{a}$ & 10.0 \\
\hline$P_{\max }$ & 0.712 \\
\hline$P_{\min }$ & 0.0 \\
\hline \hline
\end{tabular}

c) Regulador de Velocidade - GOV19
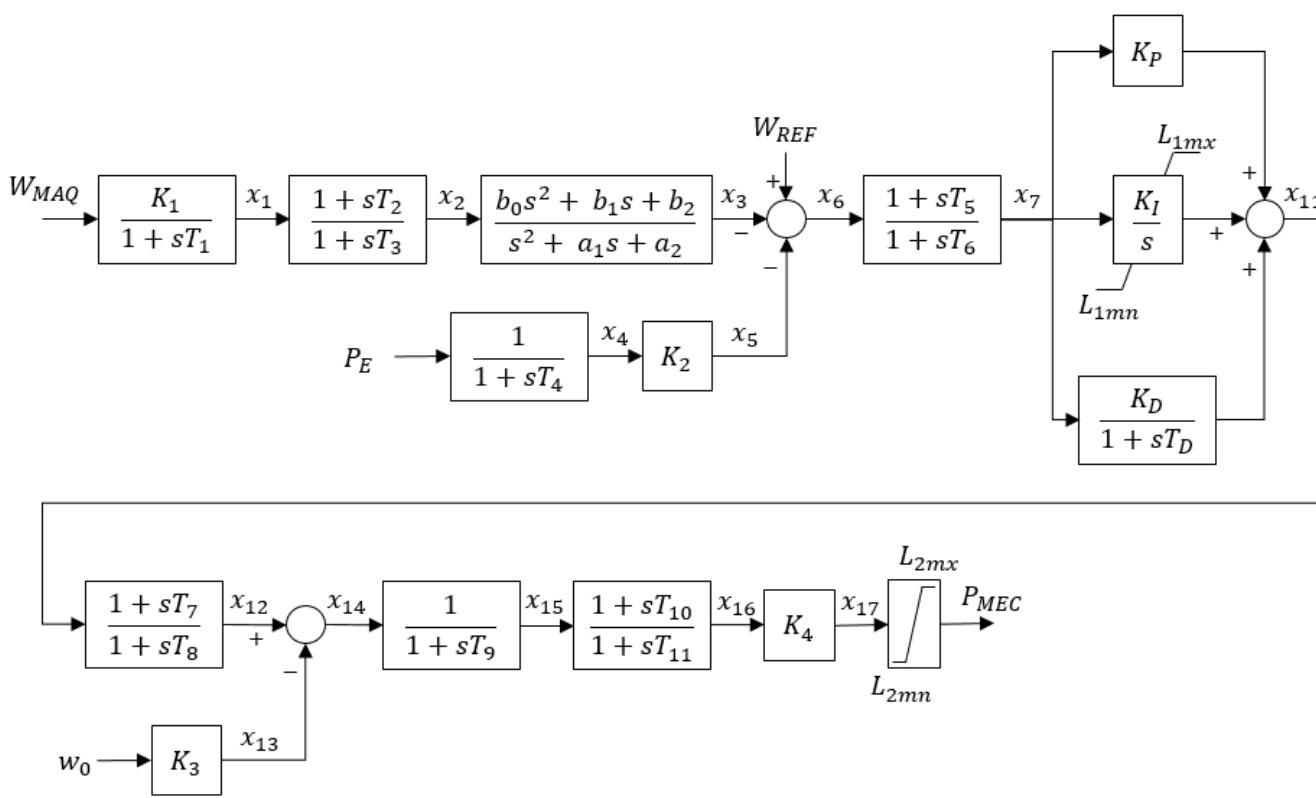

Figura C.5 - Diagrama de blocos do modelo de regulador de velocidade - GOV19.

O modelo do regulador de velocidade GOV19 da Figura C.5 foi utilizado na UTE Bonfim, na UTE Cantá, na UTE Baliza 1, na UTE Pau Rainha, na UTE Santa Luz e na UTE Forte de São Joaquim com os parâmetros da Tabela C.5 e 
foi utilizado na UTE Monte Cristo Sucuba, na UTE Palmaplan e na UTE Baliza 2 com os parâmetros da Tabela C.6.

Tabela C.5 - Parâmetros do modelo GOV19 (UTE Bonfim, UTE Cantá, UTE Baliza 1, UTE Pau Rainha, UTE Santa Luz e UTE Forte de São Joaquim)

\begin{tabular}{|c|c|}
\hline Parâmetro & $\begin{array}{c}\text { Valor } \\
\text { Implementado } \\
\end{array}$ \\
\hline$K_{1}$ & 514.0 \\
\hline$T_{1}$ & 0.0192 \\
\hline$T_{2}$ & 0.001 \\
\hline$T_{3}$ & 0.02 \\
\hline$B_{0}$ & 1. \\
\hline$B_{1}$ & 1.00 \\
\hline$B_{2}$ & 1.0 \\
\hline$A_{1}$ & 1.0 \\
\hline$A_{2}$ & 1.0 \\
\hline$K_{2}$ & 28.59 \\
\hline$T_{4}$ & 0.16 \\
\hline$T_{5}$ & 0.0543 \\
\hline$T_{6}$ & 0.0108 \\
\hline$K_{p}$ & 0.5 \\
\hline$K_{i}$ & 0.4 \\
\hline$K_{d}$ & 0. \\
\hline$T_{d}$ & 1. \\
\hline$L_{1 \max }$ & 99. \\
\hline$L_{1 \min }$ & -99. \\
\hline$T_{7}$ & 0.001 \\
\hline$T_{8}$ & 0.025 \\
\hline$K_{3}$ & 0. \\
\hline$T_{9}$ & 0.12004 \\
\hline$T_{10}$ & -0.021 \\
\hline$T_{11}$ & 0.021 \\
\hline$K_{4}$ & 0.02133 \\
\hline$L_{2 \max }$ & 1.1 \\
\hline$L_{2 \min }$ & -0.08 \\
\hline
\end{tabular}


Tabela C.6 - Parâmetros do modelo GOV19 (UTE Monte Cristo Sucuba, UTE Palmaplan e UTE Baliza 2)

\begin{tabular}{|c|c|}
\hline Parâmetro & $\begin{array}{c}\text { Valor } \\
\text { Implementado } \\
\end{array}$ \\
\hline$K_{1}$ & 514. \\
\hline$T_{1}$ & 0.0192 \\
\hline$T_{2}$ & 0.001 \\
\hline$T_{3}$ & 0.02 \\
\hline$B_{0}$ & 1. \\
\hline$B_{1}$ & 1.0 \\
\hline$B_{2}$ & 1.0 \\
\hline$A_{1}$ & 1. \\
\hline$A_{2}$ & 1. \\
\hline$K_{2}$ & 32.24965 \\
\hline$T_{4}$ & 0.16 \\
\hline$T_{5}$ & 0.0543 \\
\hline$T_{6}$ & 0.0108 \\
\hline$K_{p}$ & 0.271429 \\
\hline$K_{i}$ & 0.217143 \\
\hline$K_{d}$ & 0. \\
\hline$T_{d}$ & 1. \\
\hline$L_{1 \max }$ & 99. \\
\hline$L_{1 \min }$ & -99. \\
\hline$T_{7}$ & 0.0001 \\
\hline$T_{8}$ & 0.025 \\
\hline$K_{3}$ & 0. \\
\hline$T_{9}$ & 0.120048 \\
\hline$T_{10}$ & -0.021 \\
\hline$T_{11}$ & 0.021 \\
\hline$K_{4}$ & 0.034844 \\
\hline$L_{2 \max }$ & 0.877 \\
\hline$L_{2 \min }$ & -0.08 \\
\hline
\end{tabular}


3. Regulador de Tensão

a) Regulador de Tensão - AVR23

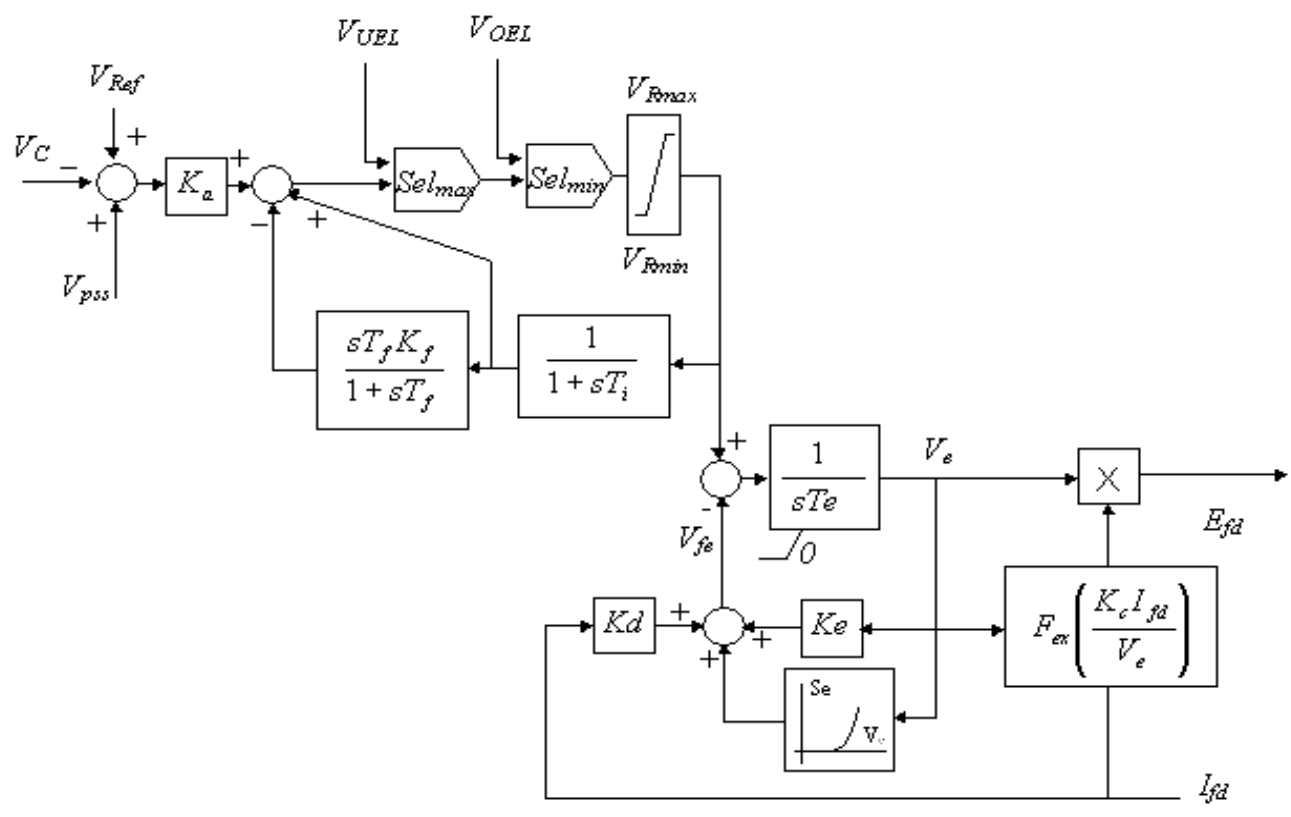

Figura C.6 - Diagrama de blocos do modelo de regulador de tensão - AVR23.

O modelo do regulador de tensão AVR23 da Figura C.6 foi utilizado na UTE Jaguatirica II a gás com os parâmetros da Tabela C.7 e foi utilizado na UTE Jaguatirica II a vapor com os parâmetros da Tabela C.8. 
Tabela C.7 - Parâmetros do modelo AVR23 (UTE Jaguatirica II gás)

\begin{tabular}{c|c}
\hline \hline Parâmetro & $\begin{array}{c}\text { Valor } \\
\text { Implementado }\end{array}$ \\
\hline \hline$K_{a}$ & 273.0 \\
\hline$T_{i}$ & 2.5 \\
\hline$T_{e}$ & 0.18 \\
\hline$K_{f}$ & 30.86 \\
\hline$T_{f}$ & 0.162 \\
\hline$K_{c}$ & 0.15 \\
\hline$K_{d}$ & 1.08 \\
\hline$K_{e}$ & 0.8 \\
\hline$E_{1}$ & 1.0 \\
\hline Sat $_{E_{1}}$ & 0.713 \\
\hline$E_{2}$ & 2.0 \\
\hline Sat $_{E_{2}}$ & 0.951 \\
\hline$V_{R \max }$ & 15.2 \\
\hline$V_{R \min }$ & -12.7 \\
\hline \hline
\end{tabular}

Tabela C.8 - Parâmetros do modelo AVR23 (UTE Jaguatirica II vapor)

\begin{tabular}{c|c}
\hline \hline Parâmetro & $\begin{array}{c}\text { Valor } \\
\text { Implementado }\end{array}$ \\
\hline$K_{a}$ & 102.0 \\
\hline$T_{i}$ & 5.0 \\
\hline$T_{e}$ & 0.15 \\
\hline$K_{f}$ & 100.0 \\
\hline$T_{f}$ & 0.1 \\
\hline$K_{c}$ & 0.15 \\
\hline$K_{d}$ & 0.47 \\
\hline$K_{e}$ & 0.43 \\
\hline$E_{1}$ & 3.8925 \\
\hline$S_{E_{1}}$ & 0.55 \\
\hline$E_{2}$ & 5.19 \\
\hline$S_{E_{2}}$ & 0.79 \\
\hline$V_{R \max }$ & 9.08 \\
\hline$V_{R \min }$ & -7.98 \\
\hline \hline
\end{tabular}


b) Regulador de Tensão - AVR24
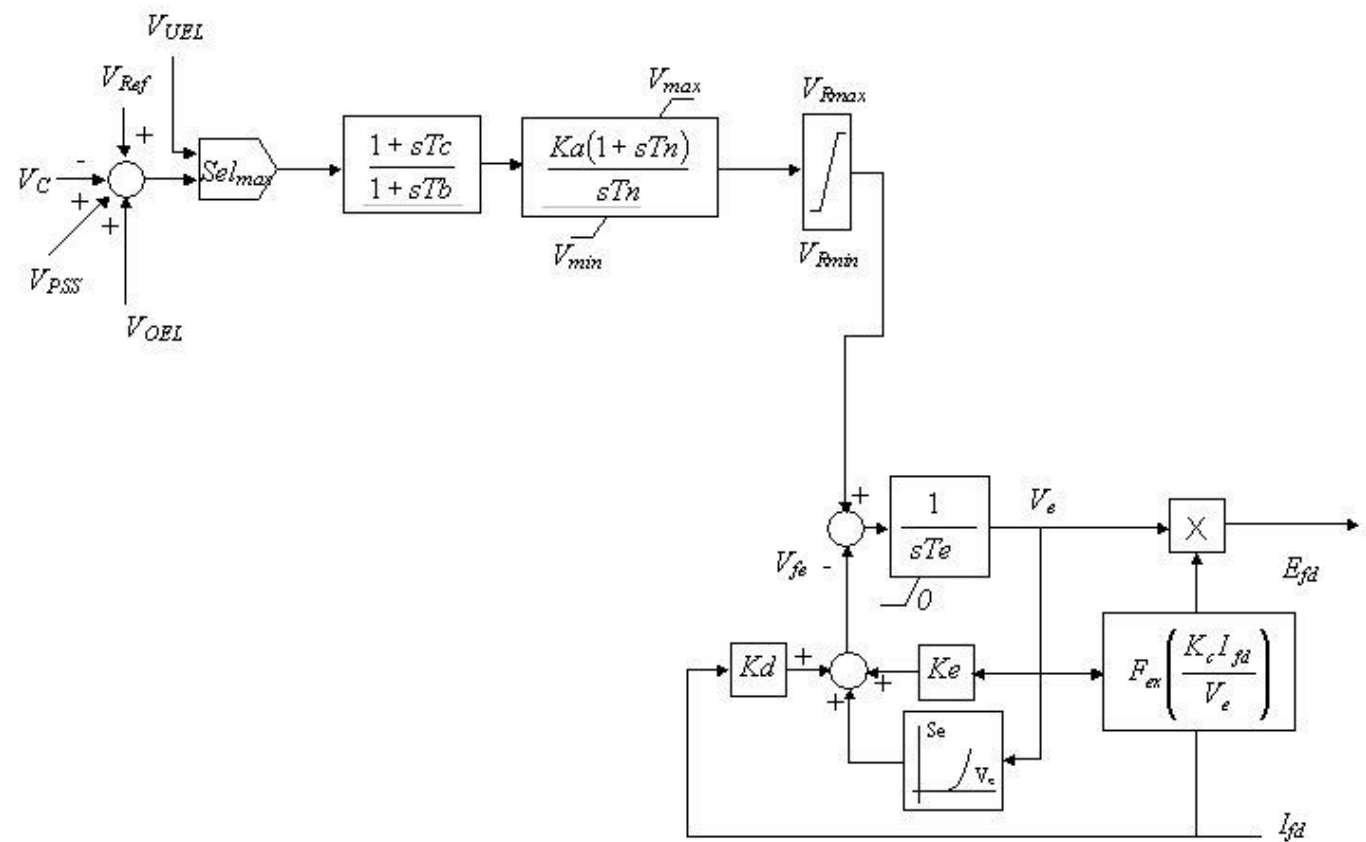

Figura C.7 - Diagrama de blocos do modelo de regulador de tensão - AVR24.

O modelo do regulador de tensão AVR24 da Figura C.7 foi utilizado na UTE Monte Cristo Sucuba, na UTE Palmaplan e na UTE Baliza 2 com os parâmetros da Tabela C.9. 
Tabela C.9 - Parâmetros do modelo AVR24 (UTE Monte Cristo Sucuba, UTE Palmaplan e UTE Baliza 2)

\begin{tabular}{|c|c|}
\hline Parâmetro & $\begin{array}{c}\text { Valor } \\
\text { Implementado }\end{array}$ \\
\hline$T_{b}$ & 0.00606 \\
\hline$T_{c}$ & 0.20606 \\
\hline$K_{a}$ & 30.0 \\
\hline$T_{n}$ & 6.40 \\
\hline$V_{\max }$ & 99. \\
\hline$V_{\text {min }}$ & -99. \\
\hline$T_{e}$ & 0.2 \\
\hline$K_{c}$ & 0.0 \\
\hline$K_{d}$ & 0.0 \\
\hline$K_{e}$ & 1.0 \\
\hline$E_{1}$ & 1.0 \\
\hline$S_{E_{1}}$ & 0.138881 \\
\hline$E_{2}$ & 1.2 \\
\hline$S_{E_{2}}$ & 0.148831 \\
\hline$V_{R \max }$ & 6.6 \\
\hline$V_{R \min }$ & 0.0 \\
\hline
\end{tabular}


c) Regulador de Tensão - AVR25

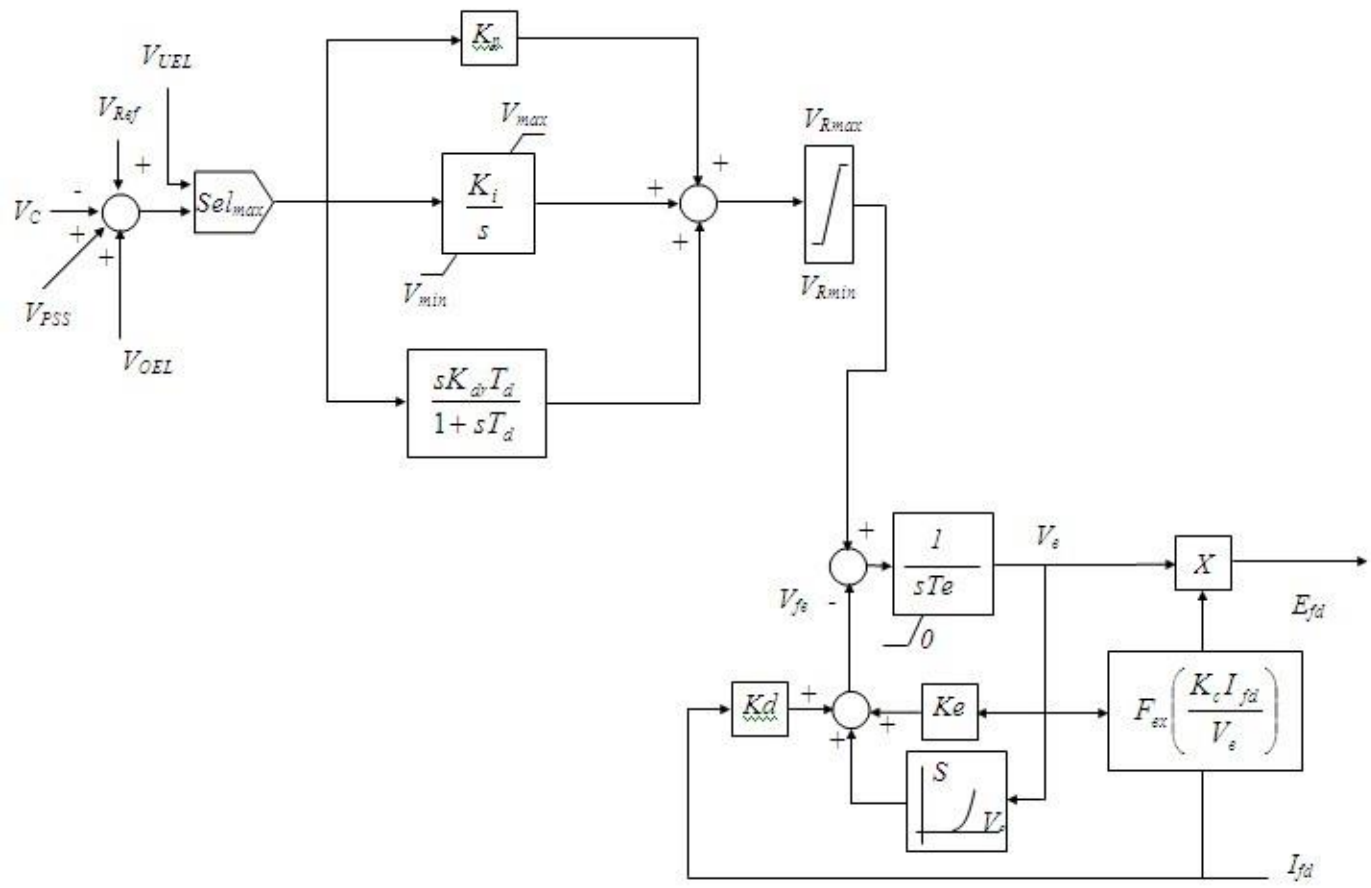

Figura C.8 - Diagrama de blocos do modelo de regulador de tensão - AVR25.

O modelo do regulador de tensão AVR25 da Figura C.8 foi utilizado na UTE Bonfim, na UTE Cantá, na UTE Baliza 1, na UTE Pau Rainha, na UTE Santa Luz e na UTE Forte de São Joaquim com os parâmetros da Tabela C.10. 
Tabela C.10 - Parâmetros do modelo AVR25 (UTE Bonfim, UTE Cantá, UTE Baliza 1, UTE Pau Rainha, UTE Santa Luz e UTE Forte de São Joaquim)

\begin{tabular}{|c|c|}
\hline Parâmetro & $\begin{array}{c}\text { Valor } \\
\text { Implementado }\end{array}$ \\
\hline$K_{d}$ & 761.9 \\
\hline$T_{d}$ & 0.021 \\
\hline$K_{i}$ & 7.692 \\
\hline$K_{p}$ & 40.0 \\
\hline$V_{\max }$ & 99.0 \\
\hline$V_{\min }$ & -99.0 \\
\hline$T_{e}$ & 0.2 \\
\hline$K_{c}$ & 0.0 \\
\hline$K_{d}$ & 0.0 \\
\hline$K_{e}$ & 1.0 \\
\hline$E_{1}$ & 1.0 \\
\hline$S_{E_{1}}$ & 0.138867 \\
\hline$E_{2}$ & 1.2 \\
\hline$S_{E_{2}}$ & 0.148817 \\
\hline$V_{R \max }$ & 5.068 \\
\hline$V_{R \min }$ & 0.0 \\
\hline
\end{tabular}


4. Estabilizador PSS

a) Estabilizador PSS - PS06

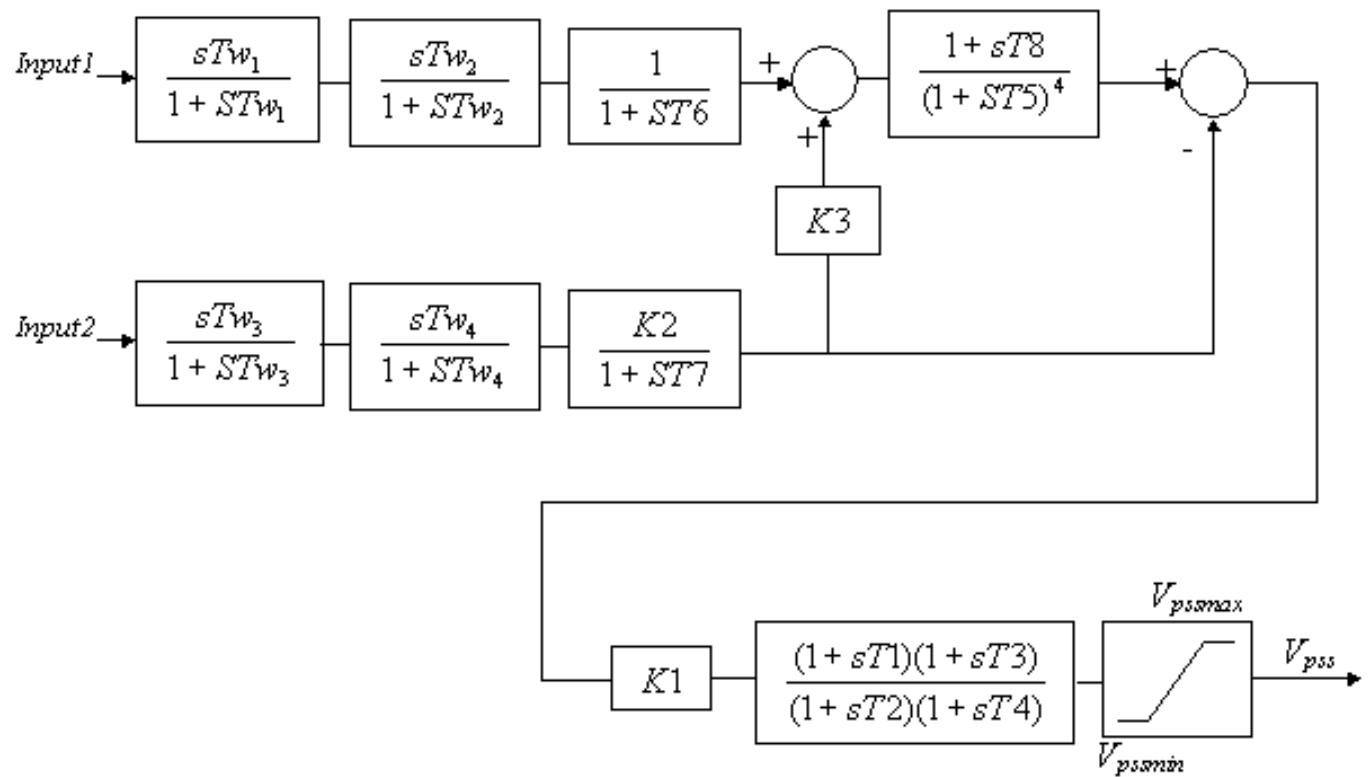

Figura C.9 - Diagrama de blocos do modelo estabilizador PSS - PS06.

O modelo de estabilizador PSS06 da Figura C.9 foi utilizado na UTE Jaguatirica II a gás com os parâmetros da Tabela C.11, foi utilizado na UTE Jaguatirica II a vapor com os parâmetros da Tabela C.12, foi utilizado na UTE Pau Rainha, na UTE Santa Luz e na UTE Forte de São Joaquim com os parâmetros da Tabela C.13 e foi utilizado na UTE Bonfim, na UTE Cantá, na UTE Monte Cristo Sucuba, na UTE Palmaplan, na UTE Baliza 1 e na UTE Baliza 2 com os parâmetros da Tabela C.14. 
Tabela C.11 - Parâmetros do modelo PS06 (UTE Jaguatirica Il gás)

\begin{tabular}{c|c}
\hline \hline Parâmetro & $\begin{array}{c}\text { Valor } \\
\text { Implementado }\end{array}$ \\
\hline$T_{1}$ & 0.12 \\
\hline$T_{2}$ & 0.04 \\
\hline$T_{3}$ & 0.12 \\
\hline$T_{4}$ & 0.04 \\
\hline$T_{5}$ & 0.1 \\
\hline$T_{6}$ & 0.01 \\
\hline$T_{7}$ & 3.0 \\
\hline$T_{8}$ & 0.4 \\
\hline$T_{w 1}$ & 3.0 \\
\hline$T_{w 2}$ & 3.0 \\
\hline$T_{w 3}$ & 3.0 \\
\hline$T_{w 4}$ & 3.0 \\
\hline$K_{1}$ & 5.0 \\
\hline$K_{2}$ & 0.25 \\
\hline$K_{3}$ & 1.0 \\
\hline$V_{\min }$ & -0.1 \\
\hline$V_{\text {max }}$ & 0.1 \\
\hline Type Imput \#1 & 1 \\
\hline Type Imput \#2 & 3 \\
\hline & \\
\hline
\end{tabular}


Tabela C.12 - Parâmetros do modelo PS06 (UTE Jaguatirica II vapor)

\begin{tabular}{c|c}
\hline \hline Parâmetro & $\begin{array}{c}\text { Valor } \\
\text { Implementado }\end{array}$ \\
\hline$T_{1}$ & 0.12 \\
\hline$T_{2}$ & 0.04 \\
\hline$T_{3}$ & 0.12 \\
\hline$T_{4}$ & 0.04 \\
\hline$T_{5}$ & 0.1 \\
\hline$T_{6}$ & 0.01 \\
\hline$T_{7}$ & 3.0 \\
\hline$T_{8}$ & 0.4 \\
\hline$T_{w 1}$ & 3.0 \\
\hline$T_{w 2}$ & 3.0 \\
\hline$T_{w 3}$ & 3.0 \\
\hline$T_{w 4}$ & 3.0 \\
\hline$K_{1}$ & 5.0 \\
\hline$K_{2}$ & 0.50 \\
\hline$K_{3}$ & 1.0 \\
\hline$V_{\min }$ & -0.1 \\
\hline$V_{\text {max }}$ & 0.1 \\
\hline Type Imput \#1 & 1 \\
\hline Type Imput \#2 & 3 \\
\hline & \\
\hline
\end{tabular}


Tabela C.13 - Parâmetros do modelo PS06 (UTE Pau Rainha, UTE Santa Luz e UTE Forte de São Joaquim)

\begin{tabular}{|c|c|}
\hline Parâmetro & $\begin{array}{c}\text { Valor } \\
\text { Implementado }\end{array}$ \\
\hline$T_{1}$ & 0.12 \\
\hline$T_{2}$ & 0.04 \\
\hline$T_{3}$ & 0.12 \\
\hline$T_{4}$ & 0.04 \\
\hline$T_{5}$ & 0.1 \\
\hline$T_{6}$ & 0.01 \\
\hline$T_{7}$ & 3.0 \\
\hline$T_{8}$ & 0.4 \\
\hline$T_{w 1}$ & 3.0 \\
\hline$T_{w 2}$ & 3.0 \\
\hline$T_{w 3}$ & 3.0 \\
\hline$T_{w 4}$ & 3.0 \\
\hline$K_{1}$ & 5.0 \\
\hline$K_{2}$ & 0.94 \\
\hline$K_{3}$ & 1.0 \\
\hline$V_{\text {min }}$ & -0.1 \\
\hline$V_{\max }$ & 0.1 \\
\hline Type Imput \#1 & 1 \\
\hline Type Imput \#2 & 3 \\
\hline
\end{tabular}


Tabela C.14 - Parâmetros do modelo PS06 (UTE Bonfim, UTE Cantá, UTE Monte Cristo Sucuba, UTE Palmaplan, UTE Baliza 1 e UTE Baliza 2)

\begin{tabular}{|c|c|}
\hline Parâmetro & $\begin{array}{c}\text { Valor } \\
\text { Implementado }\end{array}$ \\
\hline$T_{1}$ & 0.12 \\
\hline$T_{2}$ & 0.04 \\
\hline$T_{3}$ & 0.12 \\
\hline$T_{4}$ & 0.04 \\
\hline$T_{5}$ & 0.1 \\
\hline$T_{6}$ & 0.01 \\
\hline$T_{7}$ & 3.0 \\
\hline$T_{8}$ & 0.4 \\
\hline$T_{w 1}$ & 3.0 \\
\hline$T_{w 2}$ & 3.0 \\
\hline$T_{w 3}$ & 3.0 \\
\hline$T_{w 4}$ & 3.0 \\
\hline$K_{1}$ & 5.0 \\
\hline$K_{2}$ & 1.2 \\
\hline$K_{3}$ & 1.0 \\
\hline$V_{\text {min }}$ & -0.1 \\
\hline$V_{\max }$ & 0.1 \\
\hline Type Imput \#1 & 1 \\
\hline Type Imput \#2 & 3 \\
\hline
\end{tabular}


5. Modelo do Controle VSC dos Elementos Armazenadores

Tabela C.15 - Parâmetros do modelo simplificado para os Dispositivos de Armazenamento de Energia no controle de Potência Ativa

\begin{tabular}{c|c}
\hline \hline Parâmetro & $\begin{array}{c}\text { Valor } \\
\text { Implementado }\end{array}$ \\
\hline \hline$T_{\omega}$ & 0.02 \\
\hline$T_{P}$ & 0.02 \\
\hline$T_{E S D}^{P}$ & 0.005 \\
\hline$R$ & 0.05 \\
\hline$\omega_{\text {ref }}$ & 1.00 \\
\hline$K_{P P}$ & 2.00 \\
\hline$K_{I P}$ & 2.00 \\
\hline$I_{\text {mín }}$ & -1.00 \\
\hline$I_{\text {máx }}$ & 1.00 \\
\hline$P_{\text {máx }}^{E S D}$ & 1.10 \\
\hline$P_{\text {mín }}^{E S D}$ & -1.10 \\
\hline Banda Morta \#1 & 0.0016 \\
\hline Banda Morta \#2 & -0.0016 \\
\hline &
\end{tabular}

Tabela C.16 - Parâmetros do modelo simplificado para os Dispositivos de Armazenamento de Energia no controle de Potência Reativa

\begin{tabular}{c|c}
\hline \hline Parâmetro & $\begin{array}{c}\text { Valor } \\
\text { Implementado }\end{array}$ \\
\hline \hline$T_{V}$ & 0.02 \\
\hline$T_{Q}$ & 0.02 \\
\hline$T_{E S D}^{Q}$ & 0.005 \\
\hline$S e l_{1}$ & 0.00 \\
\hline$K_{P Q}$ & 1.00 \\
\hline$K_{I Q}$ & 100.0 \\
\hline$I_{\min }$ & -1.00 \\
\hline$I_{\operatorname{máx}}$ & 1.00 \\
\hline$Q_{\operatorname{máx}}^{E S D}$ & 1.10 \\
\hline$Q_{\min }^{E S D}$ & -1.10 \\
\hline &
\end{tabular}


6. Modelo do Controle de Usinas Fotovoltaicas

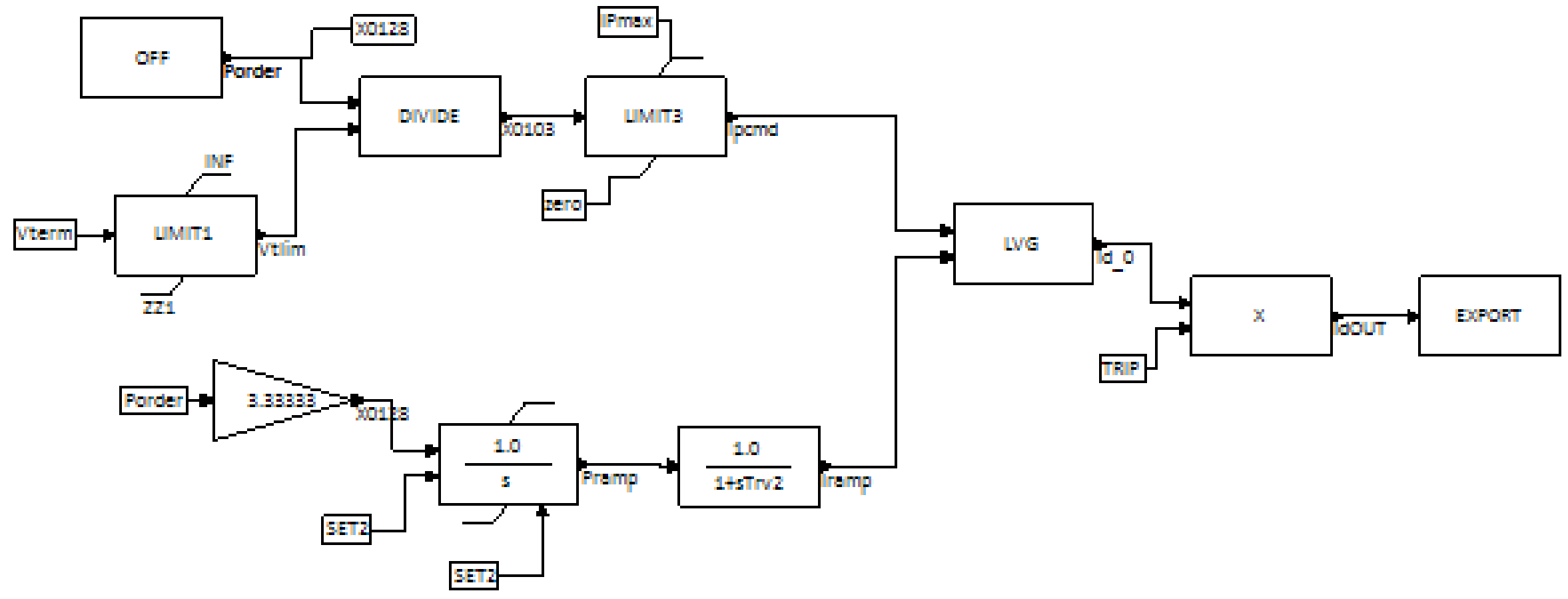

Figura C.10 - Malha de Controle da Potência Ativa. 


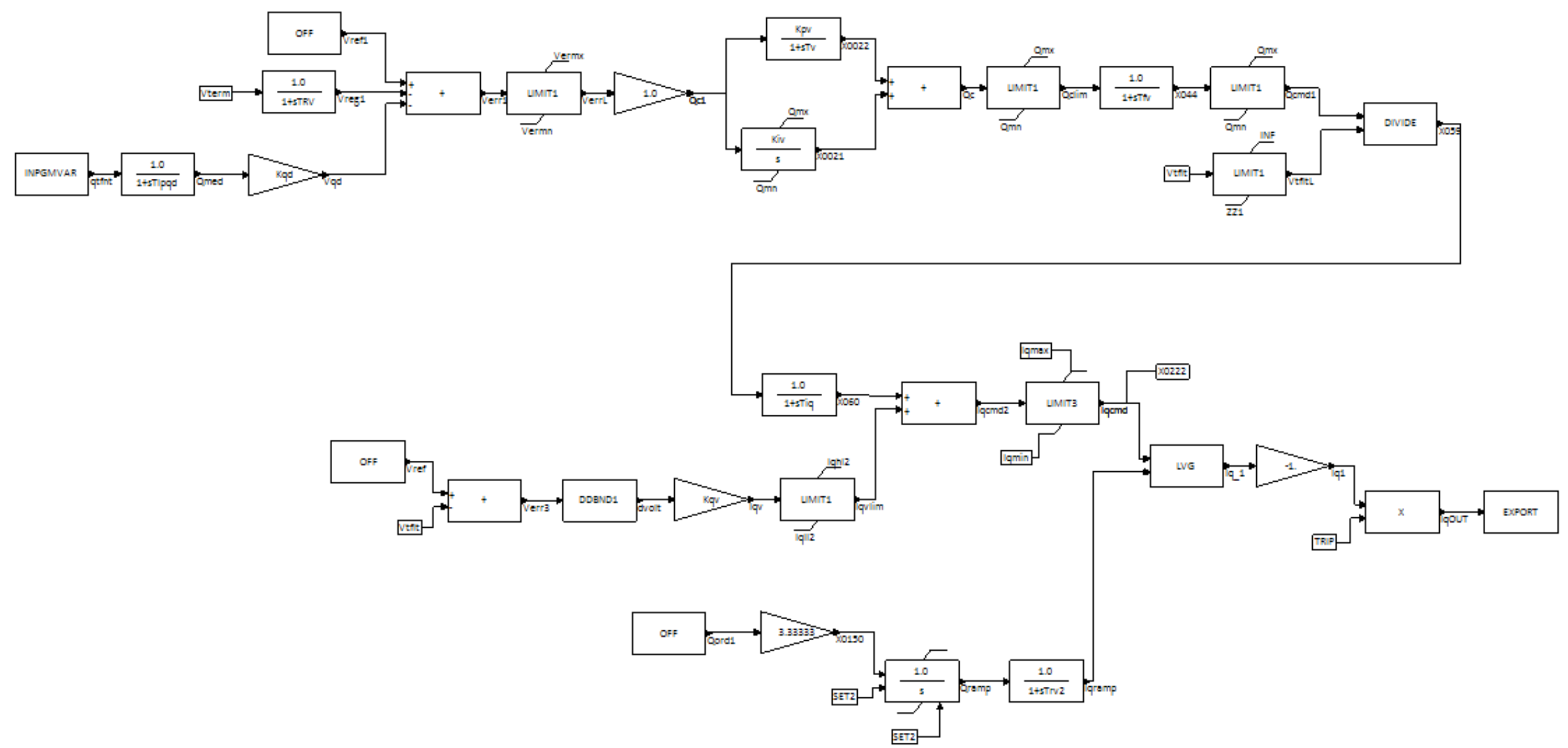

Figura C.11 - Malha de Controle da Potência Reativa. 


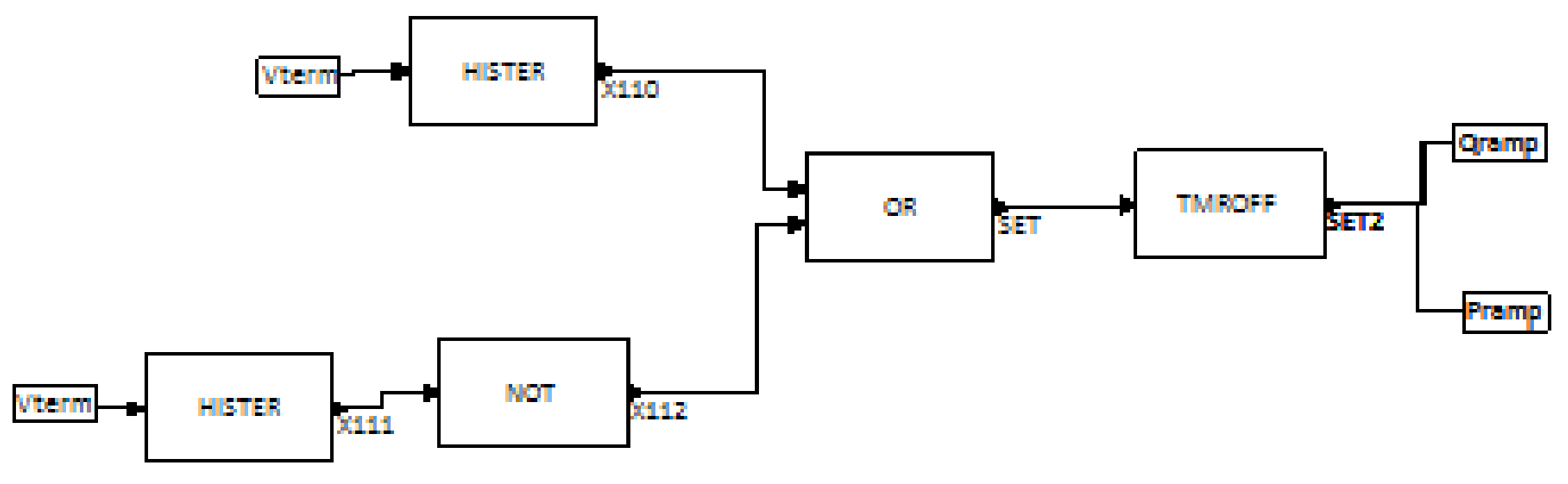

Figura C.12 - Malha de Detecção de Subtensão e Sobretensão. 

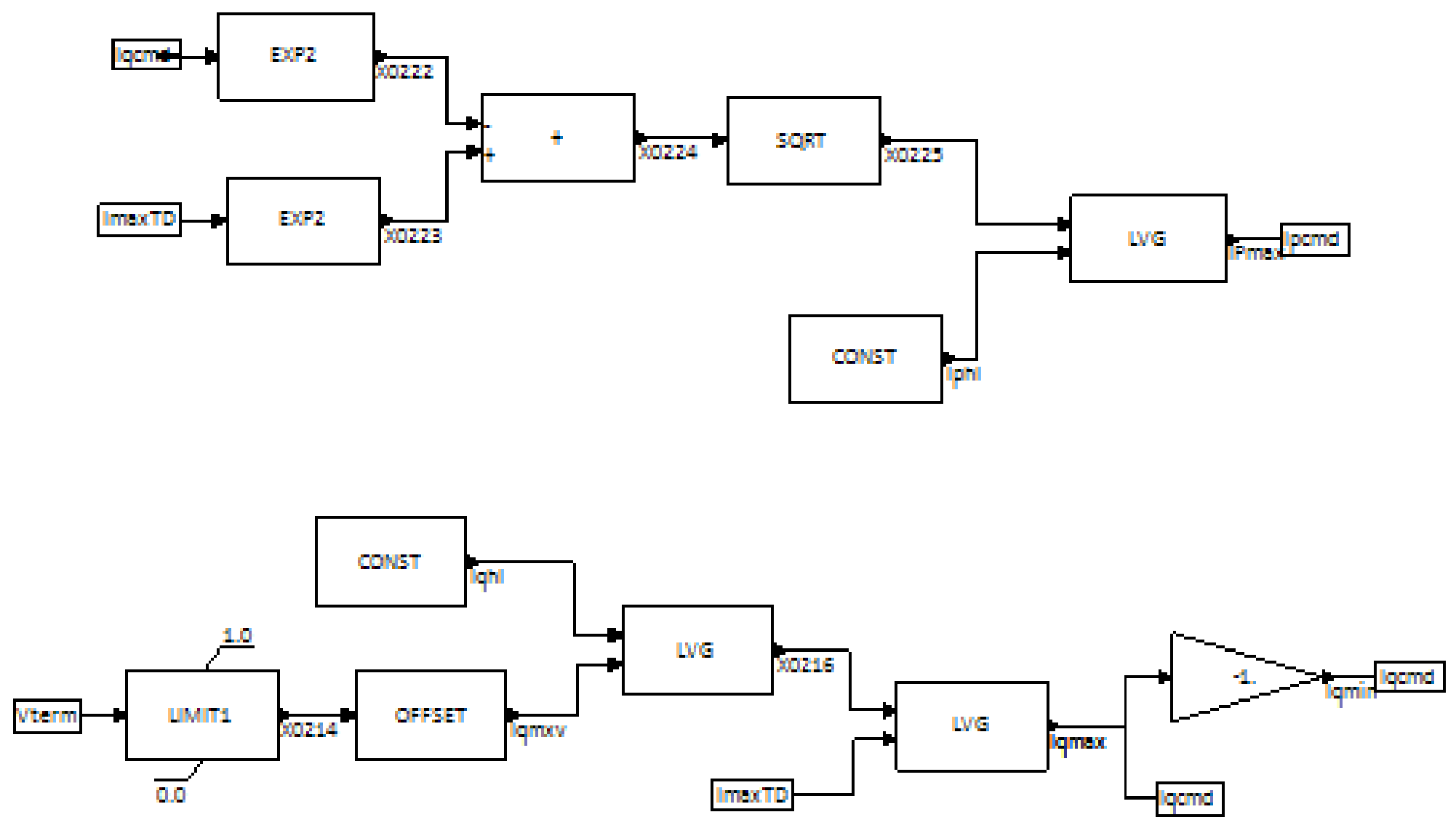

Figura C.13 - Limites de Corrente Ativa e de Corrente Reativa. 


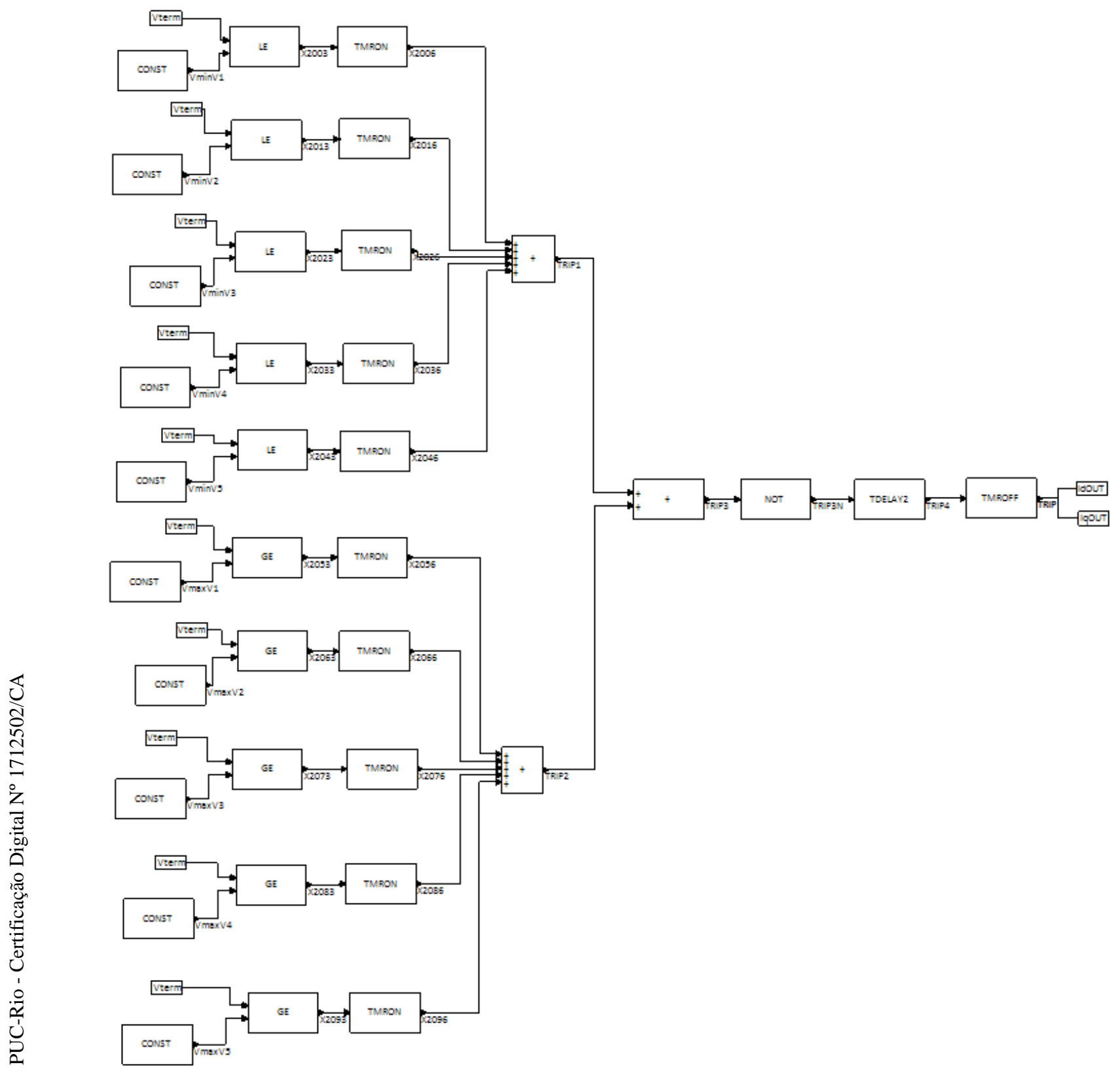

Figura C.14 - Proteções da Usina Fotovoltaica.

Os modelos para usina fotovoltaica da Figura C.10, Figura C.11, Figura C.12, Figura C.13, Figura C.14 foram utilizados na UFV Forte de São Joaquim e nas demais fotovoltaicas inseridas no sistema com os parâmetros da Tabela C.17. 
Tabela C.17 - Parâmetros do modelo do Controle de Usinas Fotovoltaicas

\begin{tabular}{|c|c|}
\hline Parâmetro & $\begin{array}{c}\text { Valor } \\
\text { Implementado } \\
\end{array}$ \\
\hline$V_{t h r d}$ & 0.60 \\
\hline$V_{\text {thru }}$ & 0.65 \\
\hline$V_{\text {hvri }}$ & 1.10 \\
\hline$V_{\text {hvro }}$ & 1.20 \\
\hline$T_{i q}$ & 0.005 \\
\hline$Q_{m n}$ & -1.0 \\
\hline$Q_{m n}$ & 1.0 \\
\hline$d b d_{1}$ & 0.1 \\
\hline$K_{q v}$ & 2.0 \\
\hline$I_{q h l 2}$ & 1.3 \\
\hline$I_{q l l 2}$ & -1.05 \\
\hline$T_{f v}$ & 0.15 \\
\hline$T_{v}$ & 0.05 \\
\hline$K_{p v}$ & 18.0 \\
\hline$V_{m x}^{e r}$ & -0.1 \\
\hline$V_{m x}^{e r}$ & 0.1 \\
\hline$T_{R V}$ & 0.02 \\
\hline$T_{l p q d}$ & 5.0 \\
\hline$K_{q d}$ & 0.04 \\
\hline$T_{i}^{\text {med }}$ & 0.3 \\
\hline$T_{r v 2}$ & 0.015 \\
\hline$K_{i v}$ & 5.0 \\
\hline$V_{\min }^{V 1}$ & 0.001 \\
\hline$T_{\min }^{V 1}$ & 0.50 \\
\hline$V_{\min }^{V 2}$ & 0.150 \\
\hline$V_{\min }^{V 3}$ & 0.400 \\
\hline$T_{\min }^{V 2}$ & 0.51 \\
\hline$T_{\min }^{V 3}$ & 0.95 \\
\hline$V_{\min }^{V 4}$ & 0.650 \\
\hline$T_{\min }^{V 4}$ & 1.40 \\
\hline$V_{\min }^{V 5}$ & 0.899 \\
\hline$T_{\min }^{V 5}$ & 1.85 \\
\hline$V_{\max }^{V 1}$ & 1.241 \\
\hline$T_{\max }^{V 1}$ & 0.001 \\
\hline$V_{\text {max }}^{V 2}$ & 1.240 \\
\hline$T_{\max }^{V 2}$ & 0.250 \\
\hline
\end{tabular}




\begin{tabular}{l|l}
\hline$V_{\max }^{V 3}$ & 1.200 \\
\hline$T_{\max }^{V 3}$ & 0.600 \\
\hline$V_{\max }^{V 4}$ & 1.180 \\
\hline$T_{\max }^{V 4}$ & 1.100 \\
\hline$V_{\max }^{V 5}$ & 1.101 \\
\hline$T_{\max }^{V 5}$ & 10.00 \\
\hline
\end{tabular}

7. Esquema Regional de Alívio de Carga (ERAC)

Tabela C.18 - Parâmetros de Ajuste do Esquema Regional de Alívio de Carga para o Sistema Roraima

\begin{tabular}{c|c|c|c|c}
\hline \hline Estágios & $\begin{array}{c}\text { Frequência de } \\
\text { Corte }(\mathrm{Hz})\end{array}$ & Corte de Carga & $\begin{array}{c}\text { Tempo de } \\
\text { sensibilidade } \\
\text { do relé }(\mathrm{s})\end{array}$ & $\begin{array}{c}\text { Tempo de } \\
\text { atraso de } \\
\text { atuação (s) }\end{array}$ \\
\hline \hline $1^{\circ}$ & 58,5 & $7 \%$ & 0.05 & 0.05 \\
\hline $2^{\circ}$ & 58,2 & $8 \%$ & 0.05 & 0.05 \\
\hline $3^{\circ}$ & 57,9 & $10 \%$ & 0.05 & 0.05 \\
\hline $4^{\circ}$ & 57,6 & $10 \%$ & 0.05 & 0.05 \\
\hline $5^{\circ}$ & 57,3 & $10 \%$ & 0.05 & 0.05 \\
\hline
\end{tabular}

8. Proteção de Sobretensão

Os parâmetros de ajuste de proteção de sobretensão estão listados na Tabela C.19 onde relés sensíveis a variação da frequência atuam por subfrequência de 58,2 Hz por mais de $150 \mathrm{~ms}$, no sentido de desligar os equipamentos shunts da rede listados, possibilitando controle de tensão em valores aceitáveis. 
Tabela C.19 - Parâmetros de Ajuste de Proteção de Sobretensão

\begin{tabular}{c|c|c|c|c|c}
\hline \hline Barra & Subestação & $\begin{array}{c}\text { Capacidade } \\
\text { Nominal de } \\
\text { Elemento Shunt } \\
\text { (Mvar) }\end{array}$ & $\begin{array}{c}\text { Frequência de } \\
\text { Corte (Hz) }\end{array}$ & $\begin{array}{c}\text { Tempo de } \\
\text { sensibilidade } \\
\text { do relé (s) }\end{array}$ & $\begin{array}{c}\text { Tempo de } \\
\text { atraso de } \\
\text { atuação (s) }\end{array}$ \\
\hline \hline 52001 & Mucajaí 13,8 kV & $2 \times 1.2$ & 58,2 & 0.15 & 0.05 \\
\hline 52009 & Rorainópolis 13,8 kV & $2 \times 1.2$ & 58,2 & 0.15 & 0.05 \\
\hline 52103 & Distrito Industrial 13,8 kV & $6 \times 3.6$ & 58,2 & 0.15 & 0.05 \\
\hline 52121 & Centro 13,8 kV & $9 \times 3.6$ & 58,2 & 0.15 & 0.05 \\
\hline 52214 & Boa Vista 13,8 kV & $5 \times 3.6$ & 58,2 & 0.15 & 0.05 \\
\hline 52216 & Boa Vista 13,8 kV & $5 \times 3.6$ & 58,2 & 0.15 & 0.05 \\
\hline 52321 & Floresta 13,8 kV & $9 \times 3.6$ & 58,2 & 0.15 & 0.05 \\
\hline
\end{tabular}

9. Modelagem de Carga

Tabela C.20 - Parâmetros da Modelagem de Carga

\begin{tabular}{c|c|c}
\hline \hline \multicolumn{3}{|c}{ Modelagem de Carga } \\
\hline \hline$Z$ & $I$ & $P$ \\
\hline 0.5 & 0.0 & 0.5 \\
\hline$Z$ & $I$ & $Q$ \\
\hline 1.0 & 0.0 & 0.0 \\
\hline
\end{tabular}

